RICARDO RUIZ MARTUCI

\title{
AVALIAÇÃO DE CERÂMICAS ODONTOLÓGICAS QUANTO À RESISTÊNCIA DE UNIÃO COM A DENTINA, POR ENSAIO DE TRAÇÃO, MICRODUREZAS KNOOP E VICKERS, RUGOSIDADE SUPERFICIAL E MICROSCOPIA DE FORÇA ATÔMICA
}




\section{Ricardo Ruiz Martuci}

\section{Avaliação de cerâmicas odontológicas quanto à resistência de união com a dentina, por ensaio de tração, microdurezas Knoop e Vickers, rugosidade superficial e microscopia de força atômica}

Tese apresentada à Faculdade de Odontologia da Universidade de São Paulo, para obter o título de Doutor, pelo Programa de PósGraduação em Odontologia.

Área de Concentração: Materiais Dentários.

Orientador: Prof. Dr. Antonio Muench

São Paulo 


\section{FOLHA DE APROVAÇÃO}

Martuci RR. Avaliação de cerâmicas odontológicas quanto à resistência de união com a dentina, por ensaio de tração, microdurezas Knoop e Vickers, rugosidade superficial e microscopia de força atômica [Tese de Doutorado]. São Paulo: Faculdade de Odontologia da USP; 2006.

São Paulo,

\section{Banca Examinadora}

1) $\operatorname{Prof}(\mathrm{a}) \cdot \operatorname{Dr}(\mathrm{a})$.

Titulação:

Julgamento:

Assinatura:

2) $\operatorname{Prof}(\mathrm{a}) \cdot \operatorname{Dr}(\mathrm{a})$.

Titulação:

Julgamento:

Assinatura:

3)Prof(a). $\operatorname{Dr}(\mathrm{a})$.

Titulação:

Julgamento:

Assinatura:

4)Prof(a). $\operatorname{Dr}(\mathrm{a})$.

Titulação:

Julgamento:

Assinatura:

5) $\operatorname{Prof}(\mathrm{a}) . \operatorname{Dr}(\mathrm{a})$.

Titulação:

Julgamento:

Assinatura: 
O princípio mais certo da vida não é reformar os outros, mas aperfeiçoar a si próprio.

B. R. Haydon 


\section{DEDICATÓRIA}

Dedico esse trabalho a Deus, aos meus pais, a minha esposa e ao meu filho.

A Deus, o qual trago no coração e que em sua infinita bondade, me deu forças e me acompanhou de perto em toda essa jornada, estendendo sua mão, nas horas mais críticas e me conduzindo sempre, no "caminho certo".

Aos meus pais, Martuci e Dolores, que abençoados por Ele, me amaram e se dedicaram plenamente até seus limites ou mais do que eles para que eu enxergasse o "caminho certo". . Amo vocês!

A minha esposa Simone, minha cara metade, pessoa que encontrei e escolhi para compartilhar comigo o "caminho certo", mesmo que às vezes a ouço suspirar bem fundo e dizer que eu sou o causador da sua insônia, que eu faço tudo errado sempre. . . Te amo hoje e sempre!

Ao querido e grandioso Mateus, meu filho que, conduzido por Deus, e orientado pelos seus pais, possa enxergar um dia e trilhar juntamente conosco o "caminho certo". . . Te amo muito filho!

Ricardo 


\section{AGRADECIMENTOS}

Professor Muench

Mestre,

Estar ao seu lado todos esses anos e poder compartilhar um pouco da sua grande sabedoria, sempre me enalteceu e me fez ficar mais confiante na vivência e no entendimento da Odontologia. Você entre suas palavras na sala, no corredor, no almoço, enfim, no nosso convívio me fez entender que não podemos descobrir novos oceanos enquanto não tivermos coragem de perder de vista a terra firme.

Agradeço por me fazer singrar os mares e entender que se não posso direcionar o vento, ao menos devo saber ajustar as velas do barco.

Muito obrigado pelas suas palavras, pelos seus ensinamentos e pelo seu exemplo de conduta, sempre de extremo caráter e plena dedicação aos seus orientados e a ciência.

Continue assim, "Grande Mestre". 


\section{AGRADECIMENTOS}

Ao Prof. Dr. Paulo Eduardo Capel Cardoso pelo apoio, pela orientação e pela grandiosa dedicação e incentivo à produção científica e aos seus alunos. Muito obrigado por compartilhar comigo seus ideais e ensinamentos;

A todos os professores, funcionários, técnicos e colegas do Departamento de Materiais Dentários da FOUSP que de uma forma ou outra me ajudaram na idealização desse trabalho;

Especialmente às minhas colegas de doutorado da FOUSP: Sandra e Andréa e aos meus colegas de doutorado da UFMA: Ferreira, Ana, Ivone, Soraia, Adriana e Cláudia pela união, amizade e particular dependência que fizemos uns dos outros.

Aos meus colegas professores da Odontologia do UniFMU e da Enfermagem da UNIP, que sempre me apoiaram e me incentivaram quando precisei;

A amiga e colega catarinense de pós-graduação Luciane, por todas as conversas e aprendizado que tivemos no convívio do Departamento;

A CAPES que me proporcionou a realização desse trabalho;

Ao Comitê de Ética, a Administração da Pós-Graduação e a Administração da Biblioteca que sempre se fizeram ativas quando delas precisei;

A minha auxiliar Cleuza que resolveu sempre da melhor maneira os fatos do consultório na minha ausência; 
Ao Laboratório de Prótese Chanceller, em especial ao protético Carlos que tanto me orientou na confecção das cerâmicas;

A Universidade Federal de São Carlos, Faculdade de Engenharia de Materiais, especialmente aos Professores Zanotto, Oscar, Pedro Íris, Eduardo e Christian pela dedicação em me ensinar um pouco sobre os vidros e as cerâmicas, pela microscopia de força atômica que enriqueceu o meu trabalho e pela verdadeira amizade que ficou.

A minha querida Tia Arlette, minha verdadeira mãe em São Paulo, a qual sempre me conduziu no caminho certo, me orientou, me abrigou durante todos esses anos os quais tenho me dedicado à Pós Graduação, como também foi minha companheira na "Pizza e no Papo da Terça";

Aos meus tios Nélio e Maria Rosa pelos ensinamentos e filosofias da Educação;

Aos meus tios Vladimir e Maria José por encorajar-me sempre na profissão;

As minhas florzinhas Izabele e Ana Carolina, minhas sobrinhas lindinhas e aos meus afilhados: Gustavo, Leonardo, Eduardo Henrique, Victória e Eduardo, por sempre me darem "alegrias de vida";

Aos meus irmãos, Daniele e Wael, obrigado por vocês existirem na minha vida, amarei vocês para sempre, nesta vida, neste tudo, neste todo, neste nada;

Aos meus avós Diogo, Rosa, Antonio e Catarina, por me darem esta Família, pois, aqueles que nos deram as contribuições mais significativas e duradouras para sermos quem somos, foram os que ousaram assumir seu lugar como iguais. 
O mundo olha fascinado para o brilho ofuscante do ego, mas somente os que caminharem ao nosso lado com amor e igualdade atingirão nossos corações e nos transformarão. 
Martuci RR. Avaliação de cerâmicas odontológicas quanto à resistência de união com a dentina, por ensaio de tração, microdurezas Knoop e Vickers, rugosidade superficial e microscopia de força atômica [Tese de Doutorado]. São Paulo: Faculdade de Odontologia da USP; 2006.

\section{RESUMO}

Foram ensaiadas quatro cerâmicas VMK 95, Omega 900, IPS d. Sign e Cergogold. Os ensaios realizados foram: 1) resistência de união, por ensaio de tração, à dentina humana, de cones $(6 \times 3 \times 5 \mathrm{~mm})$ de cerâmica, unidos por meio de cimentos fosfato de zinco, resinosos Rely X e Panávia $F(n=10) ; 2)$ rugosidade pelos parâmetros $\mathrm{Ra}, \mathrm{Rt}, \mathrm{Ry}, \mathrm{Rz}$ e $\mathrm{Rp}$, de superfícies tratadas com ácido fluorídrico a $10 \%$ e polidas $(n=10) ; 3)$ durezas Knoop e Vickers $(n=4) ; 4)$ análise por microscopia de força atômica de superfícies polidas apenas $(n=5)$. Os dados foram analisados pela análise de variância e testes de Tukey foram feitos quando necessário. A resistência de união com o fosfato de zinco e o parâmetro de rugosidade $\mathrm{Ra}$ foram analisados em separado, por apresentarem variâncias bem menores que as correspondentes aos demais agentes cimentantes e parâmetros. Os resultados mostraram que a resistência de união com o fosfato de zinco foi muito baixa $(1,61$ a 2,91MPa), nas condições dos ensaios. Com cimentos resinosos a resistência média variou de 16,61 a 18,47MPa. O cimento Rely $X$ apresentou menor resistência em média, mas isto também depende da cerâmica.As rugosidades das superfícies tratadas com ácido fluorídrico a 10\% 
foram bem maiores do que nas polidas. Nessas o parâmetro Ra variou de 2,15 a

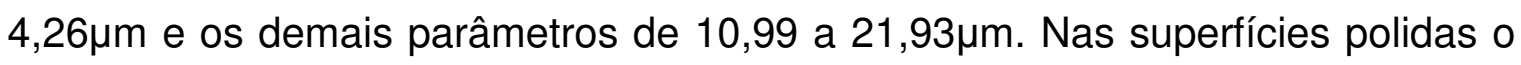
Ra variou de 0,53 a $0,84 \mu \mathrm{m}$. Os demais parâmetros apresentaram médias de 2,01 a 5,23 $\mu \mathrm{m}$. A dureza Knoop variou de 418,9 a $493,8 \mathrm{kgf} / \mathrm{mm}^{2}$ e a Vickers de 492,5 a $572,2 \mathrm{kgf} / \mathrm{mm}^{2}$. Esta última apresentou valores maiores. A microscopia de força atômica permitiu visualizar irregularidades de superfícies. As principais conclusões foram: o cimento de fosfato de zinco, na condição do ensaio (por tração) apresentou resistência de união muito baixa; com os cimentos resinosos a resistência de união foi bem alta; as rugosidades foram muito altas após o tratamento superficial com ácido fluorídrico a 10\%, mas, as polidas apresentaram valores bem baixos; as durezas Vickers fornecem valores maiores que a Knoop.

Palavras-Chave: Cerâmicas dentárias; Resistência de união; Teste de tração; Microdurezas Knoop e Vickers; Rugosidade superficial; Microscopia de força atômica 
Martuci RR. Evaluation of dental ceramics regarding tensile bond strength to dentin, Knoop and Vickers' microhardness, surface roughness and atomic force microscopy [Tese de Doutorado]. São Paulo: Faculdade de Odontologia da USP; 2006.

\section{ABSTRACT}

Four ceramics (VMK 95, Omega 900, IPS d.Sign and Cergogold) were tested regarding: 1) tensile bond strength to human dentin of ceramic cones $(6 \times 3 \times$ $5 \mathrm{~mm}$ ), cemented with zinc phosphate, and resin cements, Rely $X$ and Panávia $F$ $(n=10)$; 2) roughness by means of parameters $R a, R t, R y, R z$ and $R p$, of $H F$ (10\%) surface treated and polished surfaces $(n=10)$; 3) Knoop and Vickers hardness $(n=4) ; 4)$ atomic force microscopy; only of polished surfaces $(n=5)$. Data were analyzed by ANOVA and when necessary were used Tukey's tests. Tensile bond strength with zinc phosphate cement and Ra roughness parameter were analyzed separately because of their low variances when compared with those of resin cements and the other roughness parameter. Results showed that tensile bond strength of zinc phosphate was very low (1.61 to $2.91 \mathrm{MPa})$ in this test condition (tensile test). Resin cements presented tensile bond strength at range 16.61 to $18.47 \mathrm{MPa}$. Cement Rely X presented lower strength, but it depends also of ceramic. HF (10\%) treated surfaces presented much higher roughness than polished ones. In HF (10\%) treated surfaces parameter Ra ranged from 2.15 to $4.26 \mu \mathrm{m}$ and the other parameter ranged from 10.99 to $21.93 \mu \mathrm{m}$. Roughness of 
polished surfaces Ra ranged from 0.53 to $0.84 \mu \mathrm{m}$. Range of the other parameter was from 2.01 to $5.23 \mu \mathrm{m}$. Knoop hardness ranged from 418.9 to $493.8 \mathrm{kgf} / \mathrm{mm}^{2}$ and Vicker's from 492.5 to $572.2 \mathrm{kgf} / \mathrm{mm}^{2}$. This type presented higher values. Atomic force microscopy permited good vision of surface irregularities. Main conclusions were: zinc phosphate cement at test conditions (tensile) presented low bond strength; resin cements presented high tensile bond strength; surface treatment with $\mathrm{HF}(10 \%)$ led to high roughness but in polished one it was low; Vicker's hardness presented higher values than Knoop one

Keywords: Dental ceramics; Bond strength; Tensile test; Microhardness Knoop and Vickers; Surface roughness AFM 


\section{LISTA DE FIGURAS}

Figura 4.1 - Molde de aço desenvolvido para a confecção dos cones de cerâmica. Tampa da matriz (a) e corpo da matriz (b)

Figura 4.2 - Molde de aço para a confecção dos cones de cerâmica. Perfil do molde com (a) e sem (b) a cerâmica

Figura 4.3 - Cones cerâmicos terminados para os ensaios...............................70

Figura 4.4 - Cortes e embutimento das amostras dentárias..............................79

Figura 4.5 - Cimentação do cone cerâmico na superfície dentinária e garra especial desenvolvida para o ensaio de tração

Figura 5.1 - Microscopia de força atômica de dois corpos-de-prova (a e b) da cerâmica VMK 95 em 3 ângulos de observação $\left(1-90^{\circ}, 2\right.$ - 20ㅇ e $\left.3-60^{\circ}\right)$ .96

Figura 5.2 - Microscopia de força atômica de dois corpos-de-prova (a e b) da cerâmica Omega 900 em 3 ângulos de observação (1 - 90ㅜ, 2 - 20ํ e 3 - 60).

Figura 5.3 - Microscopia de força atômica de dois corpos-de-prova (a e b) da cerâmica IPS d.Sign em 3 ângulos de observação $\left(1-90^{\circ}, 2\right.$ - $20^{\circ}$ e $\left.3-60^{\circ}\right)$....

Figura 5.4 - Microscopia de força atômica de dois corpos-de-prova (a e b) da cerâmica Cergogold em 3 ângulos de observação (1 - 90으, 2 - 20ํ e 3 - 60\%).

Figura 6.1 - Médias de resistência de união (MPa) de cerâmicas em dentina humana, cimentadas com o cimento de fosfato de zinco,por ensaio de tração.

Figura 6.2 - Médias de resistência de união (MPa) de cerâmicas em dentina humana, correspondente à interação cerâmica $x$ cimento, cimentadas com os cimentos Rely $X \mathrm{e}$ Panávia F.

Figura 6.3 - Médias de rugosidade $(\mu \mathrm{m})$ do parâmetro Ra de superfícies de cerâmicas tratadas com ácido fluorídrico a 10\%. 
Figura 6.4 - Médias de rugosidade $(\mu \mathrm{m})$ dos parâmetros Rt, Ry, Rz e Rp de superfícies de cerâmicas, correspondentes à interação cerâmica x parâmetro de rugosidade de superfícies tratadas com ácido fluorídrico a $10 \%$

Figura 6.5 - Médias de rugosidade $(\mu \mathrm{m})$ do parâmetro $\mathrm{Ra}$ de superfícies de cerâmicas polidas.

Figura 6.6 - Médias de rugosidade $(\mu \mathrm{m})$ dos parâmetros Rt, Ry, Rz e Rp de superfícies de cerâmicas,correspondentes à interação cerâmica $x$ parâmetro de rugosidade de superfícies polidas

Figura 6.7 - Médias de dureza $\left(\mathrm{kgf} / \mathrm{cm}^{2}\right)$ correspondentes ao fator principal (cerâmica)

Figura 6.8 - Médias de dureza $\left(\mathrm{kgf} / \mathrm{cm}^{2}\right)$ correspondentes à interação cerâmica $x$ tipo de dureza e diferenças (Vickers-Knoop) 


\section{LISTA DE TABELAS}

Tabela 4.1 - Ciclos de cocção das cerâmicas................................................71

Tabela 4.2 - Esquema de distribuição dos cones de cerâmicas em função da sua respectiva divisão para os testes laboratoriais

Tabela 5.1 - Análise de variância da resistência de união de cerâmicas em dentina humana, cimentadas com o cimento de fosfato de zinco

Tabela 5.2 - Médias de resistência de união (MPa) de cerâmicas em dentina humana, cimentadas com o fosfato de zinco, por ensaio de tração e valor crítico pelo teste de Tukey.

Tabela 5.3 - Análise de variância da resistência de união de cerâmicas em dentina humana, cimentadas com os cimentos Rely $X \mathrm{e}$ Panávia F.

Tabela 5.4 - Médias de resistência de união (MPa) de cerâmicas em dentina humana, correspondentes aos fatores principais (cerâmica e cimento) cimentadas com os cimentos Rely Xe Panávia F.

Tabela 5.5 - Médias de resistência de união (MPa) de cerâmicas em dentina humana, correspondentes à interação cerâmica $x$ cimento, cimentadas com os cimentos Rely $X \mathrm{e}$ Panávia $F$ e valor crítico pelo teste de Tukey

Tabela 5.6 - Freqüências dos tipos de fratura, suas somas com e sem os dados correspondentes ao cimento de fosfato de zinco e teste qui-quadrado com exclusão deste.

Tabela 5.7 - Comparação entre os tipos de fratura (teste binomial), excluindo os de cimento de fosfato de zinco.

Tabela 5.8 - Análise de variância de rugosidade do parâmetro Ra de superfícies de cerâmicas tratadas com ácido fluorídrico a $10 \%$

Tabela 5.9 - Médias de rugosidade $(\mu \mathrm{m})$ do parâmetro Ra de superfícies de cerâmicas tratadas com ácido fluorídrico a 10\% e valor crítico pelo teste de Tukey. 
Tabela 5.10 - Análise de variância de rugosidade dos parâmetros Rt, Ry, Rz, e Rp de superfícies de cerâmicas tratadas com ácido fluorídrico a $10 \%$.

Tabela 5.11 - Médias de rugosidade $(\mu \mathrm{m})$ dos parâmetros Rt, Ry, Rz e Rp de cerâmica, correspondentes aos fatores principais (cerâmica e parâmetro de rugosidade) de superfícies tratadas com ácido fluorídrico a 10\% e valores críticos pelo teste de Tukey

Tabela 5.12 - Médias de rugosidade $(\mu \mathrm{m})$ dos parâmetros Rt, Ry, Rz e Rp de superfícies de cerâmicas, correspondentes à interação cerâmica $X$ parâmetro de rugosidade de superfícies tratadas com ácido fluorídrico a $10 \%$ e valor crítico pelo teste de Tukey.

Tabela 5.13 - Análise de variância da rugosidade do parâmetro Ra de superfícies de cerâmicas polidas.

Tabela 5.14 - Médias de rugosidade $(\mu \mathrm{m})$ do parâmetro Ra de superfícies de cerâmicas polidas e valor crítico pelo teste de Tukey

Tabela 5.15 - Análise de variância de rugosidade dos parâmetros $\mathrm{Rt}, \mathrm{Ry}, \mathrm{Rz}$, e Rp de superfícies de cerâmicas polidas

Tabela 5.16 - Médias de rugosidade $(\mu \mathrm{m})$ dos parâmetros Rt, Ry, Rz e Rp de cerâmica, correspondentes aos fatores principais (cerâmica e parâmetro de rugosidade) de superfícies polidas e valores críticos pelo teste de Tukey.

Tabela 5.17 - Médias de rugosidade $(\mu \mathrm{m})$ dos parâmetros $\mathrm{Rt}, \mathrm{Ry}, \mathrm{Rz}$ e Rp de superfícies de cerâmicas, correspondentes À interação cerâmica $x$ parâmetro de rugosidade de superfícies polidas e valor crítico pelo teste de Tukey....

Tabela 5.18 - Análise de variância das durezas das cerâmicas. 109

Tabela 5.19 - Médias de dureza $\left(\mathrm{kgf} / \mathrm{cm}^{2}\right)$ correspondentes aos fatores principais (cerâmica e tipo de dureza) e valores crítico pelo teste de Tukey.

Tabela 5.20 - Médias de dureza $\left(\mathrm{kgf} / \mathrm{cm}^{2}\right)$ correspondentes à interação cerâmica $x$ tipo de dureza e diferenças (Vickers-Knoop)... 


\section{LISTA DE ABREVIATURAS}

AFM Microscopia de força atômica

MEV Microscopia eletrônica de varredura

Ra Padrão de rugosidade da média aritmética dos desvios (picos e vales) em relação à linha central durante a análise da perfilometria.

Rp Padrão de rugosidade da média aritmética dos maiores picos em relação à linha central de sub-trajetos durante a análise da perfilometria.

Rt Padrão de rugosidade da distância entre o maior pico e maior vale em todo o trajeto na análise da perfilometria.

Ry Padrão de rugosidade da maior distância entre pico e vale dentro de um sub-trajeto na análise da perfilometria.

Rz Padrão de rugosidade da média aritmética de picos e vales de sub-trajetos na análise da perfilometria. 


\section{SUMÁRIO}

p.

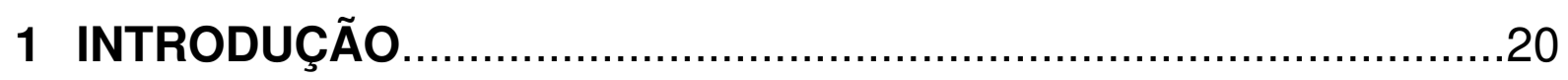

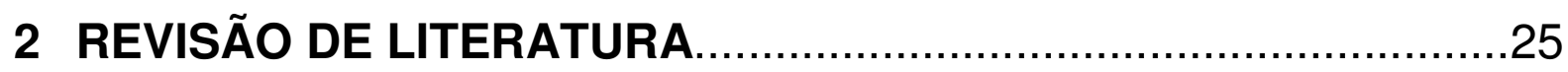

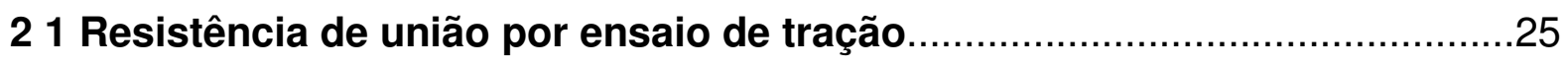

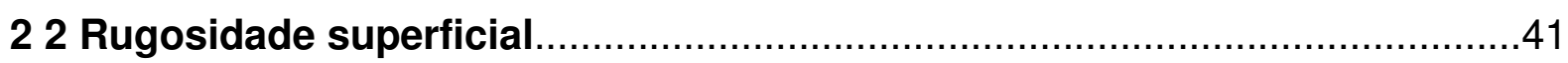





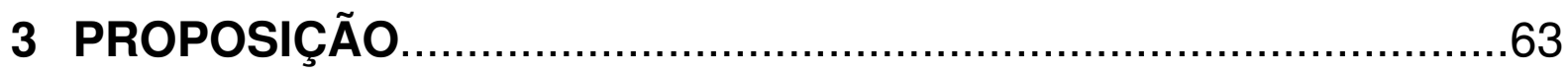

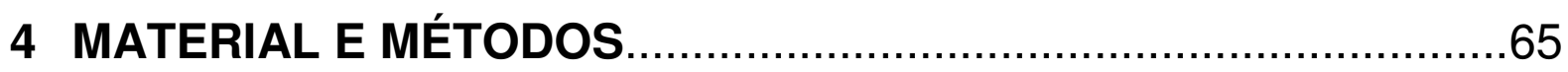



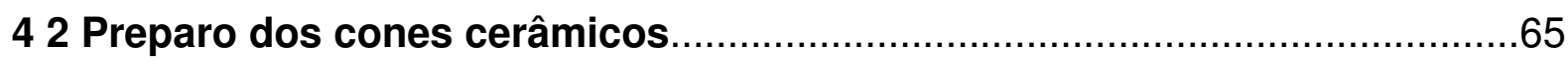

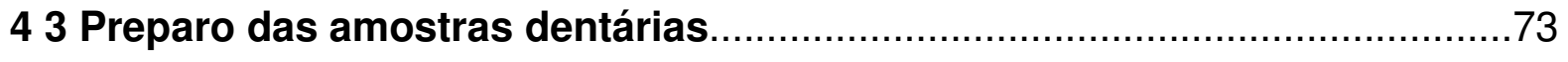

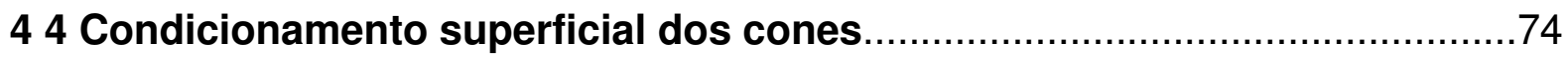

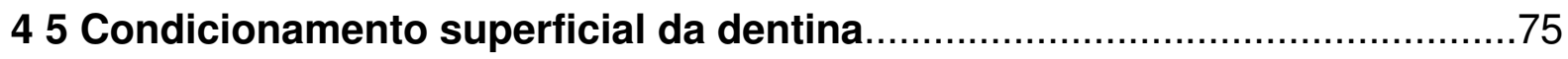

46 Cimentação, armazenagem e teste de resistência de união, por ensaio de

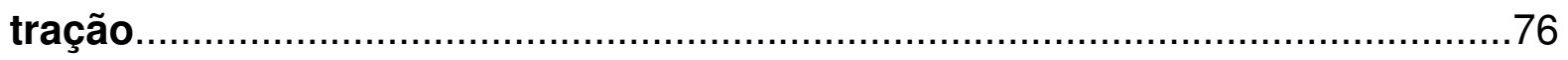

47 Ensaio de rugosidade superficial...................................................

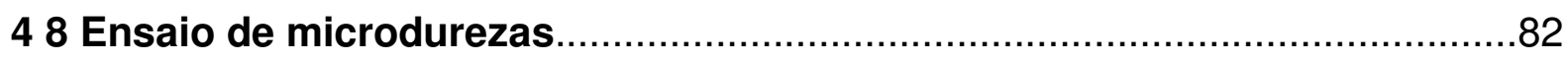

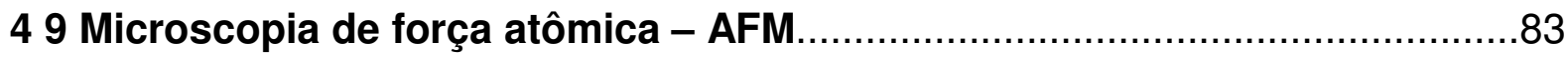


5 RESULTADOS

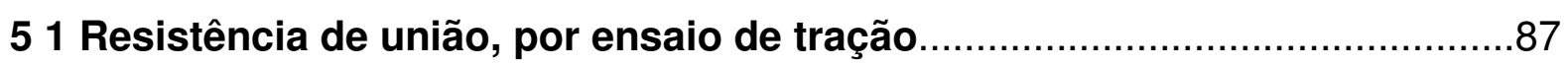

52 Rugosidade superficial das superfícies das cerâmicas..............................89

53 Durezas Knoop e Vickers das cerâmicas.........................................................

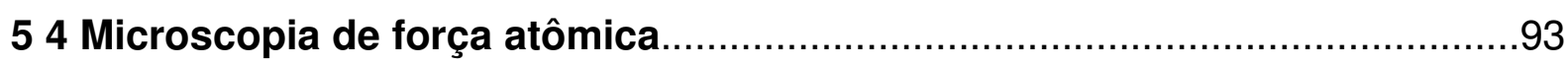

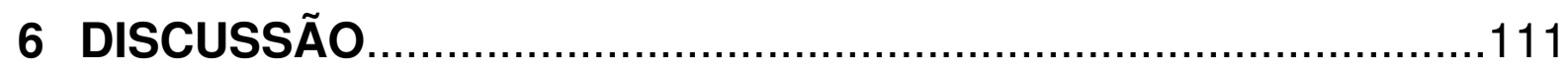

61 Resistência de união, por ensaio de tração...........................................111

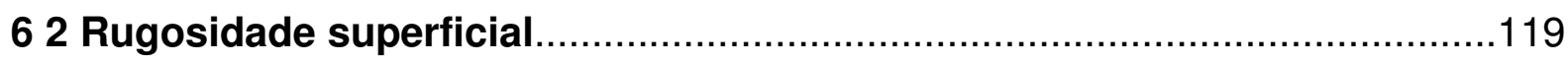



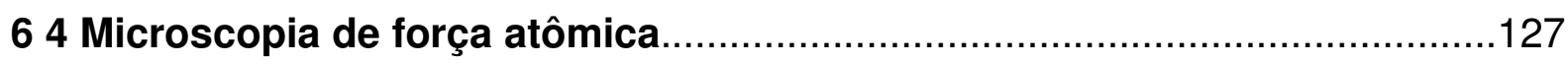

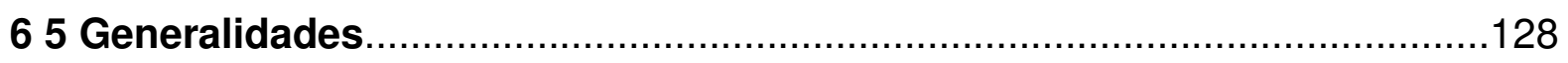

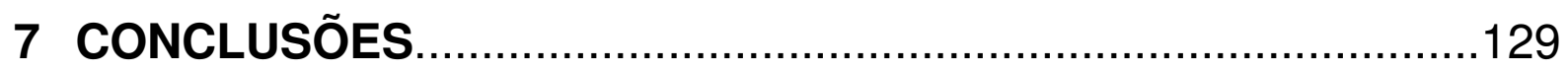



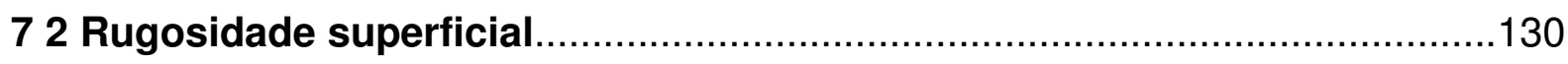

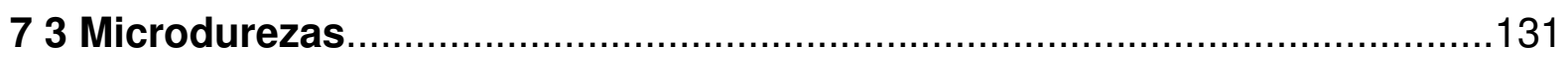



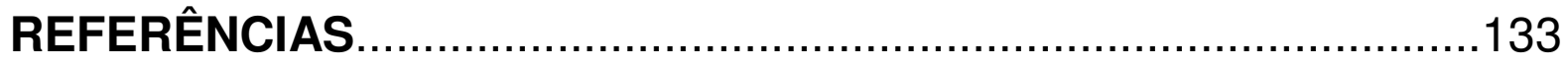

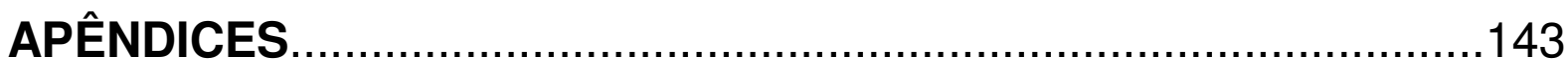

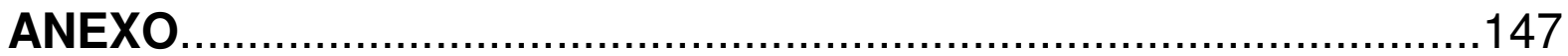




\section{INTRODUÇÃO}

Desde o início da humanidade, as cerâmicas estão presentes em nosso cotidiano. Os materiais cerâmicos foram, provavelmente, os primeiros a serem manufaturados pelo homem, devido a sua facilidade de manuseio e capacidade de ser conformado dentro de uma variedade de formas, cores, translucidez e reflectividade. Registram-se dados do aparecimento das cerâmicas em 5.500 a.C. na Turquia e 100 a.C. na China, enquanto que na Europa o uso das cerâmicas foi introduzido por volta dos séculos $X V$ e $X V I$, devido às negociações com o Oriente (CRAIG; POWERS, 2004).

Cientificamente as cerâmicas são definidas como sólidos não metálicos inorgânicos. Esta definição amplia consideravelmente a origem etimológica da palavra cerâmica que em grego "keramos" quer dizer, barro queimado.

Basicamente, as cerâmicas são materiais constituídos de elementos metálicos e não metálicos, apresentando ligações de natureza iônica e/ou covalente. Por isso, esta classe de materiais é caracterizada pela presença de estruturas variadas, podendo ser cristalina, vítrea ou mista. Devido à grande possibilidade de combinação desses elementos, podem existir vários arranjos estruturais para a mesma combinação, o que vem a ser chamado de polimorfismo (FREIMAN, 1996).

As cerâmicas podem ser obtidas pela fusão de argilas ou produtos naturais, tratamento químico de minerais e rochas ou via processos químicos 
para obtenção de pós-particulados. A etapa final do processamento cerâmico é caracterizada pelo fenômeno de sinterização, processo onde ocorre a densificação do material a altas temperaturas, tornando-o apto para uso (VAN NOORT, 2004).

Dentro dos componentes mais comuns de uma cerâmica, o caulim atua como aglutinante na cerâmica aumentando a moldabilidade da massa, é opaco, não translúcido e pode ser substituído por vidro feldspático com inclusões cristalinas de sílica; a sílica atua como agente de reforço na resistência mecânica da cerâmica e está presente como uma dispersão cristalina fina em toda a fase vítrea que é produzida pela fusão do feldspato e este, também conhecido como albita, sofre liquefação quando se funde formando uma matriz vítrea. O feldspato deve estar na proporção adequada para evitar o fluxo piroplástico excessivo, o que irá gerar um arredondamento nas bordas de uma peça protética, perdendo essas, a anatomia dental esculpida. Para assegurar essa proporção são introduzidos carbonatos na composição da cerâmica. O silicato de $\mathrm{Na}$ diminui a temperatura de fusão e o silicato de $\mathrm{K}$ aumenta a viscosidade do vidro fundido (GERMAN, 1989).

À medida que as técnicas de processamento cerâmico foram se tornando mais sofisticadas, houve a necessidade da obtenção de uma nova classe de cerâmicas, não mais convencionais, com propriedades cada vez melhores, atendendo a diferentes categorias industriais, chamadas cerâmicas avançadas, assim, a Corning Glass Works, em 1.950, desenvolve as cerâmicas vitrificadas 
ou, vidros cerâmicos, materiais que atendem com mais eficiência, às exigências clínicas em seu desempenho, ou em sua vida útil (CRAIG; POWERS, 2004).

Hoje são encontrados no âmbito odontológico, diversos tipos de cerâmicas como, por exemplo, as cerâmicas convencionais ou feldspáticas, as cerâmicas reforçadas por leucita, por dissilicato de lítio, por fluormica, por zircônia, por apatita, por alumina, as cerâmicas vitrificadas ou chamadas de vidros cerâmicos e as cerâmicas apenas infiltradas com vidros de alta resistência, considerando que as aplicações destinadas às cerâmicas são diretamente dependentes de sua composição química e microestrutura que, juntas, determinam suas propriedades, que são: elevada temperatura de fusão, baixa condutividade térmica, alta dureza e resistência à abrasão e compressão, refratariedade, resistência à oxidação, inércia química, biocompatibilidade e friabilidade (VAN VLACK, 1984).

Os vidros cerâmicos são materiais que se enquadram em algumas composições vítreas que podem ser cristalizadas após processamento (ceramização). A grande vantagem desses materiais diz respeito à facilidade de processamento que é idêntico ao do vidro e também por apresentarem propriedades típicas de materiais cristalinos. As propriedades dos vidros cerâmicos são intermediárias entre a classe das cerâmicas e dos vidros, tendo uma boa resistência ao choque térmico.

Com essa evolução na classe das cerâmicas, o tratamento para a reabilitação oral vem sofrendo ao longo do tempo mudanças importantes devido ao desenvolvimento de materiais reabilitadores estéticos, empregados nos 
tratamentos atuais. Esses materiais estão diretamente envolvidos com a tecnologia avançada, hoje presente nas empresas de materiais destinados ao mercado odontológico. Este aspecto de evolução sobre esses materiais conduz o cirurgião-dentista a alterar suas manobras clínicas perante o novo material e ao novo tratamento que será oferecido aos seus pacientes (AKGUNGOR; AKKAYAN; GAUCHER, 2005; WITZEL et al., 2003).

O que ficava restrito a peças metálicas ou metalocerâmicas associadas a cimentos não resinosos, como por exemplo, o cimento de fosfato de zinco e o cimento de ionômero de vidro, em um tratamento reabilitador, hoje ganham o mercado, as peças protéticas em cerâmica pura associadas a cimentos resinosos, abrindo um espaço clínico relevante na reabilitação estética do paciente (BRAGA; BALLESTER; CARRILHO, 1999).

A crescente demanda por materiais estéticos na odontologia tem feito com que o estudo e os testes laboratoriais das cerâmicas se desenvolvam com grande rapidez, (MARTUCI; MUENCH, 2004), pois além de proporcionarem um resultado excelente quanto à reabilitação estética, as restaurações totalmente cerâmicas apresentam vantagens incontestáveis como a estabilidade de cor, resistência ao manchamento e ao desgaste e biocompatibilidade (BRAGA; BALLESTER; DARONCH, 2000).

Apesar de toda a informação gerada até hoje, as cerâmicas ainda representam um desafio para pesquisadores e clínicos, pois, apresentam algumas deficiências que ainda impedem a sua indicação irrestrita. 
Como restam dúvidas em relação ao material cerâmico, às suas propriedades e à sua aplicação clínica, recorreremos à revisão da literatura para averiguar o que é encontrado em relação a esse biomaterial. 


\section{REVISÃO DA LITERATURA}

Para uma melhor compreensão dos diversos testes e metodologias envolvidas no desenvolvimento das diferentes propriedades das cerâmicas, este capítulo será dividido em tópicos.

\subsection{Resistência de união por ensaio de tração}

Imai (1990) estudou o efeito do pré-tratamento, das superfícies da porcelana, na resistência adesiva, com Panavia EX. Empregou um agente de ligação silano (2\% gamma MPTS), aquecido a 100,150 ou $200^{\circ} \mathrm{C}$ ou condicionamento com HF 30\%. Após imersão em água a $37^{\circ} \mathrm{C}$ por 24 horas, as retenções, por cisalhamento, variaram de 44,1 a $51,0 \mathrm{MPa}\left(450\right.$ a $520 \mathrm{kgf} / \mathrm{cm}^{2}$ ). Após a termociclagem ( 4 e $60^{\circ} \mathrm{C}$ e 20.000 ciclos) a retenção se manteve em 70 a $80 \%$ em relação à inicial, com o condicionamento com $\mathrm{HF} 30 \%$ e aquecimento com o silano em $150^{\circ} \mathrm{C}$.

Tseng, Cooley e Ivans (1992) investigaram a resistência de união de porcelana à dentina, por meio de adesivo dentinário (All-Bond), comparando-a com aquela do esmalte. As superfícies foram preparadas com lixa 600. Cilindros de porcelana em um dos lados foram tratados com ácido fluorídrico e silano. Os 
grupos foram: união ao esmalte; união à dentina e ensaio em 48 horas; união à dentina e ensaio em $24 \mathrm{~h}$, após termociclagem (800 ciclos -6 e $\left.60^{\circ} \mathrm{C}\right)$. Os resultados foram: esmalte (19,0MPa); dentina 48h (14,4 MPa); dentina após termociclagem $(10,1 \mathrm{MPa})$. A análise estatística mostrou diferença significante entre as três médias.

A influência, na resistência de união do forramento com ionômero de vidro na cimentação de facetas de porcelana, foi abordada por Kedeci, Kalipcilar e Bilir (1992). Analisaram 4 grupos: A - desgaste de $0,5 \mathrm{~mm}$ com união ao esmalte; B, C e D sofreram desgaste de $1,0 \mathrm{~mm}$ e nos grupos C e D foi aplicado forramento com ionômeros de vidro (LCL8 e lonoseal respectivamente). As resistências de união, por ensaio de cisalhamento dos diversos grupos foram (MPa): $\mathrm{A}-8,2$; $\mathrm{B}$ 9,$8 ; C-4,5 ; D-7,3$.

Khairy e Sobhy (1994) examinaram o efeito do condicionamento superficial de esmalte na resistência de união, por ensaio de cisalhamento, entre materiais e dentes humanos com diferentes sistemas adesivos. Quarenta e dois molares humanos extraídos foram usados nesse estudo. Botões de 6 × 3mm de dois tipos de resina composta e botões de $5 \times 3 \mathrm{~mm}$ de cerâmica dental foram preparados. Os botões preparados foram fixados às superfícies vestibular, lingual e proximal dos molares extraídos. As superfícies de esmalte foram desgastadas em alguns grupos e deixadas sem corte em outros grupos. Um, ou uma combinação de dois, dos seguintes materiais adesivos foram usados nos grupos de resina composta: Scotchbond quimicamente ativado; Scotchbond fotopolimerizável; Visio-Gem; Visio-Gem Glaze e Conclude e nos grupos de 
cerâmica: Scotchprime, Conclude, Silux, e Visio-Gem. A análise de variância de um fator permitiu concluir que: a) nos grupos Silux, não houve diferença significante na resistência de união entre os esmaltes cortados e não-cortados com diferentes sistemas adesivos (cerca de $1200 \mathrm{lb} / \mathrm{pol}^{2}-8,3 \mathrm{MPa}$ ); b) entre os grupos de Visio-Gem, a mais alta resistência de união foi obtida com a superfície de esmalte cortada quando usada a combinação de Visio-Gem e Visio-Gem Glaze; c) os grupos de cerâmica mostraram as mais altas resistências de união com as superfícies de esmalte cortadas e o uso da combinação Scotchprime e Conclude apresentou o maior valor de união ao esmalte $\left(2681 \mathrm{lb} / \mathrm{pol}^{2}-18,5 \mathrm{MPa}\right)$.

Preocupados com a resistência inicial da união porcelana-dentina, empregando cimento dual, Braga, Ballester e Carrilho (1999) realizaram um estudo sobre o cimento, empregando o teste de cisalhamento. Empregaram dentes molares e pré-molares humanos. Os cimentos duais foram o Porcelite e Dual. Também fizeram os testes com um cimento ativado quimicamente (C\&B luting composite). As peças de cerâmica foram condicionadas com ácido fluorídrico, cobertas com silano e cimentadas à dentina plana, com cada um dos cimentos, associados com o sistema adesivo Optibond. A fotoativação foi realizada com a intensidade de $450 \mathrm{~mW} / \mathrm{cm}^{2}$. Os espécimes foram armazenados em água a $37^{\circ} \mathrm{C}$. Os ensaios foram realizados nos períodos de 10,30 e 90 minutos e 7 dias. Os resultados nos diversos períodos, com os três cimentos respectivamente Porcelite dual cure/Dual cement/C\&B luting composite foram (MPa): $10 \min -14,0 / 13,7 / 2,7 ; 30 \min -16,4 / 13,6 / 4,6 ; 90 \min -18,7 / 22,0 / 10,5 ; 7$ dias - 72,2/70,2/60,2. Ambos os cimentos duais apresentaram resultados semelhantes. A evolução da união desses cimentos, também foi bem mais veloz. 
Braga, Ballester e Daronch (2000) investigaram a resistência de união entre sistemas adesivos e dentina bovina por ensaio de cisalhamento por extrusão. Os ensaios após cimentação foram aos 15min, 4, 12 e 24 h e 7 dias. Os cimentos foram: C\&B cement; Enforce; Rely X ARC e Variolink II. Os resultados mostraram que com os cimentos Enforce, Rely $X$ e Variolink aos 15min a resistência de união já era bem alta, e a do C\&B em 4h, também já tinha alcançado o valor de 7 dias.

Uno et al. (2000) examinaram a resistência de união, por microtração, de incrustações de Cerec II cimentadas em dentina com preparos Classe II, usando três materiais de cimentação. Um disco de VitaMark II foi unido à superfície coronária da dentina com Clapearl DC (Clearfil DC)/Linerbond Ilsigma (Linerbond 2V), AP-X/Linerbond Ilsigma ou Fluorcement (Panávia F)/ED Primer. Após 24h de armazenamento em água, foram feitos os testes de microtração. Além disso, as incrustações em Cerec II foram cimentadas aos preparos $\mathrm{MO}$ em molares com os mesmos materiais. Após termociclagem (2000 ciclos), essas incrustrações foram cortadas distomesialmente. A formação de lacunas foi examinada microscopicamente ao longo das paredes das cavidades. Não houve diferença significante na microtração entre os materiais Clapearl DC: 20,89 \pm 4,58MPa; AP-X: 24,22 \pm 5,97MPa e Fluorocement: 19,82 \pm 6,43MPa. freqüência da formação de lacunas foi maior significantemente na AP-X do que na Clapearl DC e na Fluorocement (teste qui-quadrado, $p<0,05$ ). As fraturas ocorreram com maior freqüência entre cimento/dentina do que na interface cimento/cerâmica. 
A resistência de união, por ensaio de cisalhamento, a vários substratos, de espécimes de porcelana, cimentados com o adesivo Syntac e cimento resinoso Variolink II, foi investigada por Ferrari et al. (2000). Os resultados com os diversos substratos foram os seguintes $(\mathrm{MPa})$, onde com letras iguais há semelhança: Amálgama , AMG - 6,90c; Compômero, Dyract - 15,38b; lonômero de vidro tradicional, Fuji IX - 15,12b; resinas compostas, Spectrum TPH 15,39b; idem PhotoCore - 18,06a; idem Bis-Core - 19,26a; Ouro Strator 3, sem jateamento $-10,82 c$; idem com jateamento - 14,43b; dentina - 17,0ab; esmalte $-19,9 a$.

Hooshmand, Van Noort e Keshvad (2002) estudaram a influência da silanização, da superfície de cerâmica a base de sílica, na resistência de união à resina com ensaios à tração. De 7 grupos silanizados, destacaram o grupo 5 (21,0MPa) e o grupo $7(25,7 \mathrm{MPa})$. No grupo 5 foi aplicado o silano e secado com ar a $50 \pm 5^{\circ} \mathrm{C}$, por $15 \mathrm{~s}$. No grupo 7 o espécime foi imerso em água a $80^{\circ} \mathrm{C}$, secado com ar quente e aplicada uma fina camada de resina sem carga antes de aplicar a resina de cimentação. Outros tratamentos com o silano apresentaram resistências de união de 13,7 a 19,6MPa. Para fins comparativos com a aplicação de silano em superfícies de porcelana lisa, procedeu-se o tratamento superficial com jateamento (óxido de alumínio $50 \mu \mathrm{m}$ ), condicionamento com HF 10\% por 2 minutos e jateamento mais aplicação de HF. Os resultados foram comparados com 0 grupo 7 atrás visto, não havendo diferenças significantes entre eles (23,8 a 28,3MPa). 
A resistência de união, por cisalhamento, de cimentos resinosos, à cerâmica feldspática e dentina foi abordada por Stewart, Jain e Hodges (2002). Empregaram 4 marcas de cimentos (Nexus, Panávia 21, Rely X ARC e Calebra). Os tratamentos superficiais da cerâmica foram: G1 (SiC), apenas jateamento com abrasivo; G2 (ME), microechting (microjateamento); G3 (Sil),aplicação da solução de silano; G4 (ME + Sil), microjateamento mais silano; G5 (HF), condicionamento com solução de HF 9,6\%; G6 (HF + Sil), condicionamento como em G5 e mais silano como em G3. O condicionamento da dentina foi realizado conforme instruções dos respectivos fabricantes de cada marca de cimento. Os resultados mostraram que: o tratamento superficial da cerâmica com $\mathrm{HF}+$ Sil conduziu a resultados bastante uniformes com os 4 cimentos, tanto no ensaio após 24 horas (16,0 a 21,7MPa), como naquele após 6 meses (15,9 a 21,8MPa); os tratamentos SiC e ME conduziram a valores baixíssimos em $24 \mathrm{~h}$ e zero após 6 meses; nos demais tratamentos, resultados satisfatórios dependiam do cimento; a resistência de união à dentina variou de 8,1 a $19,6 \mathrm{MPa}$, dependendo do cimento.

Gonçalves et al. (2002) estudaram a resistência de união, por ensaio de microtração entre a cerâmica IPS Empress e dois cimentos resinosos (Panávia F e Rely X). Foram construídos blocos cerâmicos, polidos em politriz mecânica até a lixa 1.200 , condicionados com ácido fluorídrico $10 \%$, silanizados e cimentados com os respectivos cimentos com blocos idênticos de resina Clearfill APX. Esses conjuntos foram armazenados em água destilada a $37^{\circ} \mathrm{C}$ por 7 dias. Posteriormente ao período da armazenagem, através desses conjuntos foram obtidos 20 palitos medindo $10 \mathrm{~mm} \times 1 \mathrm{~mm} \times 1 \mathrm{~mm}$ com área adesiva de 
aproximadamente $1 \mathrm{~mm} \pm 0,1 \mathrm{~mm}^{2}$, totalizando 10 repetições para cada cimento. Levados a máquina universal, foram testados a uma velocidade de $0,5 \mathrm{~mm} / \mathrm{min}$ com uma célula de carga de 10kgf. Aos dados foi aplicado o teste de MannWhitney e os autores concluíram que o cimento resinoso Rely X, mostrou superioridade $(40,27 \mathrm{MPa})$ quando comparado ao cimento resinoso Panávia $\mathrm{F}$ $(36,34 \mathrm{MPa})$.

Silva, Roizman e Spyrides (2002) compararam a resistência de adesão, por cisalhamento, entre a cerâmica infiltrada In-Ceram e a cerâmica feldspática Vitadur Alpha, cimentadas ao esmalte bovino com o cimento Panávia F. Vinte corpos-de-prova foram construídos e divididos em 2 grupos (n=10). Grupo 1 cilindros de cerâmica feldspática com superfície condicionada com ácido fluorídrico e silanizada. Grupo 2 - cilindros de cerâmica infiltrada com superfície jateada com óxido de alumínio $50 \mu \mathrm{m}$ e silanizada. A cimentação se deu conforme instruções do fabricante. Após cimentação e rompidos os corpos-deprova por cisalhamento na máquina Instron, os dados obtidos foram submetidos à análise de variância. Os autores concluíram que o cimento Panávia $F$ está indicado para cimentação em ambas as cerâmicas, pois os níveis de adesão não apresentaram diferenças estatísticas, sendo a resistência adesiva 27,86 \pm 3,30MPa para a cerâmica feldspática Vitadur Alpha e 23,32 $\pm 0,14 \mathrm{MPa}$ para a cerâmica infiltrada In-Ceram.

Correr-Sobrinho et al. (2002) estudaram a resistência à tração entre a cerâmica IPS Empress II e os cimentos Rely X (resinoso) e ProtecCem (ionomérico) com diferentes tratamentos superficiais. Oitenta discos com 2,5mm de espessura e 5,5mm de diâmetro foram confeccionados e cimentados aos 
pares, sendo divididos em 4 grupos. Os grupos 1 e 2 foram condicionados com ácido fluorídrico $10 \%$ por 20 segundos e silanizados. Os grupos 3 e 4 foram jateados com óxido de alumínio $100 \mu \mathrm{m}$ por 5 segundos e silanizados. Os grupos 1 e 3 foram unidos com o cimento Rely $X$ e os grupos 2 e 4 foram unidos com 0 cimento ProteCem. Os quatro grupos foram mantidos em água destilada a $37^{\circ} \mathrm{C}$ por 24h. As amostras foram submetidas ao ensaio de tração com uma velocidade constante de $1 \mathrm{~mm} / \mathrm{min}$. Aos dados foi aplicado a análise de variância e o teste de Tukey $5 \%$. Os autores concluíram que o cimento Rely X apresentou valores de resistência à tração superiores ao cimento ProtecCem $(25,36 \mathrm{MPa} / \mathrm{HF}$ e $8,35 \mathrm{MPa}$ /jateamento) tanto no condicionamento com o ácido fluorídrico como no jateamento.

Leite et al. (2002) avaliaram a resistência de união entre uma cerâmica vítrea de dissilicato de lítio (IPS Empress II) e dois cimentos resinosos (Panávia F e Rely X). Sobre blocos de cerâmica tratados com HF 10\% e silanizados foram colocados os blocos de reina. Após 7 dias de armazenagem foram obtidos os palitos $\left(1 \mathrm{~mm}^{2} \pm 0,1 \mathrm{~mm}^{2}\right)$ para os ensaios de microtração. O grupo com Panávia $\mathrm{F}(45,8 \mathrm{MPa})$ não foi significantemente diferente daquele com Rely X $(49,4 \mathrm{MPa})$.

Oh et al. (2002) estudaram o efeito da topografia superficial no molhamento de cerâmicas pela água e resina adesiva. Empregaram 3 cerâmicas. As superfícies foram tornadas rugosas por 4 métodos: abrasão com lixa 1200; jateamento com partículas $(50 \mu \mathrm{m})$ de $\mathrm{Al}_{2} \mathrm{O}_{3}$; condicionamento com gel de $\mathrm{HCl} 5 \%$; combinação de jateamento e condicionamento. Os resultados mostraram que: a molhabilidade de cerâmica por líquido foi influenciada pela 
rugosidade; os métodos de condicionamento e conjugação de jateamento e condicionamento foram mais eficientes em aumentar a superfície e molhamento.

Witzel et al. (2003) estudaram a resistência de união, entre cimentos baseados em polímeros e superfícies porcelana/dentina, avaliando a influência do modo de polimerização e carregamento cíclico inicial. A metade dos espécimes foi ciclada 15 minutos após mistura do cimento (60N, 20 vezes). Após 24 horas de armazenagem em água foram feitos os ensaios de cisalhamento por extrusão. Os sistemas adesivos foram o Choice/One-Step e Rely X ARC/Single Bond, ambos empregados como polimerização auto e dual. Ambos os sistemas adesivos na polimerização dual apresentaram resistências semelhantes $(12,8$ a 14,0 MPa) quer com ciclagem quer sem, que não apresentou influência. Os valores correspondentes a auto-polimerização foram bem menores $(4,4$ a 7,6 $\mathrm{MPa}$ ), sem influência considerável da ciclagem mecânica. No entanto saliente-se que durante a ciclagem houve alguns rompimentos. Mas os que resistiram não apresentaram a resistência diminuída em relação à condição de sem ciclagem.

Della Bona, Anusavice e Mecholsky-Júnior (2003) empregaram princípios fractográficos para classificar a forma de falha de resina composta unida a espécime cerâmico, após o teste de microtração. Uma cerâmica com leucita (IPS Empress - E1) e uma cerâmica de dissilicato de lítio (IPS Empress 2 - E2) foram selecionadas para o estudo. Quinze blocos de E1 e de E2 foram confeccionados e polidos por um abrasivo de alumina com partículas de $1 \mu \mathrm{m}$. Foram realizados os seguintes tratamentos de superfícies nas cerâmicas com $n=3$ : (1) $9,5 \%$ de ácido fluorídrico (HF) por 2min; (2) fluoreto acidulado de fosfato 4\% (APF) por 2min; (3) aplicação de silano (S); (4) HF + S; (5) APF + S. Um adesivo e uma 
resina composta foram aplicados em todas as superfícies tratadas e fotopolimerizadas. Vinte espécimes em barras de cada grupo foram preparadas dos blocos de resina e cerâmica e armazenados em água destilada a $37^{\circ} \mathrm{C}$ por 30 dias antes de serem submetidas à microtração na máquina de ensaios universais Instron. As superfícies das fraturas foram examinadas usando a microscopia de varredura de elétrons (MEV) e o raio-X de mapeamento de pontos. A estatística foi feita pela análise de variância de um fator, teste de Duncan e a análise de Weibull. Os autores concluíram que os diferentes tratamentos de superfície foram semelhantes e a adesão na interface de união foi significativamente diferente para E1 e E2. Todas as fraturas ocorreram dentro dos limites da zona de adesão. A diferença microestrutural entre as cerâmicas E1 e E2 foi o maior fator de controle da adesão.

Blatz et al. (2003) avaliaram a resistência de união de um agente de cimentação modificado com fosfato, com cerâmica Procera AllCeram, abrasionada com jatos de ar/partículas, silanizada ou não, comparado com sistema adesivo convencional. Blocos da cerâmica e resina composta, sob vários tratamentos superficiais, foram unidos pelos adesivos Panávia 21 TC ou Rely X ARC. Os ensaios de resistência de união, por cisalhamento, foram feitos após imersão em água por 3 dias ou 180 dias (com ciclagem térmica - 12.000 ciclos). Os resultados mostraram que: a resistência adesiva em decorrência do tempo de armazenagem foi altamente significante, com Rely X ARC, e sua silanização $(22,75 \mathrm{MPa})$ caiu significantemente (3,32MPa), com Panávia 21, a diminuição foi significante, mas não tão acentuadamente, 3 dias (21,42MPa) e 180 dias com ciclagem térmica $(16,09 \mathrm{MPa})$. As resistências de união com Panávia sem 
silanização foram baixas e não diferentes entre si $(3 d=8,06$ e $180 \mathrm{~d}=6,91 \mathrm{MPa})$. As falhas foram principalmente adesivas junto à superfície cerâmica.

Usumez e Aykent (2003) pesquisaram a aplicação do sistema de laser hidro-cinético (Er,Cr:YSGG), para o condicionamento de esmalte, comparativamente com aplicação de ácido fosfórico, para fins de determinação de resistência de união de laminas de cerâmica. Quarenta dentes foram divididos em 4 grupos ( $n=10)$ : 1) irradiação com laser; 2) condicionamento com ácido fosfórico a 37\%: 3) condicionamento com ácido maléico a 10\%; 4) sem nenhum tratamento superficial. Os resultados mostraram pelos testes de microtração que não houve diferença significante entre os 3 tratamentos ( 1 - 12,1MPa; 2 13,0MPa; 3 - 10,6MPa). O grupo sem tratamento superficial da dentina apresentou o menor valor significantemente. Também a resistência de união foi maior na região incisal do que na cervical.

O efeito, do emprego da silicona para fazer o ajuste de incrustrações de cerâmica, sobre a sua resistência de união, por ensaio de cisalhamento, foi realizado por Szep et al. (2003). Empregaram para os ensaios 2 tipos de cerâmica (blocos Cerec 2 e sinterizados no laboratório, Duceram). Os tratamentos foram: 1 - nenhum; 2 - emprego da silicona para fazer o ajuste; 3 antes do emprego da silicona, aplicação de glicerina. Com emprego da cerâmica Cerec formaram-se os grupos G1, G3 e G5 e com a Duceram G2, G4 e G6, respectivamente para os 3 tratamentos. Os grupos G1 e G2 apresentaram resistência de união (MPa) respectivamente 9,86 e 9,56; os grupos G3 e G5 7,49 e 8,21; os grupos G4 e G6 7,62 e 8,22. Não foram encontradas diferenças significantes entre grupos individuais. 
Usumez et al. (2004) tiveram como propósito avaliar a eficiência de duas diferentes fontes de luz para polimerizar cimentos resinosos, a fim de avaliar a resistência de união entre dente e cerâmica, por ensaio de microcisalhamento. As fontes de fotopolimerização foram de luz halógena convencional (Hilux 350, Express Dental Products) e uma outra com arco de luz de plasma (Power PAC, ADT). Diferença estatística significante foi encontrada entre a resistência de união devida à luz convencional $(20,15 \mathrm{MPa})$ e a unidade de plasma $(15,07 \mathrm{MPa})$.

Um estudo sobre a resistência de união entre resina composta e cerâmica injetada, por ensaio de microtração, foi realizado por Filho et al. (2004). A pesquisa foi feita sob 4 condições de tratamento superficial da cerâmica. G1: solução de HF a 9,5\%, por 20 segundos mais silano (S) por 3 minutos; G2: silano por 3 minutos; G3: HF a 9,5\% por 20 segundos; G4: sem tratamento. O agente adesivo foi o Scotchbond e a resina composta a Z250. As resistências de união foram em MPa: G1 - 56,8; G2 - 44,8; G3 - 35,1. No grupo G4, houve falha durante o corte para obter os palitos.

El Zohairy et al. (2004) investigaram o papel de diferentes condicionamentos ácidos das superfícies de cerâmica, envolvendo agentes de união hidrofílicos e hidrofóbicos, para fins de determinar a resistência de união entre resina e cerâmica, por ensaio de microtração. Os cimentos foram: Tetric Flow e Nexus 2. A cerâmica foi a Cerec Vitablocs. Os 6 tratamentos da superfície da cerâmica foram: 1) condicionamento com HF e silanização; 2) condicionamento com HF, silanização e aplicação de agente de união hidrofílico; 3) idem (2) mas agente hidrofóbico; 4) condicionamento com $\mathrm{H}_{3} \mathrm{PO}_{4}$ e silanização; 5) idem (4) e agente de união hidrofílico; 6) idem (5) com agente 
hidrofóbico. Os ensaios foram feitos após 1 dia, 7 dias e 28 dias de armazenagem em água. Uma análise geral dos resultados mostrou que é importante a aplicação na porcelana do HF e o silano para manter a resistência de união e o agente hidrofílico e $\circ \mathrm{H}_{3} \mathrm{PO}_{4}$, embora no início possam conduzir a resultados satisfatórios, com o tempo perdem esta característica. $\mathrm{O}$ agente hidrófobo, com HF mais silano parece conduzir a resultados favoráveis.

Dantas et al. (2004) estudaram a adesão de cimentos resinosos à cerâmica. O estudo comparou a resistência de união da cerâmica IPS Empress II, cimentada ao esmalte bovino, com os cimentos Bistite II DC, Variolink II e Enforce. Foram confeccionados 30 corpos-de-prova de cerâmica (pastilhas com $4 \mathrm{~mm}$ de diâmetro), divididos em 3 grupos $(n=10)$ e submetidos à cimentação conforme instruções do fabricante. Após a cimentação, deu-se o ensaio de cisalhamento na máquina Instron. As médias obtidas foram: 4,67MPa $\pm 3,27$ para o cimento Bistite II DC, $22,43 \mathrm{MPa} \pm 7,56$ para o cimento Variolink II e $14,35 \mathrm{MPa}$ \pm 5,37 para o cimento Enforce. A análise estatística não mostrou diferença significante entre os dois últimos, mas em relação ao primeiro.

Borba, Della-Bona e Diefenthaeler (2004) testaram a resistência de união adesiva por ensaio de tração entre a cerâmica Vita In-Ceram Zircônia - IZ (cerâmica vitrificada reforçada com zircônia) - (Z) e resina. Discos de IZ, com diâmetro de 3,5mm foram confeccionados, incluídos em resina acrílica e polidos em uma politriz mecânica até a lixa 1.200. Esses discos receberam 3 tipos diferentes de tratamentos superficiais. Grupo 1 - condicionamento com o ácido fluorídrico 9,5\% por 2 minutos; Grupo 2 - jateamento com óxido de alumínio 50 $\mu \mathrm{m}$ por 10 segundos e Grupo 3 - silicatização com Cojet - 3M Espe por 10 
segundos. Foram construídos cilindros com a resina fotopolimerizável Z100. Esses cilindros resinosos foram acoplados aos discos cerâmicos com o cimento Bencor Multi-T. Após o teste de tração, os valores médios e o DP obtidos foram: $33,8 \pm 9,9 \mathrm{MPa}$ para 0 grupo $1,73,5 \pm 11,6 \mathrm{MPa}$ para $\circ$ grupo 2 e 100,1 \pm 16,7MPa para o grupo 3. Submetidos à análise de variância e Tukey $5 \%$, os valores foram significantemente diferentes entre si e os autores concluíram que a silicatização produz a mais alta resistência de união adesiva entre a cerâmica IZ e o cimento usado.

Marson et al. (2004) investigaram a resistência de união por microtração de 4 cimentos resinosos na interface adesiva entre a cerâmica IPS Empress II e a dentina. Os sistemas adesivos Single Bond + Rely X, Excite DSC + Variolink II, ED Primer + Panávia e Unicem foram aplicados no substrato de dentina e nas pastilhas previamente confeccionas em cerâmica. Foram obtidos palitos $(1,0 \pm$ $0,2 \mathrm{~mm}^{2}$ ) para o ensaio de microtração . O ensaio se deu na máquina Instron, com uma velocidade de $0,5 \mathrm{~mm} / \mathrm{min}$. Os valores obtidos foram submetidos à análise de variância e Tukey "post hoc" e os autores concluíram que a melhor resistência adesiva se deu entre a dentina e o cimento resinoso Rely X $(17,90 \mathrm{a} \pm$ 3,53MPa) seguido pelo cimento Variolink II $(15,95 \mathrm{~b} \pm 3,07 \mathrm{MPa})$ e Panávia $(15,58 \mathrm{~b} \pm 2,90 \mathrm{MPa})$. O cimento resinoso Unicem, mostrou a pior resistência adesiva $(8,41 \mathrm{c} \pm 2,54 \mathrm{MPa})$.

Pinto et al. (2004) avaliaram a resistência de união adesiva por cisalhamento entre a cerâmica Ceramco II, processada por sinterização e por injeção e o cimento adesivo Rely X. Confeccionadas 26 amostras cerâmicas, essas foram embutidas em resina acrílica, acabadas e polidas em politriz 
mecânica. Receberam tratamento superficial recomendado pelo fabricante e a elas foram cimentados com Rely X cilindros de resina fotopolimerizável Z100. O conjunto foi armazenado em água destilada a $37^{\circ} \mathrm{C}$. Para o teste de cisalhamento a máquina universal foi calibrada com uma célula de carga de $10 \mathrm{kN}$ por $0,5 \mathrm{~mm} / \mathrm{min}$ e as amostras foram testadas. O teste estatístico de MannWhitney $(p=0,05)$ foi aplicado aos dados obtidos e os autores concluíram que a cerâmica processada por sinterização $(16,30 \mathrm{MPa} \pm 5,08)$ ou por injeção $(16,20 \mathrm{MPa} \pm 3,76)$ não apresentam diferença de resistência de união em relação ao cimento utilizado.

Urban et al. (2004) avaliaram a resistência ao cisalhamento, da união entre o cimento resinoso Rely X e os materiais cerâmicos IPS Empress II e InCeram Zircônia. Foram confeccionadas amostras $(n=18)$ das cerâmicas, embutidas em resina acrílica e polidas em politriz mecânica. Essas amostras receberam o tratamento superficial recomendado pelo fabricante. Cilindros de resina Z100 foram construídos e cimentados nas amostras cerâmicas. O teste de cisalhamento foi realizado em uma máquina Instron com célula de carga $10 \mathrm{kN}$ e velocidade de $0,5 \mathrm{~mm} / \mathrm{min}$. O teste de Mann-Whitney evidenciou maior resistência ao cisalhamento para a cerâmica IPS Empress II (18,46 $\pm 5,22 \mathrm{MPa})$ em relação à cerâmica In-Ceram Zircônia $(14,05 \pm 4,93 \mathrm{MPa})$. Concluíram ainda os autores que a maioria das falhas na cerâmica IPS Empress II foram de natureza coesiva enquanto que para a cerâmica In-Ceram Zircônia foram coesivas e adesivas.

A efetividade de sistemas adesivos na durabilidade de união de porcelana (Vita Celay Blanks) foi investigada por Ide et al. (2005). Blocos de cerâmica foram unidos com os seguintes sistemas adesivos: (1) Clapearl Bonding Agent e 
Clapearl DC; (2) Imperva Porcelain Primer e Imperva Dual; (3) Monobond S e Variolink II; (4) Tokuso Ceramics Primer e Bistite II. A resistência de união, por cisalhamento, foi determinada após 24 horas de imersão em água e após termociclagem. As médias de antes e após a termociclagem em MPa $(n=8)$ foram: 52,5 e 42,5 com o sistema adesivo (1), 47,7 e 32,8 para o (2), 55,0 e 48,8 para o (3) e 51,5 e 25,6 para o (4). Embora nos resultados antes da ciclagem não fossem encontradas diferenças estatísticas, o grupo (3) apresentou a maior resistência após a termociclagem.

Akgungor, Akkayan e Gaucher (2005) avaliaram a influência da espessura da cerâmica (com base de dissilicato de lítio) e modo de polimerização na resistência de união inicial e sua durabilidade. A fixação foi em dentina humana, condicionada com $\mathrm{H}_{3} \mathrm{PO}_{4}$ a $32 \%$, passando o adesivo One-Step sobre a mesma. Espécimes de porcelana foram obtidas com $6 \mathrm{~mm}$ de diâmetro e 1,0;1,5; ou 2,0mm de espessura. Foram lixados e condicionados com HF e tratadas com silano. A cimentação à dentina da porcelana foi com um agente de polimerização dual (Illusion) com catalisador (polimerização dual) ou sem catalizador (fotoativação). A resistência de união, por cisalhamento, foi feita após 10 minutos ou 24 horas com termociclagem (1000 ciclos entre 5 e 55ํㅡ). A resistência de união variou de 13,2 a 15,9MPa. A análise estatística mostrou que influenciaram a espessura da cerâmica, modo de polimerização, armazenagem ou combinação desses parâmetros. As falhas foram adesivas, entre a superfície de dentina e agente de união. 


\subsection{Rugosidade superficial}

Leitão e Hegdahl (1981) apresentaram um trabalho sobre a mensuração da rugosidade. Segundo os autores, a rugosidade é uma propriedade importante para fenômenos de superfície. Tem como efeito aumentar a área superficial, influenciar em friç̧ões e propiciar a retenção mecânica de materiais estranhos, como placa dental. Relataram que na literatura odontológica, o trabalho sobre medições de rugosidade, muitas vezes, tem sido apresentados, nos quais certos valores ou parâmetros não são acompanhados da devida explicação. Apresentaram o método de Ra ou CLA ("center line average" - linha central média). Esta apresenta o valor da soma das áreas abaixo dela (vales) e acima dela (picos), não especificando a diferença entre picos e vales. A soma dessas áreas, dividida pela extensão do ensaio fornece o valor de $\mathrm{Ra}$, ou Ra é a altura média em relação à linha média dessa área. Lembraram da importância de citar nos trabalhos, além do tipo de rugosidade, também a extensão da medida "cut off".

Bessing e Wiktorsson (1983) pesquisaram a rugosidade comparativa de dois diferentes métodos de polimento da cerâmica. Determinaram a rugosidade após o glazeamento, após subseqüente abrasão e depois do polimento. A rugosidade foi avaliada pela microscopia eletrônica de varredura e com o rugosímetro, determinando $\mathrm{Ra}$ e $\mathrm{Rtm}$ (Ra sendo a média aritmética e Rtm, segundo os autores, a média de 5 picos e vales, dentro de cada um de 5 
segmentos ao longo do comprimento avaliado). Os agentes de polimento foram os conjuntos Shofu e pedra-pomes mais carbonato de cálcio. Encontraram valores contraditórios entre os resultados de rugosidade determinada com o rugosímetro e o MEV. Esta mostrou que a porcelana polida era mais rugosa que a glazeada, ocorrendo o contrário com os valores de Ra. Esses autores julgaram que o parâmetro da rugosidade Rtm não seja adequado para avaliar a rugosidade. Não encontraram diferença entre os agentes de polimento.

Scurria e Powers (1994) estudaram a rugosidade $(\mathrm{Ra})$ de dois materiais cerâmicos polidos. As conclusões foram: a cerâmica feldspática pode ser polida a uma superfície mais lisa com a instrumentação clínica, quando comparada com a condição glazeada; a cerâmica Dicor MGG se tornou mais lisa que a Ceramco II; as pontas diamantadas, de granulação $25 \mu \mathrm{m}$ para baixo, conduziram a rugosidades bem baixas, tendo sido o maior valor $0,81 \mu \mathrm{m}$ e, nos casos com granulação menor, a rugosidade ainda se tornou mais baixa.

Quirynen e Bollen (1995) referiram-se à cavidade oral como sendo um sistema aberto de crescimento bacteriano. A maioria das bactérias sobrevive apenas quando conseguem aderir a superfícies duras (dentes, restaurações, implantes ou próteses). A adesão bacteriana ocorre em 4 fases: transporte à superfície; adesão inicial com um estágio reversível e irreversível, união por interação específica e finalmente colonização. Durante esse processo a rugosidade e a energia livre de superfície desempenham um papel importante. A redução da rugosidade da superfície resultaria em um acentuado retardamento de formação de placa e sua maturação. Uma redução na energia livre do 
substrato resultaria em diminuição do crescimento da placa, diminuição da capacidade de retenção da placa e na seleção de organismos específicos. Embora ambos os parâmetros (rugosidade e energia livre) apresentem interação, a influência da rugosidade é predominante. A importância de ambos os parâmetros justifica a demanda para superfícies lisas com energia de superfície baixa a fim de prevenir a formação de placas.

Ward, Tate e Powers (1995), também estudaram a rugosidade superficial de cerâmicas opalescentes após o polimento, empregando o parâmetro Ra. Após o glazeamento as médias de Ra foram de 2,60 a $3,18 \mu$ m e após os polimentos os valores não chegaram nem a $0,80 \mu \mathrm{m}$, e alguns ficaram abaixo de $0,10 \mu \mathrm{m}$. Concluíram que as superfícies polidas se tornam mais lisas que as existentes após o glazeamento.

Feher e Mormann (1995) estudaram quatro grupos de amostras de

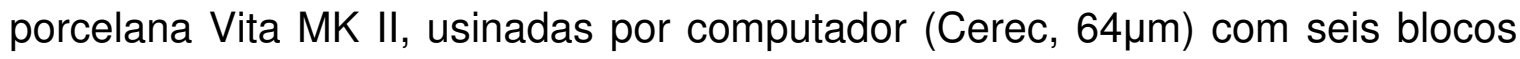
medindo (12 x $7 \times 1,5 \mathrm{~mm})$. O acabamento foi feito com pontas de diamante muito finos $(15,8,4 \mu \mathrm{m})$ e limas $(15,8,4 \mu \mathrm{m})$. Adicionalmente, essas amostras foram polidas com discos de corte redondos (padrão) e com discos de corte angular experimentais. A rugosidade superficial foi medida após cada tratamento. Para controle, superfícies de cerâmica foram polidas com alto brilho com uma máquina de polimento laboratorial (LPM). Os valores de rugosidade R15/8/4 obtidos com pontas de diamante de $15 / 8 / 4 \mu \mathrm{m}$ foram significativamente diferentes entre os tamanhos de grãos de diamante utilizados: R15 - 1,49 $\pm 0,44>\mathrm{R} 8-0,86$ $\pm 0,25(p<0,05) ; R 8-0,86 \pm 0,25>R 4-0,56 \pm 0,10(p<$ ou = 0,055); R4 - 0,56 
$\pm 0,10>\operatorname{RLPM}=0,05 \pm 0,01(p<0,001)$. As pontas grosas de diamante causaram os seguintes valores de rugosidade: $R P 15=0,53 \cup \pm 0,17>R P 8=0,24 \pm 0,06(p<$ 0,01); RP4 não atingiu valores de rugosidade mais baixos. A cobertura de $8 \mu \mathrm{m}$ de diamante causou uma superfície muito fina com qualidade de "pré-polimento" na cerâmica. Os discos angulares apresentaram a mesma habilidade de polimento que os discos redondos padrão, mas foram mais eficazes quando usados em fissuras.

O efeito sobre a rugosidade superficial de porcelana, pela ação ultrasônica e curetagem periodontal, foi investigado por Lee, Lai e Morgano (1995). Espécimes de porcelana para metalocerâmica foram divididos em duas zonas, empregando assim as duas técnicas de profilaxia periodontal. A rugosidade foi determinada antes e após a instrumentação. Quanto à rugosidade os dois procedimentos de profilaxia não conduziram a resultados significantemente diferentes entre si. Os resultados entre pré/pós aplicação de ultra-som foram $(\mu \mathrm{m}): \mathrm{Ra}-0,131 / 0,124 ; \mathrm{Rz}-1,159 / 1,121 ; \mathrm{Rmax}-2,113 / 1,978$. Os valores correspondentes à curetagem manual foram: Ra - 0,136/0,143; Rz 1,269/1,386; Rmax - 1,973/2,092. Por outro lado, o exame com MEV mostrou riscos profundos na instrumentação com ultra-som e numerosos riscos menores com o método manual.

Whitehead et al. (1995) compararam dois métodos para avaliar a rugosidade da cerâmica dental após acabamento. Empregaram a reflexão de raios LASER e a rugosimetria de contato. Os resultados mostraram pouca correlação entre os dois métodos de mensuração. Recomendaram que o método 
LASER não seja empregado como exclusivo para avaliar a textura superficial de cerâmicas dentais. Os valores obtidos foram, conforme o método de tratamento superficial da porcelana, em $\mu \mathrm{m}$ : LASER - 0,19 a 0,25; Ra - 0,21 a 0,54; Rz 1,1 a 2,9. Sugeriram os autores que os parâmetros de medida devem ser escolhidos de forma que possa ser obtida a rugosidade superficial e ser fornecida informação sobre a forma da superfície.

Fuzzi, Zaccheroni e Vallania (1996), avaliaram a rugosidade da cerâmica Vita VMK 95 após o glazeamento e depois do desgaste seguido de polimento. Os meios para avaliar a rugosidade foram perfilômetria $(\mathrm{Ra})$ e a microscopia eletrônica de varredura. A avaliação pela MEV mostrou superfícies mais lisas pelo glazeamento do que pelo polimento. Pela rugosimetria os melhores resultados foram encontrados com os instrumentos diamantados, empregados na seqüência: 30, 15 e $8 \mu \mathrm{m}$. Não encontraram correlação entre os resultados obtidos pela MEV e pela perfilometria. Os valores de $\mathrm{Ra}(\mu \mathrm{m})$ variaram em torno de 0,44 a 1,31, conforme técnica de acabamento superficial.

Al-Hiyasat et al. (1997), por sua vez, investigaram o efeito abrasivo de várias formas de superfícies de cerâmicas sobre esmalte humano. Os espécimes de cerâmica e de esmalte foram submetidos a deslocamentos cíclicos um em relação ao outro, sob carga padronizada. Os ensaios foram em condição imersa em água, ficando adicionada ou não, intermitentemente, de bebida gaseificada. A rugosidade $\mathrm{Ra}$ das superfícies de cerâmica, ensaiadas em água foram: glazeada, $0,68 \mu \mathrm{m}$; não glazeada, $1,56 \mu \mathrm{m}$; polida, $0,73 \mu \mathrm{m}$. $O$ desgaste do 
esmalte após 25.000 ciclos não foi diferente para a porcelana glazeada ou polida. Contudo, com aquela sem glazeamento, o desgaste foi maior.

Metzler et al. (1999) propuseram avaliar o desgaste do esmalte humano em 3 cerâmicas odontológicas (Ceramco II, Finesse e Omega 900). Blocos de cerâmica foram obtidos de acordo com as recomendações do fabricante. Esses foram polidos por meio de ponta de diamante $(0,25 \mu \mathrm{m})$. Blocos de esmalte foram adequadamente montados, permitindo seu deslocamento em relação às cerâmicas, sob carga de $600 \mathrm{~g}$. Nos tempos de 6, 12, 24, 48horas de ensaio foram determinadas a perda do volume e a rugosidade das cerâmicas. A rugosidade superficial da cerâmica foi obtida pelos parâmetros Ra e Rmax. A rugosidade variou em função do tempo da ação da friç̧ão entre esmalte e cerâmica. Os valores de Ra variaram de 0,41 a 2,06 $\mu$ m (Ceramco II), de 0,75 a $1,39 \mu \mathrm{m}$ (Finesse) e de 0,43 a $0,72 \mu \mathrm{m}$ (Omega 900). Para o parâmetro Rmax, respectivamente nos períodos de ação e fricção os valores foram: 4,3 a 21,4 4 m;

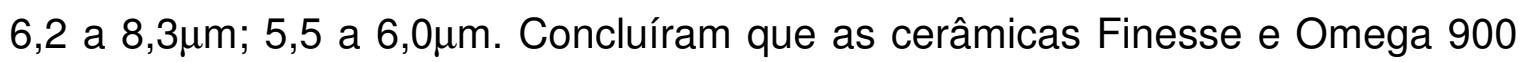
não foram tão destrutivas do esmalte humano como a cerâmica Ceramco II.

Kawai, Urano e Ebisu (2000) estudaram o efeito, da rugosidade superficial da porcelana, na adesão de bactérias. Os valores de rugosidade $\mathrm{Ra}(\mu \mathrm{m})$ em função dos acabamentos foram: polimento com $n^{\circ} 120-0,53$; polimento com $n^{\circ}$ $600-0,25$; pasta de diamante $-0,12$; superfície glazeada $-0,15$. Os resultados mostraram que quanto menor a rugosidade, menor a adesão de placas bacterianas. Entretanto o maior acúmulo de placa ocorreu na superfície glazeada, apesar de baixa rugosidade. 
A influência da rugosidade superficial, na resistência flexural (biaxial) de porcelanas, foi realizada por De Jager, Feilzer e Davidson (2000). Avaliaram 4 porcelanas comerciais, das quais duas para metalocerâmica (Flexo Ceram Dentine e Vita VMK 68) e duas para facetas e incrustrações (Duceram LFC Dentine e Cerinate). Foram empregados 12 diferente métodos de acabamento. Os valores médios de rugosidade $\mathrm{Ra}$, conforme o tratamento superficial, das diversas porcelanas foram $(\mu \mathrm{m})$ : Cerinate, 0,3 a 3,7; Duceram LFC 0,4 a 5,0; Flexo Ceram Dentine, 0,3 a 2,9; Vita VMK 68, 0,3 a 6,8. Com exceção do material Flexo Ceram dentine, uma significante correlação foi encontrada entre a rugosidade superficial e a resistência flexural (biaxial). Quanto mais lisa a superfície, maior a resistência. O fato foi atribuído a uma concentração de tensões da aplicação da carga do ensaio. A não influencia na porcelana Flexo Ceram dentine foi atribuída, possivelmente, ao tamanho das partículas de leucita, que aparentemente induzem maior concentração de tensões.

Chu, Frankel e Smales (2000), também, se preocuparam em estudar a relação entre resistência flexural e rugosidade de lâminas de porcelana InCeram/Vitadur Alpha. Ensaiaram superfícies auto-glazeadas, polidas e reglazeadas. As rugosidades $(\mathrm{Ra})$ variaram de cerca de 0,3 a 1,1 $\mu \mathrm{m}$. Concluíram que: o reglazeamento reduz significantemente a rugosidade superficial, de porcelana abrasionada e polida, quando comparada com polimento apenas; foi encontrada uma correlação negativa entre rugosidade superficial e resistência flexural. 
Agra e Vieira (2002) abordou extensa pesquisa envolvendo vários parâmetros de rugosidade. Objetivou comparar a rugosidade de cerâmicas (Duceram Plus e IPS d.Sign) com os seguintes tratamentos superficiais: glazeado; desgaste com instrumentos rotatórios, de forma clínica; polimento. Avaliou vários parâmetros de rugosidade, entre eles Ra, Ry e Rz. Encontrou para determinadas condições o valor de $1,13 \mu \mathrm{m}$ para $\mathrm{Ra}, 6,62 \mu \mathrm{m}$ para Ry e $3,69 \mu \mathrm{m}$ para Rz. Algumas das conclusões obtidas foram: 1) o desgaste promoveu uma rugosidade bem maior que a existente para as condições de glazeado e polido; 2) com o parâmetro Ra os 2 materiais apresentaram rugosidades semelhantes, mas com os Ry e Rz, o Dulceram Plus foi em média menos rugoso; 3) a condição glazeado apresentou maiores valores de Ry e Rz, que a polida, em ambos os materiais; 4) o parâmetro Ra não apresentou correlação significante com outros, o que sugere complementar a informação com vários parâmetros.

Machado (2002) determinou a rugosidade superficial do esmalte dental humano, nas faces vestibulares de 40 dentes extraídos. A determinação da rugosidade foi realizada nas regiões cervical, mediana e incisal nas direções horizontal e vertical. Os parâmetros de rugosidade determinados foram Ra, Rt, Ry e Rz. Concluiu que a região cervical apresentou em média maior rugosidade, significantemente, do que as regiões medianas e incisais, mas detectada apenas com os parâmetros Rt, Ry e Rz; nas regiões mediana e incisal, as rugosidades foram semelhantes; nas direções vertical e horizontal as rugosidades foram semelhantes; os quatro parâmetros de rugosidade foram significantemente diferentes entre si; o parâmetro Rt (o maior) conduziu a um valor médio de cerca 
de 5,5 vezes maior do que $\mathrm{Ra}$ (o menor); $32 \%$ dos dentes apresentaram rugosidade menor que $1 \mu \mathrm{m}(\mathrm{Ra}), 54 \%$ até $7 \mu \mathrm{m}(\mathrm{Rt}), 62,5 \%$ até $6 \mu \mathrm{m}(\mathrm{Ry})$ e $68,8 \%$ até $4 \mu \mathrm{m}(\mathrm{Rz})$.

Jung (2002) estudou a influência de acabamento e polimento na superfície de um compósito híbrido e uma cerâmica vítrea para a obtenção de peças por pressão e temperatura. Empregou vários materiais de abrasão e polimento. Em geral as rugosidades $(\mathrm{Ra})$ entre os dois materiais foram muito próximas, entre 0,4 e $0,8 \mu \mathrm{m}$.

Turker e Biskin (2003) estudaram o efeito de agentes clareadores nas propriedades de superfície de três materiais restauradores estéticos. Os produtos de clareamento foram: Nite White, Opalescence e Rembrandt Lighten Gel. Os materiais restauradores foram: Duceram, Fuji II LC e Silux Plus. O parâmetro de rugosidade foi o $\mathrm{Ra}$. As mensurações foram feitas em 24 e 48 horas, e em 1, 2, 3 e 4 semanas. Os três agentes clareadores conduziram a resultados semelhantes. A porcelana não sofreu qualquer alteração significante (inicial de $0,47 \mu \mathrm{m}$ e após 4 semanas de 0,48 a 0,69 $\mu \mathrm{m})$. O ionômero de vidro modificado sofreu aumento significante da rugosidade (inicial de 0,40 a 0,48um e após 4 semanas de 0,63 a $0,83 \mu \mathrm{m})$. A resina composta sofreu apenas pequena alteração (inicial de 0,14 a 0,23um e após 4 semanas de 0,18 a $0,27 \mu \mathrm{m}$ ). Verifica-se que a resina composta apresentou a superfície mais lisa.

Wright et al. (2004) propuseram estudar a rugosidade superficial produzida por 3 sistemas de polimento de porcelana (Axis Dental, Jelenko e Brasseler). A porcelana (Finesse) foi glazeada e em metade do espécime foi feito 
o polimento. Os resultados de rugosidade Ra foram analisados pela diferença entre as duas medidas. Comparativamente, também foi feita a microscopia eletrônica de varredura. Os 3 sistemas de polimento conduziram a superfícies mais lisas do que a autoglazeada. O sistema Axis conduziu à superfície mais lisa. As imagens obtidas com o MEV mostraram ser consistentes com os resultados de perfilometria.

Butler et al. (2004) estudaram a influência de agentes clareadores sobre a rugosidade de 3 diferentes porcelanas (Ceramco II, All-Ceram e Finesse). Cada espécime de porcelana foi abrasionado com broca de diamente de granulação média e autoglazeado. Depois um dos lados do espécime foi abrasionado e polido, como se faria clinicamente. Os meios de imersão desses espécimes foram: 1) água destilada (controle); 2) solução de fosfato acidulado 1,23\% (APF); 3) fluoreto de estanho, $0,4 \% \mathrm{pH} 4,1$; 4) solução a $10 \%$ de carbamida. Os resultados mostraram que o APF atacou a superfície glazeada das 3 porcelanas. A imersão das superfícies polidas não alterou a rugosidade das 3 cerâmicas ensaiadas.

\subsection{Microdurezas}

Muitos dos tipos de dureza tem como dimensão física força dividido por área $\left(\mathrm{F} / \mathrm{L}^{2}\right)$. Até anos atrás o número correspondia a $\mathrm{kgf} / \mathrm{mm}^{2}$. Essas durezas, muito conhecidas na odontologia, como Knoop, Vickers, Brinell eram 
representadas apenas pelo número, isto porque mundialmente era subentendido que fosse $\mathrm{kgf} / \mathrm{mm}^{2}$. Entretanto pela nomenclatura da ISO, recentemente introduzida, essas durezas passaram a ser representadas por gigapascals (GPa), o que é um bilhão de newtons sobre um metro quadrado. É claro que a mesma dureza física não é mais representada por um mesmo número.

Para não repetir sempre a conversão de uma representação em outra, o que será feita apenas na primeira vez, estão sendo representados os fatores de conversão: Dureza $\left(\mathrm{kgf} / \mathrm{mm}^{2}\right)$ x 0,009807, fornece GPa e GPa (1 bilhão de N/m²) x 101,967982, fornece o número de dureza $\left(\mathrm{kg} / \mathrm{mm}^{2}\right)$.

Como simplificação divida-se o número de $\mathrm{kgf} / \mathrm{mm}^{2}$ por 100 e se terá GPa, ou GPa multiplique-se por 100 e se terá $\mathrm{kgf} / \mathrm{mm}^{2}$, o que fornece o valor em ordem de grandeza.

Tradicionalmente é conhecido que as porcelanas apresentam uma dureza bastante elevada, como também o esmalte dental humano. Assim Peyton et al. (1960) apresentaram os valores para diversos materiais em dureza Knoop $\left(\mathrm{kgf} / \mathrm{mm}^{2}\right)$ e GPa entre parênteses foi calculado: porcelana, 460 (4,51); esmalte dental humano, 343 (3,36); amálgama, $110(1,08)$; dentina humana $68(0,67)$; resina acrílica, $20(0,20)$.

Naylor et al. (1991) avaliaram o efeito do tratamento superficial na dureza Knoop da porcelana Dicor. Foi atribuída uma vantagem a essa porcelana por apresentar uma dureza Knoop comparável ao esmalte humano. Empregaram três condições de tratamento: 1) ceramização e polimento; 2) ceramização, aplicação de 4 camadas de matizes e polimento; 3) seccionado e polido. Os resultados mostraram que os três tratamentos conduziram a resultados 
significantemente diferentes entre si, em dureza Knoop $\left.\left.\left(\mathrm{kgf} / \mathrm{mm}^{2}\right): 1\right) 505 ; 2\right)$ 447; 3) 369 .

Baharav et al. (1996) estudaram a influência da velocidade de resfriamento, na tenacidade de fratura e na microdureza, de uma porcelana reforçada com alumina e glazeada. O resfriamento foi feito com velocidade rápida, média e lenta. Os resultados mostraram que a velocidade influenciou na tenacidade de fratura, mas não siginificantemente na dureza Vickers, variando de 530 e $540\left(\mathrm{kgf} / \mathrm{mm}^{2}\right)$.

O trabalho de Abe et al. (1997) embora se relacionasse com desgaste, apresenta interesse para a presente pesquisa, por terem determinado a dureza de vários materiais. As durezas Knoop $\left(\mathrm{kgf} / \mathrm{mm}^{2}\right)$ foram: resina composta, 37,0; policarbonato com fibras de vidro (10\%), 12,8; polietersulfone, 15,5; resina acrílica, 16,6; liga de Au-Ag-Pd-Cu, 260,4; liga de Co-Cr, 447,5; cerâmicas injetadas, 351,2; porcelana feldspática, 567,5; esmalte, 337,3. Verifica-se a relativa alta dureza da porcelana.

Rasmussen, Groh e O’Brien (1998) avaliaram a influência da adição de um composto de césio $\left(\mathrm{Cs}_{2} \mathrm{O}\right)$ em uma porcelana odontológica, no coeficiente de expansão térmica, tenacidade e dureza. A adição variou de 0 a $2 \%$ em mol. A dureza Vickers não variou continuamente com o aumento de $\mathrm{Cs}_{2} \mathrm{O}$, entretanto os valores com $0 \%$ foi de $4,25 \mathrm{GPa}$ e com $2 \% 3,86 \mathrm{GPa}$, com diferença significante entre as duas médias. O coeficiente de expansão térmica e a tenacidade de fratura diminuíam com o aumento do teor de $\mathrm{Cs}_{2} \mathrm{O}$.

Nesse trabalho de Baharav et al. (1999) foi avaliada a influência da espessura da camada de glazeado na porcelana, decorrente de tempo de 
exposição a alta temperatura, na tenacidade de fratura e na dureza Vickers. Os valores variaram alcançando um mínimo e depois aumentando novamente, com maior tempo de exposição, tanto na tenacidade como na dureza. Os valores de dureza Vickers $\left(\mathrm{kgf} / \mathrm{mm}^{2}\right)$ em função do tempo de glazeamento (s) foram: 0 510,$8 ; 30-507,3 ; 60-454,5 ; 90-553,6 ; 120-546,6$.

Gorman, McDevitt e Hill (2000), compararam propriedades de duas porcelanas prensadas a quente (Empress e OPC). Os testes feitos foram de dureza Vickers, tenacidade de fratura e resistência flexural (método biaxial). Os resultados mostraram que não houve diferença significante entre os dois materiais em nenhuma das grandezas estudadas. As durezas (GPa) foram: Empress - 6,94; OPC - 7,28.

Denry e Holloway (2000) se propuzeram a estudar o efeito do conteúdo de magnésio na microestrutura e fases cristalinas de cerâmicas vítreas do sistema $\mathrm{SiO}_{2}-\mathrm{MgO}-\mathrm{CaO}-\mathrm{Na}_{2} \mathrm{O}-\mathrm{K}_{2} \mathrm{O}-\mathrm{F}$. Determinaram a dureza Vickers com as porcentagens de $\mathrm{MgO}$ de 12, 16 e 18, em detrimento diminuindo o teor de $\mathrm{SiO}_{2}$. As durezas obtidas em função da concentração do MgO (\%) foram (GPa): 12 6,$76 ; 16-6,95 ; 18-8,15$. Este último valor foi significantemente maior em relação aos dois primeiros, que foram semelhantes entre si.

Almeida et al. (2002), avaliaram a dureza e a rugosidade superficial da cerâmica prensada Cergogold (Degussa) antes e após simulação com pontas diamantadas seguida de polimento com borrachas abrasivas Edenta. Foram confeccionados 10 discos de cerâmica e armazenados em água destilada a $37^{\circ} \mathrm{C}$ por 7 dias. Foi realizada a leitura da rugosidade superficial, usando 3 percursos distintos de cada disco e avaliando o parâmetro Ra. A dureza foi realizada em 
um microdurômetro com carga de $300 \mathrm{~g}$ por 15 segundos obtendo 10 penetrações em cada corpo-de-prova. Obtidos os dados estes foram submetidos à análise de variância e Tukey (5\%). Concluíram que após a simulação do ajuste, a dureza Vickers aumentou significantemente (Antes 426,8 - Após 569,9) enquanto que a rugosidade diminuiu com significância estatística (Antes

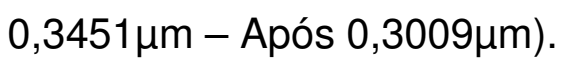

Guazzato et al. (2002), compararam as propriedades mecânicas do InCeram Zirconia (ICZ) e do In-Ceram Alumina (ICA). Noventa e quatro discos e seis barras foram preparados. Os discos foram usados para avaliar a resistência flexural biaxial (apoio em três bolas), o módulo de Weibull, a dureza, e a tenacidade à fratura com dois métodos. As barras foram usadas para medir o módulo de elasticidade, e o coeficiente de Poisson. A análise de difração de raios-x das amostras foi feita em cada passo da preparação das mesmas e das superfícies fraturadas. Não foi encontrada diferença na resistência flexural entre ICZ e ICA. ICZ foi mais tenaz por um dos métodos, mas não pelo outro. As análises de difração de raio-x mostraram pouca transformação entre as fases tetragonal e monoclínica. A dureza Vickers foi determinada conforme especificação da American Society for Testing of Materials (132794). As durezas encontradas dos dois materiais foram semelhantes, em GPa: ICZ - 10,0 e ICA 11,5 .

Borges et al. (2002) avaliaram a dureza Vickers na cerâmica DuceramPlus glazeada e polida após simulação de ajuste oclusal. Vinte discos de cerâmica para esmalte foram obtidos, autoglazeados e armazenados em água destilada a $37^{\circ} \mathrm{C}$ por uma semana. Foram considerados 2 grupos para a 
determinação da dureza Vickers: Grupo 1 - manteve o glazeamento. Grupo 2 teve sua superfície desgastada com pontas diamantadas em alta rotação simulando ajuste oclusal. Posteriormente ao desgaste, essa superfície foi polida com um sistema específico para polimento em cerâmicas (Edenta). O grupo 2 mostrou dureza superior $(553,2)$ quando comparado ao grupo $1(513,1)$. Concluíram os autores que o ajuste e o polimento aumentam a dureza da cerâmica.

A fragilidade de porcelana, unida a titânio puro, foi avaliada, pela tenacidade de fratura, durezas (Vickers e Knoop) e energia de fratura por Higashino et al. (2003). Empregaram duas porcelanas para titânio (Duceratin DV; Titanium porcelain - TP) e uma convencional (Vintage halo - VH). As três porcelanas apresentaram durezas semelhantes. A dureza Vickers apresentou valores em torno de 480 e a Knoop cerca de 850 . Os autores concluíram que as propriedades mecânicas, como tenacidade de fratura, durezas Vickers e Knoop, não conseguem explicar a fragilidade clínica da porcelana aplicada sobre o titânio. Entretanto, considerando que a energia de fratura foi menor nas porcelanas para titânio do que na convencional, foi concluído que ocorre um crescimento lento de trincas.

Kawai, Inoue e Tsuchitani (2003) estudaram o efeito da troca de íons nas propriedades de novas cerâmicas dentais. Empregaram 3 porcelanas e 3 cerâmicas de fundição. Um grupo foi mantido como controle e o outro foi coberto com uma pasta de troca de íons. As propriedades determinadas foram a dureza Vickers, resistência flexural e tenacidade de fratura. Os resultados mostraram que a troca de íons aumentou a resistência flexural e tenacidade de fratura das 
porcelanas tradicionais, mas não daquelas para fundição. $O$ tratamento pela troca de íons não aumentou a dureza de nenhum dos dois grupos. A dureza variou, conforme o tipo de cerâmica (GPa): de cerca de 600 a 800 .

A avaliação da tenacidade de fratura e da dureza de três cerâmicas injetáveis para blocos inteiriços foi realizada por Albakry, Guazzato e Swain (2003). Os materiais utilizados foram: IPS - Empress, Empress 2 e um experimental. A dureza Vickers foi determinada pela norma da American Society for Testing Materials (1327-99). Pelos resultados não foi encontrada diferença significante entre os materiais Empress 2 e o experimental, apresentando maiores valores para a tenacidade de fratura e menor dureza para estes. As durezas (GPa) foram: IPS - Empress (6,6); Empress $2(5,3)$ : experimental $(5,5)$. Às menores durezas foram atribuídas vantagens clínicas.

Rosa, Della-Bona e Pinzetta (2004) determinaram a tenacidade de fratura e a dureza da cerâmica Vita VM7 (cerâmica vítrea bifásica). Foram confeccionados 10 corpos-de-prova e polidos até a lixa 1.200 na politriz mecânica + pasta de diamante de granulação 4 e $1 \mu \mathrm{m}$. Cada corpo-de-prova recebeu 3 penetrações Vickers com carga de 1,5kg por 30 segundos, totalizando 30 aferições. As diagonais das penetrações e as trincas radiais foram medidas. Os valores da dureza e a tenacidade à fratura foram calculados usando os valores médios obtidos. O valor médio para a dureza foi de 10,6 $\pm 0,5 \mathrm{GPa}$ e para a tenacidade foi $0,874 \pm 0,09\left(\mathrm{MPa} \mathrm{m}^{1 / 2}\right)$. Concluíram os autores que os valores obtidos estão em concordância com os valores encontrados em outras cerâmicas da mesma classe. 
Oliveira et al. (2004) avaliaram a dureza Vickers de quatro cerâmicas feldspáticas (d.Sign - Ivoclar Vivadent, Duceram Plus - Degudent, Noritake EX3 - Noritake e HeraCeram - Kulzer) e uma cerâmica hidrotérmica (Duceragold Degussa). Vinte discos de cerâmica com $7 \mathrm{~mm}$ de diâmetro foram confeccionados e glazeados conforme instruções do fabricante. Os discos foram armazenados em água destilada a $37^{\circ} \mathrm{C}$ por 7 dias e divididos em 2 grupos. Grupo 1 - manteve o glazeamento. Grupo 2 - Teve sua superfície desgastada com pontas diamantadas em alta rotação simulando ajuste oclusal. Posteriormente ao desgaste, essa superfície foi polida com um sistema específico para polimento em cerâmicas (Edenta). Nove penetrações foram feitas em cada disco com carga de $300 \mathrm{~g}$ por 30 segundos. Os dados foram submetidos à análise de variância e teste de Tukey (5\%). Os autores concluíram que a cerâmica Duceram Plus apresentou os maiores valores de dureza Vickers em relação às demais, tanto glazeada $(511,9)$ quanto polida $(553,2)$.

Denry e Holloway (2004) investigaram as constantes elásticas, dureza Vickers e tenacidade de fratura de cerâmicas vítreas, com base em terita rica em flúor $\left(\mathrm{SiO}_{2}-\mathrm{MgO}-\mathrm{CaO}-\mathrm{Na}_{2} \mathrm{O}-\mathrm{K}_{2} \mathrm{O}-\mathrm{F}\right)$. A variação do $\mathrm{Na}_{2} \mathrm{O}$ (porcentagem em peso) foi de 0,0 a 7,4 . Os valores de menor tenacidade de fratura foram encontrados com 3,8 e $5,6 \%$ de $\mathrm{Na}_{2} \mathrm{O}$. Os maiores valores de dureza Vickers foram encontrados com teores de $\mathrm{Na}_{2} \mathrm{O}$ intermediários, em GPa: 0,0\% - 5,48; 1,9\% 6,$44 ; 3,8 \%-6,20 ; 5,6 \%-6,19 ; 7,4 \%-5,23$.

Guazzato et al. (2004a) estudaram algumas propriedades de algumas cerâmicas para peças inteiriças. Empregaram para os ensaios cerâmicas termoprensadas (IPS-Empress, Empress 2 e uma experimental) e uma cerâmica de 
vidro com alumínio (In-Ceram Alumina). Entre outras propriedades estudaram a dureza Vickers (método da norma da American Society for Testing Materials (1327-99). As três primeiras apresentaram durezas de 5,3 a 6,5 GPa. Entretando a cerâmica de vidro com alumínio alcançou 11,0 GPa.

Neste outro trabalho Guazzato et al. (2004b) estudaram cerâmicas à base de zircônia e compararam suas propriedades com as do anterior (GUAZZATO et al., 2004a). Os resultados mostraram que a resistência a melhoria das propriedades mecânicas devido a zircônia é influenciado pela presença de outras fases e a transformação de fase metaestável. A dureza Vickers variou de (GPa) 10,5 a $13,0$.

Gorman e Hill (2004) estudaram uma série de vidros ceramizados para desenvolver cerâmicas dentais. Os vidros foram termo-prensados e submetidos a diferentes ciclos de tratamento térmico. Amostras foram testadas em dureza, tenacidade à fratura e resistência flexural (método bi-axial). Favoráveis propriedades mecânicas foram obtidas com os tratamentos térmicos em temperaturas mais baixas $\left(1150^{\circ} \mathrm{C}\right)$. Em temperaturas medianas de tratamento térmico, as vitrocerâmicas se tornaram altamente cristalinas, o que não favorece as propriedades mecânicas. Parece haver uma relação inversa entre a tenacidade à fratura e resistência flexural. Aumentar o tempo de cocção aumenta o tamanho do cristal e através disso a extensão de micro trincas nas cerâmicas de vidro se acentua e a resistência flexural diminui. A dureza Vickers variava com a temperatura e tempo de cocção, mas não muito acentuadamente. As variações ficaram em torno de 650 a $750 \mathrm{GPa}$. 


\subsection{Microscopia de força atômica}

Uma nova técnica, para avaliar a estrutura superficial em três dimensões foi empregada por Marshall-Júnior et al. (1993). Trata-se da microscopia de força atômica (AFM - atomic force microscopy). Os autores empregaram essa técnica para estudar o condicionamento ácido da dentina e ligações com a mesma. Verificaram que essa técnica parece ser promissora para pesquisar o condicionamento e aplicação de primer na união da dentina.

Em outro trabalho Marshall-Júnior et al. (1998) continuaram os estudos envolvendo o condicionamento ácido da dentina com AFM e verificaram que o colapso da matriz de dentina é quase que totalmente recuperado pela reidratação do colágeno.

Siedlecki e Marchant (1998), também se empenharam em aplicar a microscopia de força atômica (AFM) para estudar as interfaces de biomaterials. Segundo os autores os recentes avanços sugerem que este tipo de microscopia é uma das mais importantes técnicas disponíveis para elucidar a interação biomaterial hospedeiro a nível molecular.

O emprego da microscopia de força atômica, também foi realizada por Hegedüs et al. (1999) para estudar o efeito de agentes clareadores sobre a superfície do esmalte dental. Compararam o estudo com AFM ao de varredura, observando que aquele avaliava superfícies de esmalte não reidratado. 
Wen et al. (2000), são outros autores que empregaram a microscopia de força atômica para estudar os efeitos da amelogenesia na transformação da microestrutura superficial de biovidros em soluções calcificadoras. Mostraram imagens, obtidas ao longo de apenas $1 \mu \mathrm{m}$, com suas irregularidades em 3 dimensões. Apesar da pequena extensão, a topografia mostrou irregularidades de altos e baixos.

Marshall-Júnior et al. (2001) utilizaram a microscopia de força atômica para analisar superfícies de dentina sem e com lesão de cárie, condicionadas com ácido cítrico. O objetivo do estudo foi avaliar o substrato dentinário em relação às modificações peritubular e intertubular da dentina, o que influencia o processo de adesão de materiais adesivos a esta superfície.

El Feninat et al. (2001) utilizaram a microscopia de força atômica para avaliar as mudanças superficiais do colágeno dentinário quando exposto através do condicionamento com ácido fosfórico a 37\%. Os autores conseguiram constatar com a AFM a distância (67nm) a que as fibras colágenas ficam uma das outras após o condicionamento e secagem parcial da dentina. Também verificaram que essa distância diminui com um aumento do tempo de secagem na dentina, devido ao colapso dessas fibras. Concluíram ainda que a MEV esta mais indicada para esses casos, pois, a AFM mostra uma maior sensibilidade operacional de técnica.

Kraul et al. (2004) avaliaram a rugosidade superficial de um material cerâmico (d.Sign - Ivoclar) quando polido com o sistema Shofu com e sem refrigeração e com o uso de pasta diamantada da Kota. Foi realizada análise quantitativa da rugosidade encontrada $(\mathrm{Ra})$ e análise qualitativa em microscopia 
de força atômica. As amostras foram divididas em 4 grupos. Grupo 1 - as amostras tiveram suas superfícies glazeadas. Grupo 2 - acabamento em ordem decrescente de pontas diamantadas e polimento com pasta diamantada. Grupo 3 - acabamento em ordem decrescente de pontas diamantadas e polimento com o sistema Shofu com refrigeração. Grupo 4 - idem o grupo 3, porém, sem refrigeração. Os autores concluíram que o grupo 1 apresentou a menor rugosidade e os resultados obtidos no rugosímetro foram elucidados com as imagens ilustrativas em microscopia de força atômica.

Martuci e Muench (2004), verificaram a influência do condicionamento com o HF $10 \%$ e o polimento com um sistema de borrachas na rugosidade das cerâmicas VMK 95, Omega 900, IPS d.Sign e Cergogold, determinando os parâmetros Ra e Ry de rugosidade e analisando a topografia dessas cerâmicas como microscopia de força atômica - AFM. Cones de cerâmica foram confeccionados $(3 \times 5 \times 6 \mathrm{~mm})$, embutidos em resina acrílica e polidos mecanicamente por uma seqüência de lixas. Para o teste de rugosidade, 6 cones foram condicionados e 6 cones foram polidos. Para a AFM usou-se 3 cones apenas polidos e limpos com acetona, água deionizada e álcool etílico. Para o teste de rugosidade, os dados foram tratados estatisticamente pela análise de variância e pelo teste de Tukey, onde médias $(\mu \mathrm{m})$ com mesma letra, indicam semelhança $(p<0,05)$. Ra/Pol: VMK 0,8b; Omega 0,6ab; IPS 0,6ab e Cergogold 0,5a. Ra/HF: VMK 4,5d; Omega 2,7c; IPS 2,4c e Cergogold 2,3c. Ry/Pol: VMK 5,0f: Omega 4,6ef; IPS 4,6ef e Cergogold 3,5e. Ry/HF: VMK 31,7h: Omega 17,1g; IPS 15,5g e Cergogold 17,5g. Para as imagens obtidas pela AFM, usouse a análise qualitativa de lisura superficial. Os autores concluíram que a 
cerâmica VMK 95 e o vidro cerâmico cergogold demostraram, respectivamente, a maior rugosidade superficial frente ao condicionamento e a maior lisura superficial após o polimento. 


\section{PROPOSIÇÃO}

Perante as dúvidas que se fizeram aparecer mediante a revisão da literatura, principalmente àquelas que envolvem as propriedades e os tipos das cerâmicas, segundo as suas composições, nos propusemos a estudar "in vitro", tendo como objetivos:

3.1 Avaliar a resistência de união adesiva, por ensaio de tração, entre a dentina e cerâmicas odontológicas, unidas por meio de diferentes agentes cimentantes.

3.2 Determinar a rugosidade superficial pelos parâmetros Ra, Rt, Ry, Rz e Rp após condicionamento superficial com o ácido fluorídrico a 10\% por 2 minutos.

3.3 Determinar a rugosidade superficial pelos parâmetros Ra, Rt, Ry, Rz e Rp após emprego de um sistema especial de borrachas para acabamento e polimento. 
3.4 Determinar as microdurezas Knoop (KHN) e Vickers (VHN) de diferentes cerâmicas odontológicas.

3.5 llustrar com as imagens obtidas através da microscopia de força atômica, a superfície das diferentes cerâmicas que foram polidas. 


\section{MATERIAL E MÉTODO}

\subsection{Cerâmicas}

Para a confecção dos cones cerâmicos, foram selecionadas diferentes cerâmicas odontológicas, todas na cor A3/dentina.

As cerâmicas utilizadas e seus respectivos fabricantes encontram-se no Quadro 4.1.

A composição básica dos líquidos utilizados juntamente com os pós, fornecidas pelos fabricantes e independente desses, para as cerâmicas VMK 95, Omega 900 e IPS d.Sign, é água, butilenoglicol, derivado de celulose e aditivos.

\subsection{Preparo dos cones cerâmicos}

Os cones de cerâmicas para todos os testes foram confeccionados com a ajuda de um molde de aço especialmente desenvolvido para essa confecção como demonstrado na Figura 4.1. 


\begin{tabular}{|c|c|c|c|}
\hline \multirow{2}{*}{$\begin{array}{c}\text { Cerâmica } \\
\text { Fabricante } \\
\text { Tipo }\end{array}$} & \multicolumn{3}{|c|}{ Material } \\
\hline & Pó & Líquido & Pastilha \\
\hline $\begin{array}{c}\text { VMK } 95 \\
\text { VITA } \\
\begin{array}{c}\text { Cerâmica feldspática } \\
\text { convencional }\end{array} \\
\end{array}$ & $\begin{array}{l}\text { Vita VMK } 95 \text { Metall } \\
\text { Keramik 12g Lot } \\
6220 \mathrm{~A} \text { J017B3053120 } \\
\text { Vita Zahnfabrik - Bad } \\
\text { Säckingen - Germany }\end{array}$ & $\begin{array}{c}\text { Vita Modelling Fluid } \\
\text { 50ml J017BMFMF600 } \\
\text { Lot 6107S } \\
\text { Vita Zahnfabrik - Bad } \\
\text { Säckingen - Germany }\end{array}$ & \\
\hline $\begin{array}{c}\text { Omega } 900 \\
\text { VITA } \\
\begin{array}{c}\text { Cerâmica reforçada } \\
\text { por leucita }\end{array}\end{array}$ & $\begin{array}{c}\text { Vita Omega Metall } \\
\text { Keramik 12g Lot } \\
\text { 6304T J017B9369120 } \\
\text { Vita Zahnfabrik - Bad } \\
\text { Säckingen - Germany }\end{array}$ & $\begin{array}{c}\text { Vita Modelling Fluid } \\
\text { 50ml J017BMFMF600 } \\
\text { Lot 6107S } \\
\text { Vita Zahnfabrik - Bad } \\
\text { Säckingen - Germany }\end{array}$ & 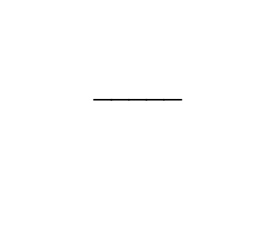 \\
\hline $\begin{array}{l}\text { IPS d.Sign } \\
\text { IVOCLAR } \\
\text { Vidro cerâmico } \\
\text { convencional }\end{array}$ & $\begin{array}{l}\text { IPS d.Sign Keramik } \\
20 \mathrm{~g} \text { dentin body } \\
\text { Ivoclar } \\
\text { Schaan/ } \\
\text { Liechtenstein }\end{array}$ & $\begin{array}{l}\text { IPS d.Sign Liquid } \\
50 \mathrm{ml} \\
\text { Modellierliquid } \\
\text { Build-Up Ivoclar } \\
\text { Schaan/ } \\
\text { Liechtenstein }\end{array}$ & \\
\hline $\begin{array}{l}\text { Cergogold } \\
\text { DEGUSSA } \\
\text { Vidro cerâmico } \\
\text { Injetado }\end{array}$ & & & $\begin{array}{c}\text { Cergogold Dentin } \\
\text { Presskeramik - } \\
\text { Degussa-Hüls AG } \\
\text { Gesdräftsberuch } \\
\text { Dental - Germany }\end{array}$ \\
\hline
\end{tabular}

Quadro 4.1 - Cerâmicas utilizadas e respectivos fabricantes* *Informações fornecidas pelos respectivos fabricantes 


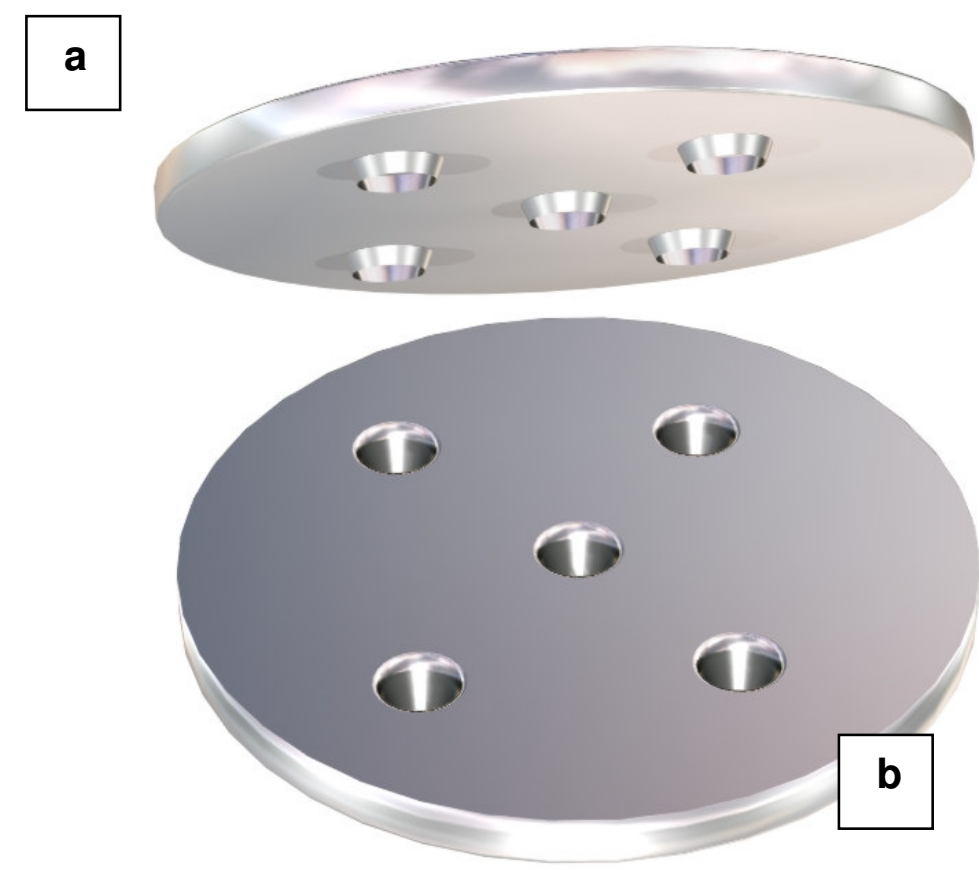

Figura 4.1 - Molde de aço desenvolvido para a confecção dos cones de cerâmica. Tampa da matriz (a) e corpo da matriz (b)

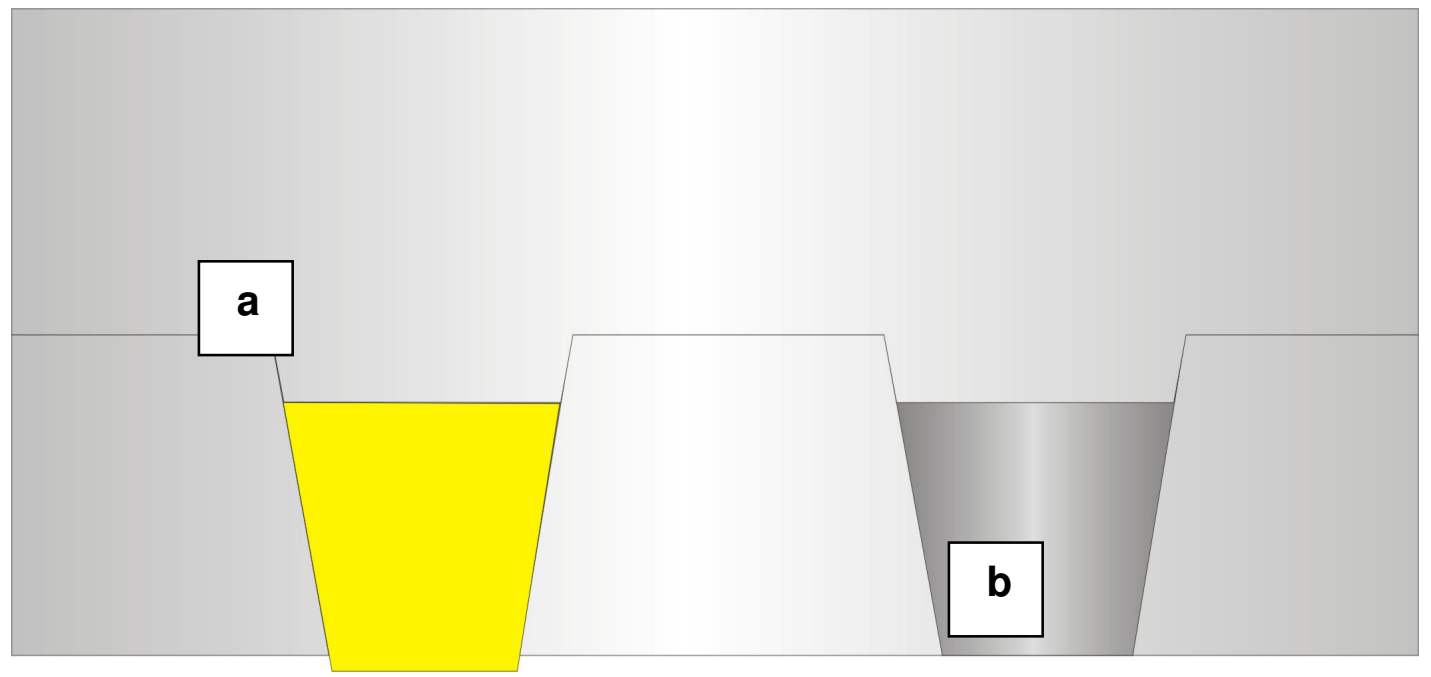

Figura 4.2 - Molde de aço para a confecção dos cones de cerâmica. Perfil do molde com (a) e sem (b) a cerâmica 
Esse molde de aço tem a forma de uma grande moeda com cinco perfurações em forma de cone, medindo $6 \mathrm{~mm}$ na base maior, $3 \mathrm{~mm}$ na base menor e 5mm na altura. Acompanha o molde, uma tampa em aço, a qual possui cinco projeções de formato cônico, com $1 \mathrm{~mm}$ de altura cada, as quais se encaixam perfeitamente nas perfurações do molde, simulando pequenos encaixes do tipo macho-fêmea. As perfurações foram isoladas com Isolante Odahcam - (Dentsply Indústria e Comércio Ltda, Petrópolis, RJ) e os cones de cerâmicas foram confeccionadas nessas perfurações manipulando o pó e o líquido com a espátula, o pincel e a godê para aplicação da Renfert.

O excesso de material na superfície das perfurações foi removido com uma espátula e em seguida o molde era vertido sobre a base de um refratário para que as amostras se soltassem das perfurações. Essa base refratária com os cones de cerâmica era levada ao forno para a realização do ciclo de cocção seguindo rigorosamente as instruções dadas por cada fabricante para que pudessem ser obtidas as propriedades desejáveis para esses materiais.

Essa técnica de confecção de cones de cerâmicas foi utilizada para as cerâmicas VMK 95, Omega 900 e IPS d.Sign.

Os cones das cerâmicas VMK 95, Omega 900 e IPS d.Sign, num total de cinco, foram posicionados no centro da base do forno para evitar distorções durante a queima.

Para a cerâmica Cergogold, a confecção dos cones foi realizada de forma diferente devido esta cerâmica ser fundida e posteriormente injetada. 
Primeiramente, foi realizada com uma cera para escultura a modelagem dos cones, nas perfurações do molde em aço (Figuras 4.1 e 4.2). A cera utilizada foi a Cera EZ Waxes - (Williams - USA).

Estes padrões de cera, depois de fixados no conduto de alimentação preso ao anel de borracha, com base formadora de cadinho, foram incluídos em revestimento Flash - Cergofit (CNG Soluções Protéticas - São Paulo - Brasil), num total de cinco amostras.

Posteriormente à presa do revestimento, a cera era eliminada em forno $\left(500^{\circ} \mathrm{C}\right)$, deixando no revestimento 0 molde dos cones para que a cerâmica Cergogold pudesse ser injetada.

Para a cocção das cerâmicas, foi usado o forno Phoenix Quick Cool (Ceramco Inc Burlington, NJ08016PC070467 Six Teni Lane - USA).

Depois da queima, os cones de cerâmica Cergogold foram jateados com microesferas de vidro (NMartins - 75nm - Colombo - PR) para que fossem removidos os resquícios de revestimento. Em seguida, foi feito o corte dos cones de cerâmica do conduto de alimentação com brocas diamantadas em alta rotação e discos de carburundum sob refrigeração.

Para todas as cerâmicas, os cones que apresentaram pequenas rebarbas foram ajustados com as pontas abrasivas - Dura Green Stones (Shofu Dental Corporation - 4025 Bohannon USA), sempre na seqüência, Shank HP, Shape WH4 e PN 0046.

Os cones de cerâmicas que apresentaram defeitos, trincas, falta de material, poros ou outras situações que comprometessem seu desempenho nos testes foram descartados. 
Esses cones de cerâmicas tiveram suas superfícies na base maior e menor regularizadas e polidas com a Politriz Mecânica (STRUERS- Denmark) fazendo a seqüência de lixas 180, 220, 320, 400 e 600 por 5 minutos cada uma com gotejamento de água sobre a lixa, como especifica o fabricante da politriz. $\mathrm{Na}$ troca das lixas, esses cones ficaram por 10 minutos no ultra-som para eliminar os detritos da lixa e ao final da última lixa, ficaram 15 minutos com feltro para polimento, seguido de 10 minutos de ultra-som.

$\mathrm{Na}$ regularização e polimento das bases menores dos cones de cerâmicas, juntamente com a politriz mecânica foi utilizado o molde e a tampa de aço para permitir uma completa planicidade de superfície dessas bases que se destinaram à cimentação no teste de resistência de união, por tração.

Ao final do polimento, os cones de cerâmicas tiveram o formato de uma peça cônica, com as bases aplainadas, medindo $6 \mathrm{~mm}$ na base maior, $3 \mathrm{~mm}$ na base menor e $5 \mathrm{~mm}$ na altura como mostra a Figura 4.3.
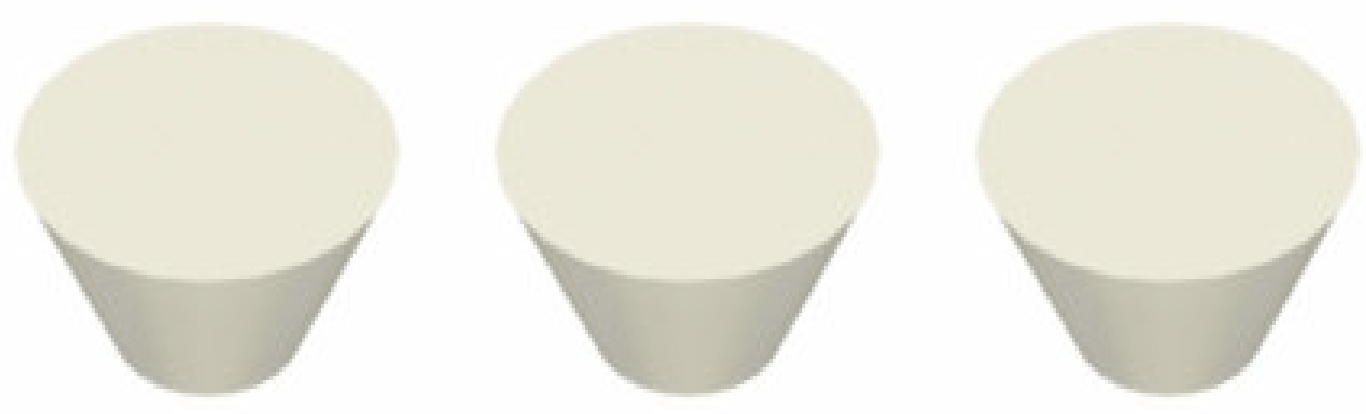

Figura 4.3 - Cones cerâmicos terminados para os ensaios 
Os ciclos de queima das cerâmicas utilizadas no presente estudo estão expressos na Tabela 4.1.

Tabela 4.1 - Ciclos de cocção das cerâmicas*

\begin{tabular}{|c|c|c|c|c|}
\hline \multirow{2}{*}{ Ciclo } & \multicolumn{4}{|c|}{ Cerâmicas } \\
\hline & VMK 95 & Omega 900 & IPS d.Sign & Cergogold \\
\hline $\begin{array}{l}\text { Temperatura } \\
\text { Inicial }\end{array}$ & $500^{\circ} \mathrm{C}$ & $600^{\circ} \mathrm{C}$ & $450^{\circ} \mathrm{C}$ & $700^{\circ} \mathrm{C}$ \\
\hline $\begin{array}{l}\text { Temperatura } \\
\text { final }\end{array}$ & $940^{\circ} \mathrm{C}$ & $920^{\circ} \mathrm{C}$ & $900^{\circ} \mathrm{C}$ & $700^{\circ} \mathrm{C}$ \\
\hline $\begin{array}{l}\text { Manutenção } \\
\text { com vácuo }\end{array}$ & $1 \mathrm{~min} 30 \mathrm{~s}$ & $1 \mathrm{~min} 30 \mathrm{~s}$ & $1 \mathrm{~min} 30 \mathrm{~s}$ & $45 \mathrm{~min}$ \\
\hline $\begin{array}{l}\text { Manutenção } \\
\text { sem vácuo }\end{array}$ & $1 \mathrm{~min}$ & $1 \mathrm{~min}$ & $1 \mathrm{~min}$ & \\
\hline $\begin{array}{l}\text { Resfriamento } \\
\text { forno }\end{array}$ & $50^{\circ} \mathrm{C} / 9 \mathrm{~min}$ & $75^{\circ} \mathrm{C} / 4,2 \mathrm{~min}$ & $90^{\circ} \mathrm{C} / 5 \mathrm{~min}$ & \\
\hline Abertura forno & $500^{\circ} \mathrm{C}$ & $600^{\circ} \mathrm{C}$ & $450^{\circ} \mathrm{C}$ & $700^{\circ} \mathrm{C}$ \\
\hline $\begin{array}{l}\text { Resfriamento } \\
\text { completo }\end{array}$ & $30 \mathrm{~min}$ & $30 \mathrm{~min}$ & $30 \mathrm{~min}$ & $3-5 h$ \\
\hline
\end{tabular}

*Informações fornecidas pelos respectivos fabricantes

Os cones cerâmicos ficaram armazenados em água destilada a $37^{\circ} \mathrm{C}$ até serem requisitados para os testes. 
Para o teste de resistência à tração foi utilizada a base de $3 \mathrm{~mm}$ do cone de cerâmica para ser cimentada, enquanto que para os testes das durezas e rugosidades, como também para o teste de microscopia, foram utilizadas as bases de $6 \mathrm{~mm}$ do cone de cerâmica.

Foram confeccionados 120 cones de cerâmicas para o teste de resistência de união, por tração, sendo 30 cones de cada tipo de cerâmica.

Para os testes de durezas, foram confeccionados 32 cones de cerâmicas, aonde 16 cones foram submetidos à dureza Knoop e os outros 16 cones submetidos à dureza Vickers sendo 4 cones de cada tipo de cerâmica.

No teste de rugosidade superficial, foram confeccionados 80 cones de cerâmicas, sendo 40 desses destinados ao teste com condicionamento ácido (HF a 10\%) superficial e 40 destinados ao teste com acabamento e polimento da superfície, perfazendo um total de 10 cones de cada tipo de cerâmica para cada teste.

Para a microscopia de força atômica foi feita a cocção de 20 cones, 5 de cada tipo de cerâmica, os quais foram submetidos à microscopia para a obtenção das imagens.

Foram confeccionados 252 cones dos 4 tipos de cerâmicas e a distribuição desses cones para os testes laboratoriais se encontram na Tabela 4.2. 
Tabela 4.2 - Esquema de distribuição dos cones de cerâmicas em função da sua respectiva divisão para os testes laboratoriais

\begin{tabular}{l|c|c|c|c}
\hline \multirow{2}{*}{ Teste } & \multicolumn{4}{|c}{ Cerâmica } \\
\cline { 2 - 5 } & VMK 95 & Omega 900 & IPS d.Sign & Cergogold \\
\hline Resistência de União & 30 & 30 & 30 & 30 \\
Dureza Knoop & 4 & 4 & 4 & 4 \\
Dureza Vickers & 4 & 4 & 4 & 4 \\
$\begin{array}{l}\text { Rugosidade Superficial } \\
\text { Condicionamento com HF }\end{array}$ & 10 & 10 & 10 & 10 \\
$\begin{array}{l}\text { Rugosidade Superficial } \\
\text { Acabamento e Polimento }\end{array}$ & 10 & 10 & 10 & 5 \\
$\begin{array}{l}\text { Microscopia de } \\
\text { Força Atômica - AFM }\end{array}$ & 5 & 5 & 5 & 10 \\
\hline
\end{tabular}

\subsection{Preparo das amostras dentárias}

Após a aprovação pela Comissão de Ética em Pesquisa (Anexo A) foram coletados 60 terceiros molares com indicação terapêutica para exodontia e armazenados em água destilada a $37^{\circ} \mathrm{C}$.

Os mesmos foram preparados tendo um corte coronal expondo a dentina, um corte sagital, separando a coroa em duas partes e um corte para que as raízes fossem removidas. Esses cortes foram realizados com uma cortadeira (Cortadeira LabCute 1010 - Extec - Excel Technologies, Inc., Enfield, 99 
Phoenix Avenue - CT - USA). O corte coronal teve a profundidade de $5 \mathrm{~mm}$ a partir da ponta de cúspide dos elementos com a intenção de padronização da região dentinária. Após o corte coronal, a remoção radicular, e a divisão da coroa dental em duas partes, esses elementos dentários foram embutidos no interior de um tubo de PVC, com resina acrílica ativada quimicamente (JetClássico - São Paulo - Brasil), como aborda a Figura 4.4.

Uma vez polimerizada a resina no interior do tubo e o dente fixado, essas superfícies de dentina passaram pela mesma regularização e polimento dado às superfícies dos cones cerâmicos com a politriz mecânica, inclusive, seguindo a mesma seqüência de lixas. Detalhe importante: no tubo de PVC foram feitas duas perfurações diametralmente opostas para que nelas fosse fixada a junta universal da garra desenvolvida especialmente para este ensaio de tração. Os dentes ficaram imersos em água destilada a $37^{\circ} \mathrm{C}$ até serem requisitados para o teste.

\subsection{Condicionamento superficial dos cones}

Para todas as cerâmicas utilizadas nesse estudo, foi feito, na superfície dos cones cerâmicos, o mesmo condicionamento para a cimentação. Os corposde-prova, destinados ao ensaio de tração tiveram suas superfícies da base menor limpas com um detergente aniônico (Tergestesim - Degussa/SP) e em seguida foram lavados e secos. Após essa limpeza, foi aplicado o ácido 
fluorídrico a 10\% (Dentsply - Petrópolis/RJ - Brasil) e esperados 2 minutos, como recomendam os fabricantes. Os cones foram lavados após esse tempo de condicionamento, tendo-se o cuidado de remover todo o ácido na lavagem.

Em seguida, os cones foram secos e as superfícies observadas para se constatar a efetividade do condicionamento ácido. Feito o condicionamento, foram aplicadas com uma microbrush nessas superfícies, duas camadas de primer específico para cerâmicas em um intervalo de 1 minuto e secas com leves jatos de ar. Foi utilizado o Ceramic Primer (3M) para a cimentação com o cimento Rely X (3M) e foi usado o Ceramic Primer (Kuraray) para a cimentação com o cimento Panávia $F$, como preconizado pelos fabricantes. Apenas para a cimentação com o cimento fosfato de zinco, essas superfícies não receberam as camadas de primer, pela não recomendação do fabricante.

\subsection{Condicionamento superficial da dentina}

Para as amostras dentárias, as superfícies polidas em dentina, foram limpas com detergente aniônico e em seguida lavadas e secas. Foi aplicado o ácido fosfórico a $37 \%$ por 15 segundos e depois lavado por 20 segundos. A dentina foi parcialmente seca com papel filtro nas amostras destinadas à cimentação com os cimentos resinosos. Para a cimentação com o cimento de fosfato de zinco, não foi feito o condicionamento da superfície em dentina e a mesma foi seca totalmente. 
Após o condicionamento da dentina, para o cimento Rely $X$, foi feita a hibridização com o adesivo Single Bond (3M), com uma microbrush, sendo essa aplicação de forma ativa (esfregando), apenas uma camada por 15 segundos do adesivo na dentina seguido de fotopolimerização por 10 segundos. Para o cimento Panávia $F$, foram aplicadas da mesma forma com a microbrush, duas camadas de ED Primer (Kuraray) do próprio sistema de cimentação no intervalo de 1 minuto como preconiza o fabricante. Para a cimentação com o cimento fosfato de zinco, não foi realizado o condicionamento superficial da dentina com o ácido fosfórico a 37\%.

\subsection{Cimentação, armazenagem e teste de resistência de união, por ensaio de tração}

4.6.1 Cimento de fosfato de zinco

Foram cimentados 10 corpos-de-prova com o cimento de fosfato de zinco (SSWhite - Rio de Janeiro - Brasil) sob carga de 2kgf para cada tipo de cerâmica. A espatulação do cimento seguiu as recomendações especificadas pelo fabricante. Esperado o tempo de presa do cimento que está por volta de 8 minutos, os excessos de cimento na superfície de dentina foram removidos e o 
conjunto (dente-cone cimentado) foi armazenado em água destilada a $37^{\circ} \mathrm{C}$ por 30 dias.

\subsubsection{Cimento Rely X}

Foram cimentados 10 corpos-de-prova com o cimento Rely X (3M Americana - S.P. - Brasil) para cada tipo de cerâmica. A espatulação do cimento seguiu critérios fornecidos pelo fabricante. Removidos os excessos de cimento, as quatro faces da interface dente/cimento/cerâmica foram fotopolimerizadas por 40 segundos e foram esperados cerca de 6 minutos, tempo este recomendado pelo fabricante pela polimerização do cimento ser dual. Foi utilizado um aparelho de fotopolimerização com intensidade luminosa de $690 \mathrm{~mW} / \mathrm{cm}^{2}$ (Optilux 501 Model VCL 501 Demetron Res. Corp., Danbury - CT - USA). Terminada a cimentação, o conjunto foi armazenado em água destilada a $37^{\circ} \mathrm{C}$ por 30 dias.

\subsubsection{Cimento Panávia F}

Foram cimentados 10 corpos-de-prova com o cimento Panávia F (Kuraray - Kyoto - Japão) para cada tipo de cerâmica. A espatulação do cimento seguiu critérios fornecidos pelo fabricante. Removidos os excessos de cimento, 
procedu-se com os mesmos critérios de cimentação, citados anteriormente para o cimento Rely $X$. Terminada a cimentação, o conjunto foi armazenado em água destilada a $37^{\circ} \mathrm{C}$ por 30 dias.

Após a espatulação, para todos os tipos de cimentos, os conjuntos cimentados (cone cerâmico - superfície de dentina) eram levados a um dispositivo posicionador, onde recebia uma carga constante de $2 \mathrm{kgf}$ até o final de sua presa.

4.6.4 Teste de resistência de união por ensaio de tração

Para o teste de resistência de união por ensaio de tração foi usada a Máquina de Ensaios Universal Wolpert (Ludwigshafen- Germany) do Departamento de Materiais Dentários da Universidade de São Paulo. A máquina foi calibrada em uma velocidade constante de $10 \mathrm{~N} / \mathrm{min}$. $\mathrm{O}$ conjunto foi preso à máquina com dispositivos especiais contento duas juntas universais para que existisse um correto posicionamento e alinhamento para a aplicação da carga tracional (axialização), evitando assim a giroversão do conjunto, o que poderia resultar em tensões de cisalhamento alterando assim, os resultados obtidos. Após a ruptura, o valor em kgf registrado no painel da máquina foi transformado em MPa e esses dados foram tabulados e submetidos à análise. 


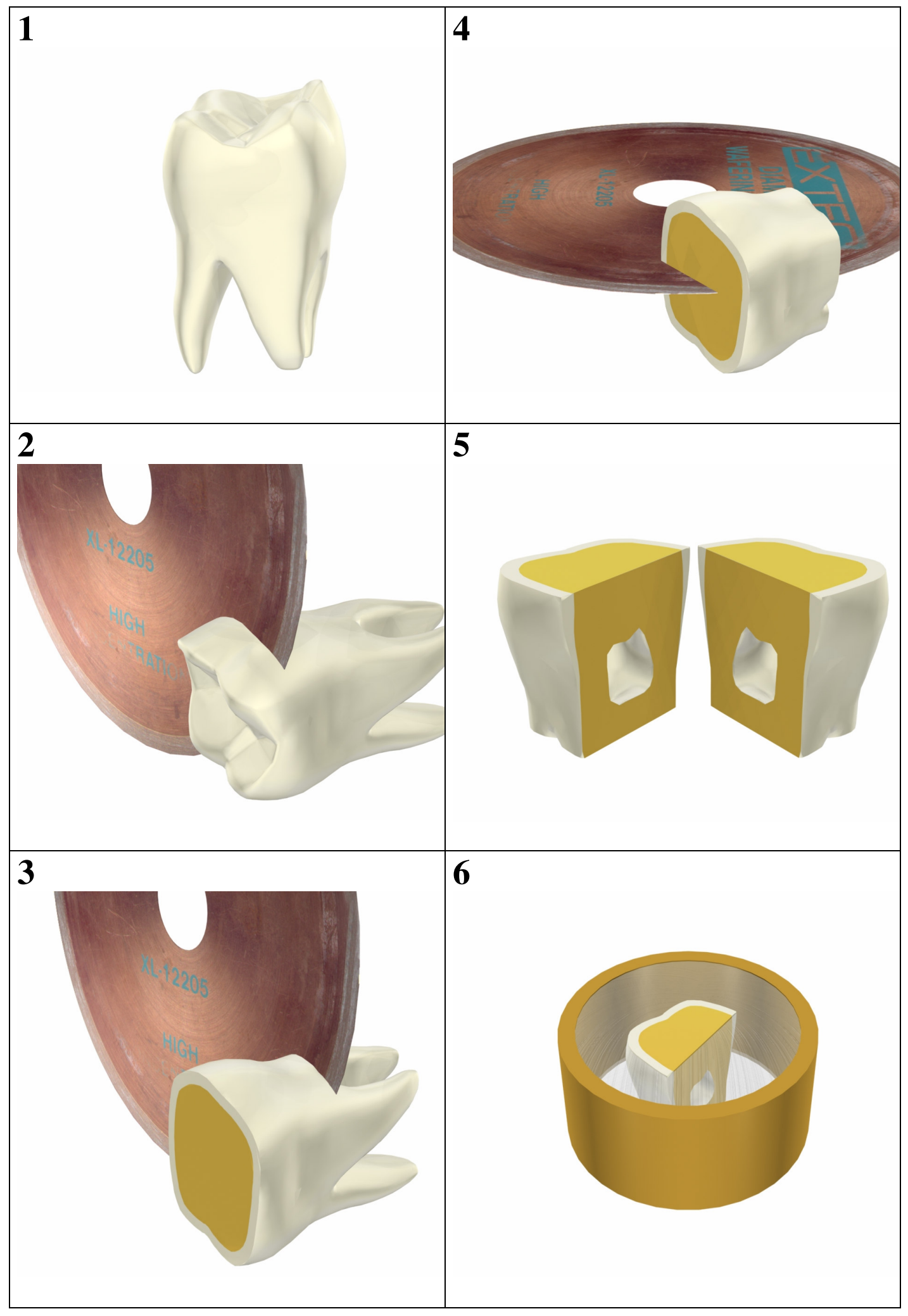

Figura 4.4 - Cortes e embutimento das amostras dentárias 
Também foi observado após a ruptura, o tipo de fratura que ocorria no conjunto. Foram observadas fraturas coesivas em cerâmica, fraturas adesivas de união e fraturas coesivas da dentina. Essas fraturas foram observadas com lupa de quatro aumentos e complementaram o ensaio de união, por tração.

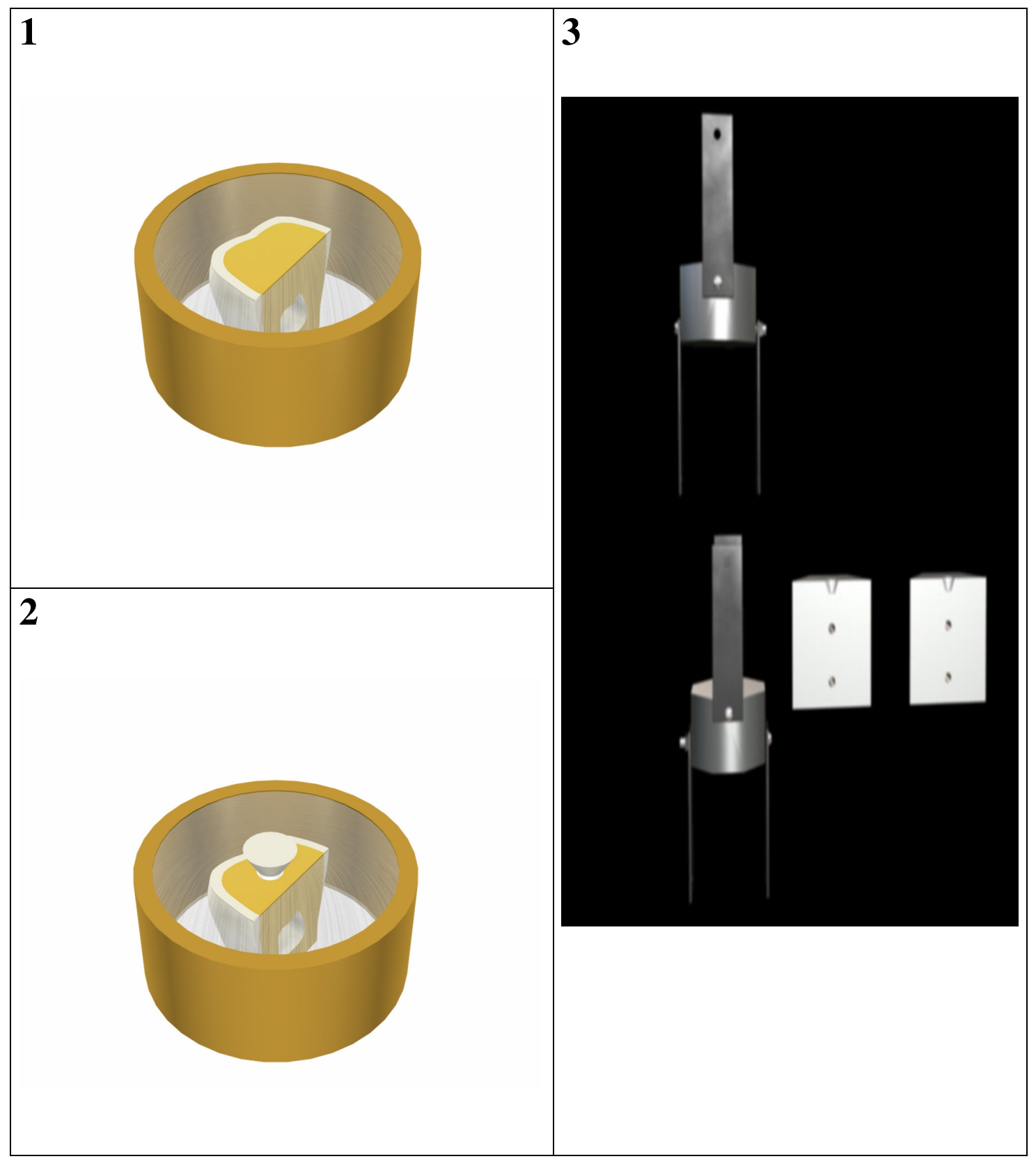

Figura 4.5 - Cimentação do cone cerâmico na superfície dentinária e garra especial desenvolvida para o ensaio de tração 


\subsection{Ensaio de rugosidade superficial}

Para o ensaio da rugosidade superficial, foi utilizado o aparelho Surftest 301 - Surface Roughness Tester (Mitutoyo Corporation - Tokyo/Japan) do Departamento de Materiais Dentários da Universidade de São Paulo. Foram avaliados os parâmetros de rugosidade: Ra (média aritmética dos valores absolutos do perfil na linha central), Rt (distância entre o maior vale e o maior pico do perfil completo), Ry (distância máxima entre o maior vale e o maior pico, em um sub-trajeto), $R z$ (média entre vales e picos de vários sub-trajetos do perfil completo) e $R p$ (média aritmética dos maiores picos em relação à linha central do perfil) em todos os corpos-de-prova, percorrendo sempre $5 \mathrm{~mm}$ em cada superfície.

Os cones cerâmicos foram embutidos com sua base maior voltada para cima em resina acrílica ativada quimicamente (Jet-Clássico-São Paulo-Brasil) em um dispositivo especial com forma retangular.

Foram destinados 80 corpos-de-prova para esse teste. Metade dos corpos-de-prova tiveram suas superfícies condicionadas com o ácido fluorídrico a 10\% (Dentsply-Petrópolis/RJ-Brasil) por 2 minutos. Logo após esse condicionamento essas amostras foram lavadas e secas para serem levadas ao rugosímetro. Então, foram destinados ao teste de rugosidade 10 cones de cada tipo de cerâmica condicionada com o HF 10\% e submetidas a duas leituras em forma de cruz sobre a superfície. Os valores obtidos foram tabulados e submetidos à análise. 
A outra metade dos corpos-de-prova, também com 10 cones para cada tipo de cerâmica, tiveram suas superfícies acabadas e polidas através de borrachas especiais do sistema de abrasivos em silicone para cerâmicas, da Reddish Stone SAS (Torino-Italy), importadas por Cepoline-Rivoli Equipamentos Industriais Ltda. Essas borrachas foram utilizadas na seqüência especificada pelo fabricante: RK 1 roda $7 / 8$, LK 2 roda $7 / 8$, RK 4 roda $7 / 8$ celeste. Após o término do acabamento e polimento nos cones em cerâmica, os mesmos foram lavados com água e detergente aniônico, foram secos e submetidos às duas leituras no rugosímetro. Os valores obtidos foram tabulados e submetidos à análise.

\subsection{Ensaio das microdurezas}

Para o ensaio de microdureza foram destinados 32 corpos-de-prova, sendo 4 para cada tipo de dureza e de cerâmica. Foram realizadas 5 penetrações em cada corpo-de-prova, sendo 5 endentações do tipo Knoop e 5 do tipo Vickers. A média das 5 penetrações constituiu a unidade amostral.

Os cones cerâmicos foram embutidos com sua base maior voltada para cima em resina acrílica ativada quimicamente (Jet-Clássico-São Paulo-Brasil) em um dispositivo especial com a forma de um retângulo. Polimerizada a resina, os corpos-de-prova foram submetidos a um criterioso polimento na politriz mecânica dentro do padrão citado anteriormente. 
Para fazer o teste de microdureza foi utilizado o Microdurômetro - HMV 2 series, Micro Hardness Tester (Shimadzu-Corporation - Kyoto/Japan) do Departamento de Materiais Dentários da Universidade de São Paulo. Foi utilizada uma célula de carga de $300 \mathrm{~g}$ por 30 segundos para ambos os tipos de dureza. Também foi padronizado o tamanho da endentação feita em ambas as durezas para que se pudesse chegar a um resultado confiável. O padrão da endentação ficou em torno de 80 a $100 \mu \mathrm{m}$.

Os valores obtidos foram tabulados e submetidos à análise.

\subsection{Microscopia de força atômica - AFM}

Os cones de cerâmica destinados à microscopia de força atômica foram em número de 20, sendo 5 cones para cada tipo de cerâmica. Nessa avaliação microscópica, apenas os cones de cerâmica polidos com o sistema de acabamento e polimento com borrachas foram avaliados, devido à acuidade do microscópio ser menor que a necessária para avaliar-se os cones de cerâmica que foram condicionados. Isso porque os cones condicionados apresentaram um perfil de rugosidade maior que a própria acuidade do microscópio de força

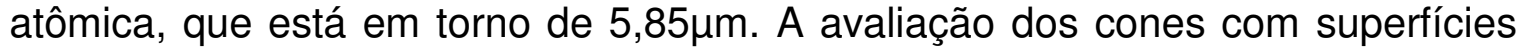
polidas foi feita de maneira qualitativa. 
Esses corpos-de-prova tiveram suas superfícies nas bases maiores regularizadas e polidas com a Politriz Mecânica (STRUERS- Denmark) seguindo a seqüência de lixas $180,220,320,400$ e 600 por 5 minutos cada uma com gotejamento de água sobre a lixa, como especifica o fabricante da politriz. $\mathrm{Na}$ troca das lixas, esses corpos de prova ficaram por 10 minutos no ultra-som para eliminar os detritos da mesma e ao final tiveram mais 15 minutos de polimento com feltro sem gotejamento de água seguido por mais 10 minutos de ultra-som. Após o polimento mecânico, esses cones tiveram as superfícies acabadas e polidas através de borrachas especiais do sistema de abrasivos de silicone para cerâmicas, da Reddish Stone SAS (Torino-Italy), importadas por Cepoline-Rivoli - Equipamentos Industriais Ltda. Essas borrachas foram utilizadas na seqüência especificada pelo fabricante: RK 1 roda $7 / 8$, LK 2 roda $7 / 8$, RK 4 roda $7 / 8$ celeste. Após o término do acabamento e polimento, os cones em cerâmica, foram limpos com acetona e algodão, lavados com detergente e água deionizada e finalmente limpos com álcool etílico. Após esse preparo, os corpos-de-prova foram armazenados em ambiente seco, até o momento da microscopia.

Foi utilizado o microscópio de força atômica NanoScope III-a com agulha NP piramidal (Digital Corporation - USA) do Departamento de Engenharia de Materiais da Universidade Federal de São Carlos. As imagens obtidas foram trabalhadas em diferentes angulações $\left(90^{\circ}, 60^{\circ} \mathrm{e} 20^{\circ}\right)$.

Os dados numéricos colhidos (resistência de união, rugosidade e dureza) foram submetidos a análise de variância e as médias contrastadas pelo teste de Tukey. Freqüências de tipos de fratura foram comparadas pelo teste binomial. 
As figuras obtidas na microscopia de força atômica foram analisadas qualitativamente. 


\section{RESULTADOS}

Conforme visto, os dados numéricos paramétricos (resistência de união, rugosidade e dureza) foram submetidos à análise de variância e médias correspondentes, quando necessário, contrastadas pelo teste de Tukey.

Na grandeza resistência de união, os dados correspondentes ao cimento de fosfato de zinco, que foi incluído para fins comparativos, a análise de variância foi feita em separado não por apresentar valores menores, mas pela variância bem menor $(0,2367)$ quando comparada com a dos outros cimentos, com variância bem maior $(8,6287)$. Este fato impede a análise conjunta.

$\mathrm{Na}$ análise da resistência de união ainda foram anotados os tipos de fratura e as freqüências comparadas pelo teste binomial.

Com a grandeza rugosidade, também, foi necessário fazer análises em separado, como na resistência de união, por motivos semelhantes aos dessa grandeza. A separação, no caso, foi necessária ser feita em relação às superfícies tratadas com o ácido fluorídrico ou polida. Ainda foi necessário analisar em separado o parâmetro de rugosidade Ra, pois este, também, é acompanhado não apenas de valores menores, mas a separação se fez necessária devido às grandes diferenças das variâncias.

Os resultados são apresentados por grandeza. As tabelas foram todas colocadas em seqüência no final deste capítulo, pois, julga-se, que com isto pela numeração será mais fácil de localiza-los, do que no meio de cada sub-capítulo. 


\subsection{Resistência de união, por ensaio de tração}

As Tabelas relacionadas com a resistência de união são as Tabelas 5.1 a 5.7 e Figuras 6.1 e 6.2 .

5.1.1 Resistência de união com cimentação feita com fosfato de zinco

As Tabelas 5.1 e 5.2 apresentam os resultados de resistência de união com o cimento de fosfato de zinco entre cerâmica e dentina humana.

A Tabela 5.1 apresenta a análise de variância (correspondente ao cimento de fosfato de zinco). Mostra alta significância entre cerâmicas e as médias correspondentes encontram-se na Tabela 5.2. Isoladamente a cerâmica Omega 900 apresenta a maior resistência significantemente $(2,91 \mathrm{MPa})$. Os demais três materiais não apresentaram diferenças significantes entre si (1,61 a 2,01MPa).

5.1.2 Resistência de união com sistemas adesivos de cimentos resinosos 
As Tabelas 5.3 a 5.5 contém os resultados da resistência de união, por ensaio de tração, entre cerâmicas e dentina humana, unidas com os cimentos Rely Xe Panávia F.

A Tabela 5.3 da análise de variância mostra que, como fator isolado, não houve diferença significante entre as médias dos níveis desse fator (Tabela 5.4). Entretanto isto precisa ser interpretado com restrições, já que a interação correspondente foi significante.

O fator cimento foi significante e mostra a Tabela 5.4 que em média o cimento Panávia $F$ apresentou maior resistência adesiva, significantemente, $(18,67 \mathrm{MPa})$ do que o Rely $X(16,98 \mathrm{MPa})$. Também aqui a interpretação precisa ser feita com ressalvas, que a interação correspondente foi significante.

As médias correspondentes à interação significante cerâmica $x$ cimento estão na Tabela 5.5. A cerâmica $V M K 95$ apresentou resistências de união semelhantes com os dois cimentos. O material Omega 900, também, não apresentou resistências diferentes significantemente, embora se note uma tendência de maior valor para o Panávia F. As cerâmicas IPS d.Sign e Cergogold apresentaram valores invertidos, significantemente, em relação aos agentes cimentantes. Assim, o material IPS d.Sign apresentou os valores (MPa): Rely $X$, 20,47; Panávia F, 15,89;. Inversamente, quanto aos valores com Cergogold: Rely X, 14,61; Panávia F, 22,34. 


\subsubsection{Freqüência dos tipos de fratura}

A Tabela 5.6 apresenta as freqüências dos tipos de fratura. Ainda contém o teste qui-quadrado entre as freqüências, excluindo aquelas correspondentes ao fosfato de zinco que sempre apresentou ruptura acc (adesivo cimento/lado da cerâmica). O teste quiquadrado mostrou significância e as freqüências foram: adesivo cimento/lado da cerâmica (acc), 51; adesivo cimento/lado da dentina (acd), 4; coesivo no corpo da cerâmica (ccc), 25. A Tabela 5.7 apresenta a comparação das freqüências dos três tipos de fratura. As três comparações possíveis foram siginificantes, pertencendo a maior freqüência a acc e a menor a acd.

\subsection{Rugosidade superficial das superfícies das cerâmicas}

As Tabelas 5.8 a 5.17 e as Figuras 6.3 a 6.6 apresentam os resultados das análises da rugosidade superficial. 
5.2.1 Rugosidade do parâmetro Ra das superfícies tratadas com ácido fluorídrico a $10 \%$

As Tabelas 5.8 e 5.9 contém os resultados de rugosidade do parâmetro Ra, das superfícies tratadas com o ácido fluorídrico a 10\%.

A análise de variância da Tabela 5.8 mostra alta significância do fator cerâmica. Na Tabela 5.9, verifica-se que a maior rugosidade, significantemente, corresponde à cerâmica VMK $95(4,26 \mu \mathrm{m})$, não havendo diferença significante

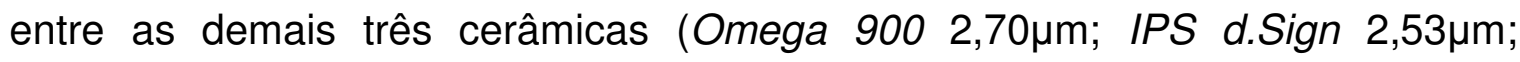

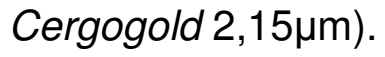

5.2.2 Rugosidade dos parâmetros Rt, Ry, Rz e Rp das superfícies tratadas com ácido fluorídrico a $10 \%$

As Tabelas 5.10 a 5.12 e a Figura 6.4 apresentam os resultados de rugosidade dos parâmetros $R t, R y, R z$ e $R p$.

A análise de variância da Tabela 5.10 mostra que houve diferença significante dos fatores principais cerâmica e parâmetro, bem como da interação correspondente.

A Tabela 5.11 mostra que em média a cerâmica VMK 95 apresentou a maior rugosidade, significantemente em relação aos outros três materiais, que 
foram semelhantes entre si. Ainda por esta tabela verifica-se que os parâmetros Rt e Ry apresentaram os maiores valores significantemente. $O$ menor corresponde a Rp.

As médias da Tabela 5.12 mostram que, em linhas gerais, com os valores da interação ocorreu uma certa semelhança com aqueles dos fatores principais. Assim Rt e Ry apresentaram em geral os maiores valores, mas Rp nem sempre os menores.

5.2.3 Rugosidade do parâmetro Ra das superfícies de cerâmica polidas

As Tabelas 5.13 e 5.14 e Figura 6.5 apresentam os resultados da rugosidade do parâmetro Ra das superfícies polidas.

A análise de variância da Tabela 5.13 mostra significância entre cerâmicas. A Tabela 5.14 indica que a maior média corresponde ao material VMK 95, significantemente. Também aqui os demais três materiais apresentam médias semelhantes. 
5.2.4 Rugosidade dos parâmetros Rt, Ry, Rz e Rp das superfícies de cerâmicas polidas

As Tabelas 5.15 a 5.17 e a Figura 6.6 apresentam os resultados das análises dos parâmetros Rt, Ry, Rz e Rp das superfícies polidas.

A análise de variância da Tabela 5.15 mostra que houve significância para os fatores principais (cerâmica e parâmetro de rugosidade) e para a interação corespondente.

A Tabela 5.16 mostra que, no caso, a cerâmica VMK 95 não apresenta, em média, a maior rugosidade de forma isolada $(5,39 \mu \mathrm{m})$. A cerâmica IPS d.Sign, embora com tendência de menor rugosidade $(3,76 \mu \mathrm{m})$ não chega a caracterizar menor valor significantemente. Os parâmetros Rt e Ry apresentam os maiores valores, semelhantes entre si.

As médias da Tabela 5.17, correspondentes à interação cerâmica $x$ parâmetro de rugosidade, mostram que as cerâmicas VMK 95 e IPS d.Sign, nos parâmetros Rt e Ry não foram semelhantes, o que não ocorreu nos parâmetros Rz e Rp. 


\subsection{Durezas Knoop e Vickers das cerâmicas}

As Tabelas 5.18 a 5.20 e figuras 6.7 e 6.8 apresentam os resultados das durezas.

A Tabela 5.18 mostra que os fatores principais (cerâmica e tipo de dureza) foram significantes, mas não foi a interação correspondente.

A menor dureza, significantemente, entre as cerâmicas IPS d.Sign e VMK 95, corresponde a esta (Tabela 5.19). Excluindo o mencionado contraste, nos demais casos há muita semelhança entre as médias. A Tabela 5.19, também mostra que o número da dureza Knoop é menor que a da Vickers.

A Tabela 5.20, correspondente às oito condições experimentais, mostra as tendências vistas para os fatores principais.

\subsection{Microscopia de força atômica}

Muitos são os testes que podem ser realizados na superfície de um material, entre eles o teste de rugosidade superficial; o teste da cristalografia, a microscopia eletrônica de varredura (MEV), enfim, testes esses, largamente usados em laboratório, sempre com o intuito de poder observar as propriedades físicas inerentes ao material estudado, bem como a constituição de sua estrutura. Atualmente, o teste de microscopia de força atômica (AFM) vem sendo 
usado quando o estudo está diretamente voltado à superfície do material, devido ao detalhamento que este equipamento realiza na superfície envolvida.

Embora os microscópios de força atômica possuam uma acuidade avançada de imagem, pois, interpretam a estrutura atômica da superfície do material, a área de abrangência da varredura ainda é de porte restrito $(50 \mu \mathrm{m})$. A imagem obtida pode ser trabalhada em diferentes angulações para melhor interpretação dos detalhes exibidos, porém, a profundidade máxima avaliada pelo equipamento chega apenas aos $5,85 \mu \mathrm{m}$, restringindo dessa maneira, a avaliação de superfícies condicionadas, que apresentam rugosidade maior que este parâmetro, ficando assim, a avaliação atômica, apenas para as superfícies polidas, ou superfícies rugosas que não ultrapassem esse limite de rugosidade.

Portanto, apenas uma análise qualitativa das imagens obtidas poderá ser feita, pois, mesmo com superfícies semelhantes em rugosidade superficial, as imagens se mostram diferentes devido às diversas composições das cerâmicas. Devido a essa diferença na composição, essas cerâmicas apresentam uma estrutura atômica diferente, o que gera imagens diferentes.

Em relação à rugosidade superficial, a avaliação estatística (quantitativa) da profundidade, ainda deve ser realizada pelo teste da rugosimetria superficial feito com o rugosímetro, com grandeza e distância da área avaliada compatível com o tamanho da amostra, pois, embora a AFM faça a perfilometria da superfície, a grandeza (nm) e a distância da área avaliada, não são compatíveis para a interpretação dos dados coletados.

Nas Figuras 5.1 a 5.4 é apresentada a microscopia de força atômica das quatro cerâmicas envolvidas nesse estudo. As imagens são para fins 
comparativos dispondo-se da análise qualitativa. Nessas figuras encontram-se do lado esquerdo, três imagens representadas pela letra "a" e do lado direito, três imagens representadas pela letra "b". Imagens de letras iguais indicam o mesmo corpo-de-prova utilizado no teste da AFM.

Ao lado das letras "a" ou "b", encontram-se os números 1,2 e 3. O número "1" indica a imagem obtida diretamente da leitura atômica, com inclinação de observação em 90․ As imagens com os números "2" e "3", são imagens trabalhadas em computação gráfica, indicando o número "2" uma inclinação de observação em 20, e o número "3" em 60‥

Em relação à cor da imagem, cores mais escuras indicam uma profundidade maior, enquanto que cores mais claras, indicam baixa profundidade. 


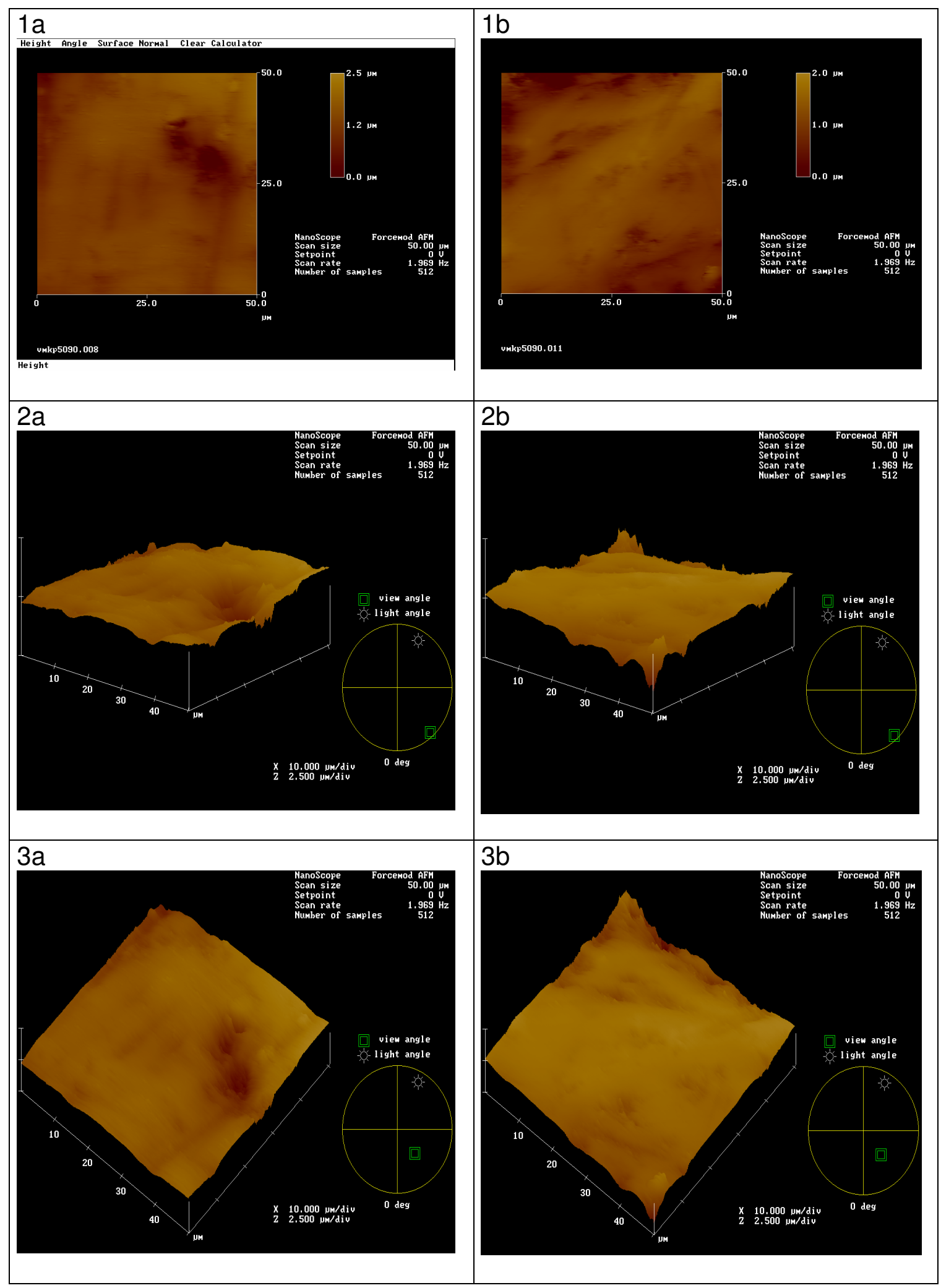

Figura 5.1 - Microscopia de força atômica de dois corpos-de-prova (a e b) da cerâmica VMK 95 em 3 ângulos de observação (1 - 90ำ, 2 - 20ํ e 3 - 60ํ) 


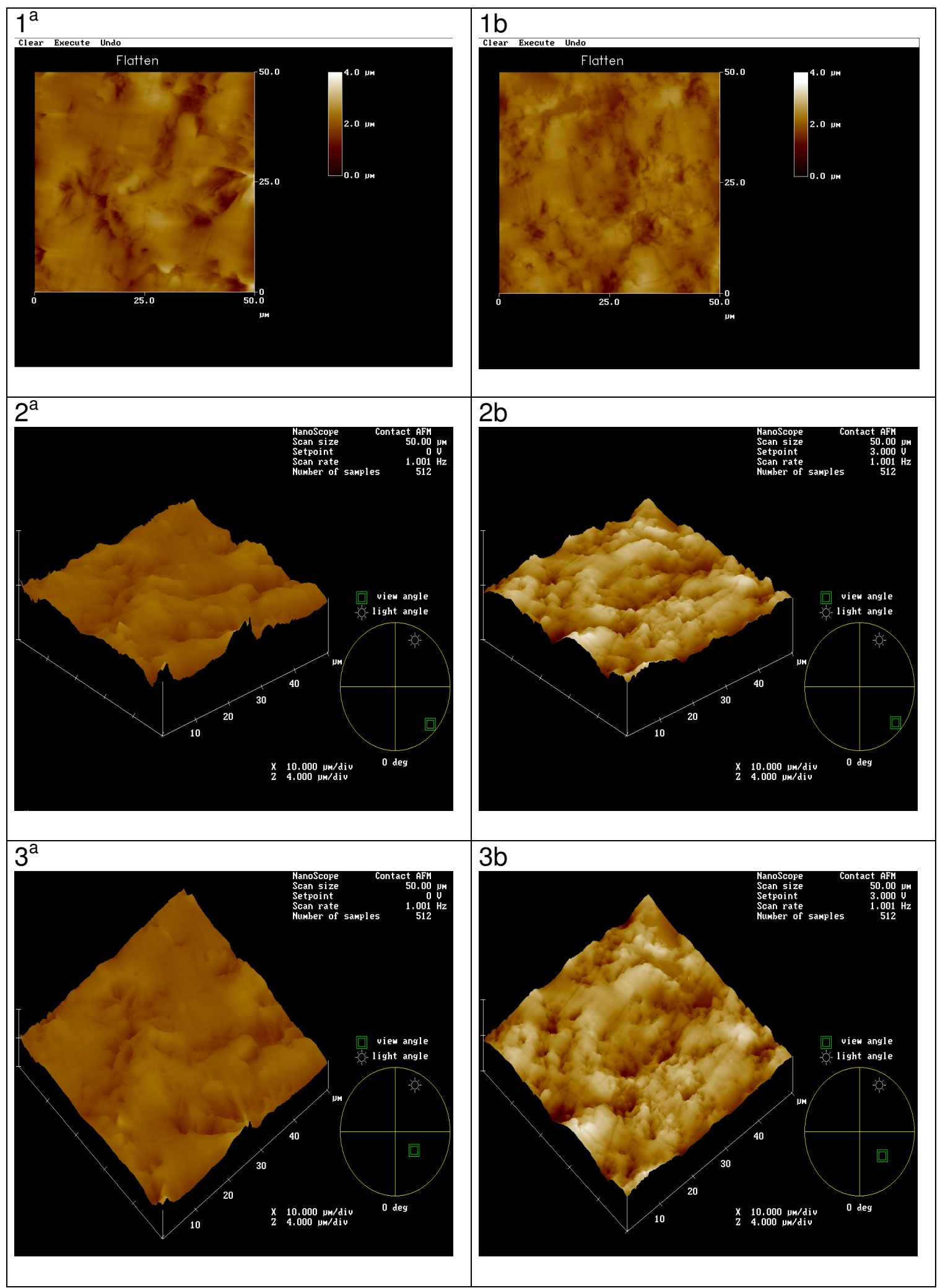

Figura 5.2 - Microscopia de força atômica de dois corpos-de-prova (a e b) da cerâmica Omega 900 em 3 ângulos de observação (1 - 90ำ 2 - 20ำ e 3 - 60) 

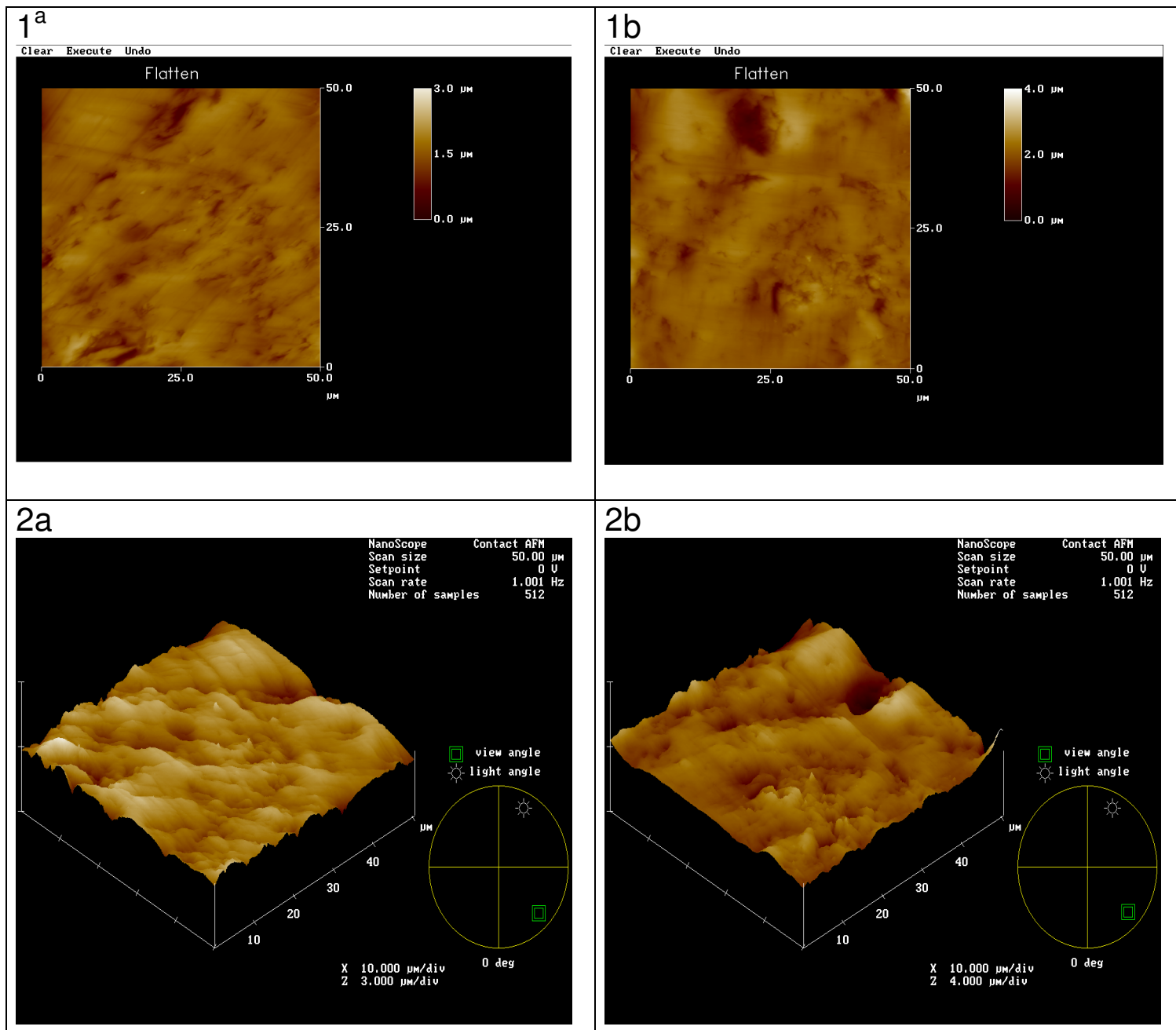

\section{$2 b$}

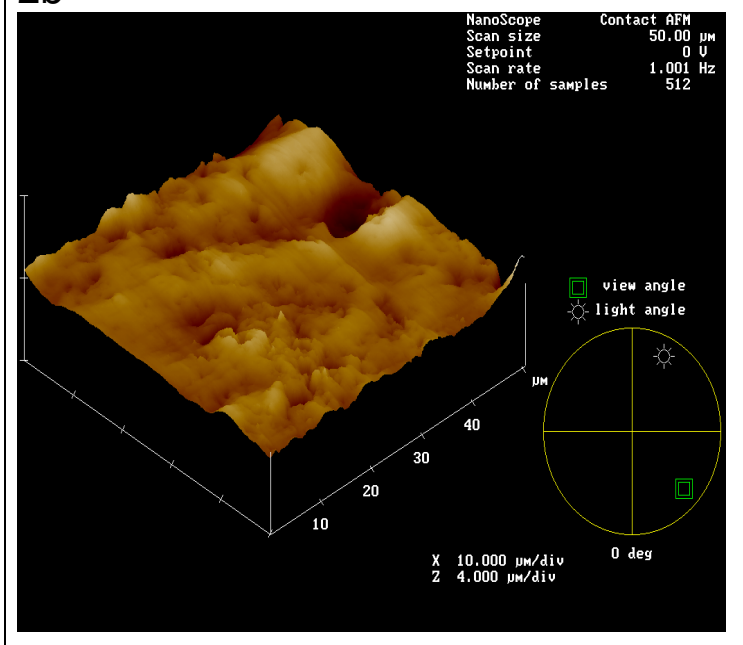

\section{$3 a$}

$3 b$
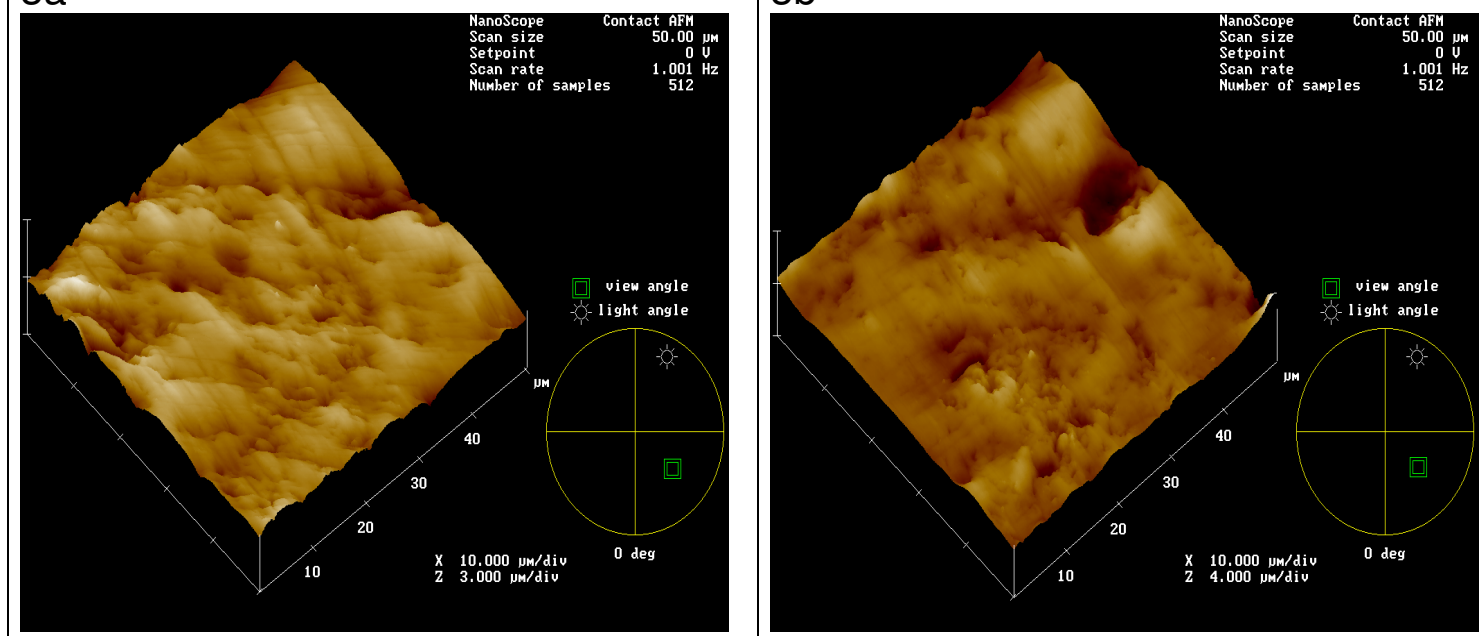

Figura 5.3 - Microscopia de força atômica de dois corpos-de-prova (a e b) da cerâmica IPS d.Sign em 3 ângulos de observação ( 1 - 90ㅇ, 2 - 20ํำ 3 - 60ํ) 


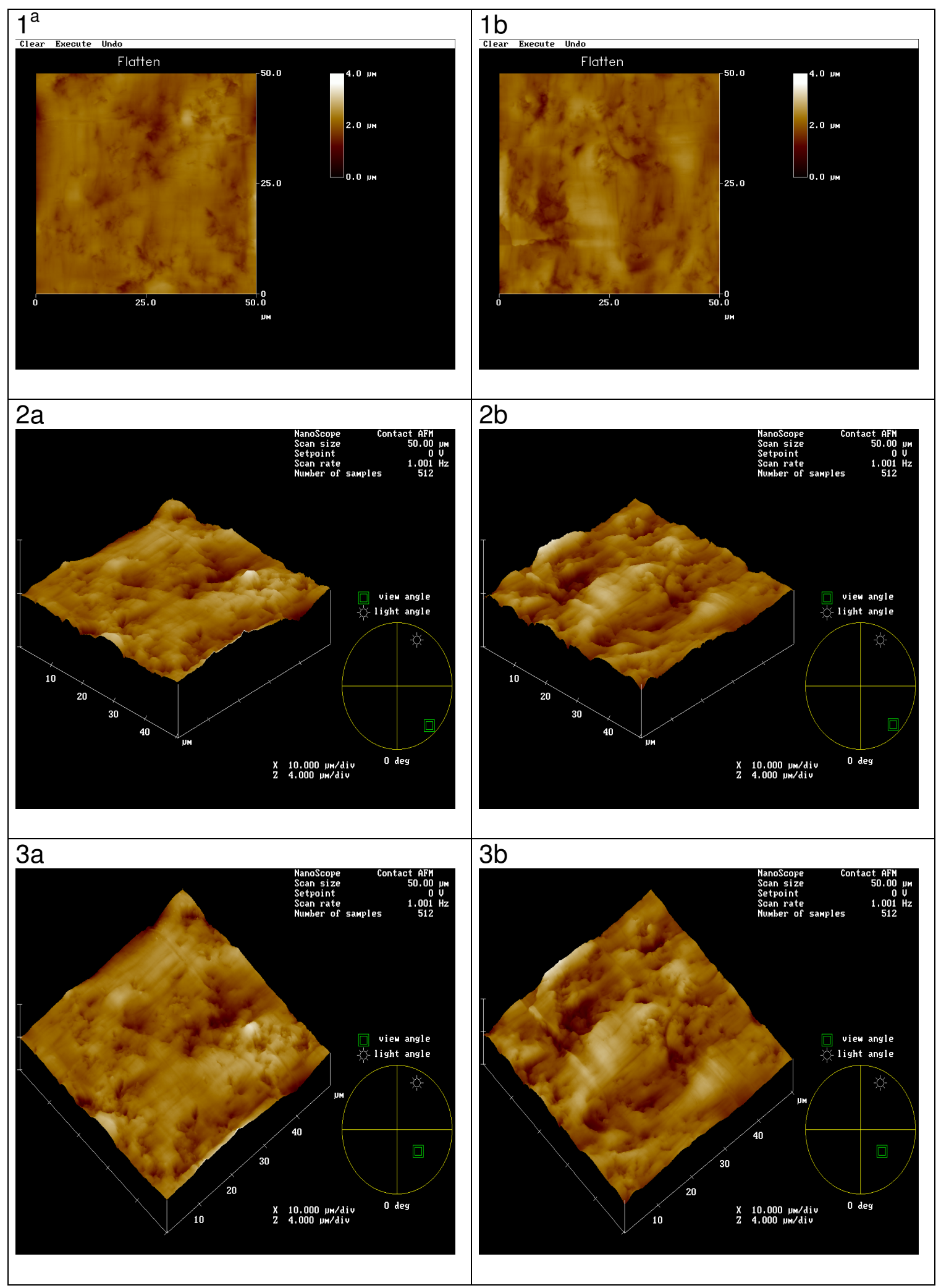

Figura 5.4 - Microscopia de força atômica de dois corpos-de-prova (a e b) da cerâmica Cergogold em 3 ângulos de observação (1 - 90ำ, 2 - 20ำ e 3 - 60) 
Tabela 5.1 - Análise de variância da resistência de união de cerâmicas em dentina humana, cimentadas com o cimento de fosfato de zinco

\begin{tabular}{c|c|c|c|c}
\hline $\begin{array}{c}\text { Fonte de } \\
\text { variação }\end{array}$ & G.L. & $\begin{array}{c}\text { Quadrados } \\
\text { médios }\end{array}$ & “F” & $\begin{array}{c}\text { Prob (H) } \\
\text { (\%) }\end{array}$ \\
\hline Cerâmica & 3 & 3,3787 & 14,27 & 0,002 \\
Resíduo & 36 & 0,2367 & - & \\
Total & 39 & $(0,4784)$ & - & \\
\hline
\end{tabular}

Tabela 5.2 - Médias de resistência de união (MPa) de cerâmicas em dentina humana, cimentadas com o fosfato de zinco, por ensaio de tração e valor crítico pelo teste de Tukey*

\begin{tabular}{|c|c|c|c|c|}
\hline \multicolumn{4}{|c|}{ Cerâmicas } & \multirow{2}{*}{$\begin{array}{c}\text { Tukey } \\
(5 \%)\end{array}$} \\
\hline VMK 95 & Omega 900 & IPS d.Sign & Cergogold & \\
\hline $2,01 \mathrm{~b}$ & $2,91 \mathrm{a}$ & $1,77 \mathrm{~b}$ & $1,61 \mathrm{~b}$ & 0,586 \\
\hline
\end{tabular}

${ }^{*}$ Médias com letras iguais são semelhantes 
Tabela 5.3 - Análise de variância da resistência de união de cerâmicas em dentina humana, cimentadas com os cimentos Rely Xe Panávia F

\begin{tabular}{c|c|c|c|c}
\hline $\begin{array}{c}\text { Fonte de } \\
\text { variação }\end{array}$ & G.L. & $\begin{array}{c}\text { Quadrados } \\
\text { médios }\end{array}$ & “F” & $\begin{array}{c}\text { Prob (H) } \\
\text { (\%) }\end{array}$ \\
\hline Cerâmica (P) & 3 & 13,8280 & 1,60 & 19,497 \\
Cimento (C) & 1 & 57,2465 & 6,63 & 1,162 \\
Int. PxC & 3 & 133,3100 & 15,45 & 0,000 \\
Resíduo & 72 & 8,6287 & - & - \\
Total & 79 & $(14,1763)$ & - & - \\
\hline
\end{tabular}

Tabela 5.4 - Médias de resistência de união (MPa) de cerâmicas em dentina humana, correspondentes aos fatores principais (cerâmica e cimento) cimentadas com os cimentos Rely Xe Panávia F

\begin{tabular}{|c|c|c|c|c|}
\hline \multicolumn{4}{|c|}{ Cerâmica } & \multirow{2}{*}{$\begin{array}{c}\text { Significância } \\
(\%)\end{array}$} \\
\hline VMK 95 & Omega 900 & IPS d.Sign & Cergogold & \\
\hline 18,04 & 16,61 & 18,18 & 18,47 & n.s. \\
\hline \multicolumn{4}{|c|}{ Cimento } & \\
\hline \multicolumn{2}{|c|}{ Rely X } & \multicolumn{2}{|c|}{ Panávia F } & - \\
\hline \multicolumn{2}{|c|}{16,98} & \multicolumn{2}{|c|}{18,67} & 1,162 \\
\hline
\end{tabular}


Tabela 5.5 - Médias de resistência de união (MPa) de cerâmicas em dentina humana, correspondentes à interação cerâmica $x$ cimento $_{2}$ cimentadas com os cimentos Rely $X$ e Panávia $F$ e valor crítico pelo teste de Tukey*

\begin{tabular}{|c|c|c|c|}
\hline \multirow{2}{*}{ Cerâmica } & \multicolumn{2}{|c|}{ Cimento } & \multirow{2}{*}{ Tukey (5\%) } \\
\hline & Rely X & Panávia F & \\
\hline VMK 95 & $17,85 \mathrm{bc}$ & 18,23 bc & \\
\hline Omega 900 & $14,99 \mathrm{c}$ & $18,23 \mathrm{bc}$ & 4,101 \\
\hline IPS d.Sign & $20,47 a b$ & $15,89 \mathrm{c}$ & \\
\hline Cergogold & $14,61 \mathrm{c}$ & $22,34 \mathrm{a}$ & \\
\hline
\end{tabular}

* Médias com letras iguais são semelhantes 
Tabela 5.6 - Freqüências dos tipos de fratura, suas somas com e sem os dados correspondentes ao cimento de fosfato de zinco e teste qui-quadrado com exclusão deste

\begin{tabular}{|c|c|c|c|c|}
\hline \multirow{2}{*}{ Cerâmica } & \multirow{2}{*}{ Cimento } & \multicolumn{3}{|c|}{ Tipo de fratura* } \\
\hline & & acc & acd & $\mathrm{CCC}$ \\
\hline VMK 95 & $\begin{array}{c}\text { Fosfato de Zn } \\
\text { Rely X } \\
\text { Panávia F }\end{array}$ & $\begin{array}{l}10 \\
6 \\
9\end{array}$ & $\begin{array}{l}0 \\
1 \\
0\end{array}$ & $\begin{array}{l}0 \\
3 \\
1\end{array}$ \\
\hline Omega 900 & $\begin{array}{c}\text { Fosfato de Zn } \\
\text { Rely X } \\
\text { Panávia F }\end{array}$ & $\begin{array}{l}10 \\
6 \\
6\end{array}$ & $\begin{array}{l}0 \\
2 \\
1\end{array}$ & $\begin{array}{l}0 \\
2 \\
3\end{array}$ \\
\hline IPS d.Sign & $\begin{array}{c}\text { Fosfato de Zn } \\
\text { Rely X } \\
\text { Panávia F }\end{array}$ & $\begin{array}{l}10 \\
8 \\
7\end{array}$ & $\begin{array}{l}0 \\
0 \\
0\end{array}$ & $\begin{array}{l}0 \\
2 \\
3\end{array}$ \\
\hline Cergogold & $\begin{array}{c}\text { Fosfato de Zn } \\
\text { Rely X } \\
\text { Panávia F }\end{array}$ & $\begin{array}{l}10 \\
4 \\
5\end{array}$ & $\begin{array}{l}0 \\
0 \\
0\end{array}$ & $\begin{array}{l}0 \\
6 \\
5\end{array}$ \\
\hline \multicolumn{2}{|c|}{$\begin{array}{l}\text { Total das freqüências com } \\
\text { fosfato de zinco }\end{array}$} & 91 & 4 & 25 \\
\hline \multicolumn{2}{|c|}{$\begin{array}{l}\text { Total das freqüências sem } \\
\text { fosfato de zinco }\end{array}$} & $\begin{array}{c}51 \\
(63,8 \%)\end{array}$ & $\begin{array}{c}4 \\
(5,0 \%)\end{array}$ & $\begin{array}{c}25 \\
(31,2 \%)\end{array}$ \\
\hline
\end{tabular}

Qui-quadrado (sem fosfato de zinco) $=41,576(p<0,001)$

\footnotetext{
* acc - adesivo cimento / lado da cerâmica acd - adesivo cimento / lado da dentina ccc - coesivo no corpo da cerâmica
} 
Tabela 5.7 - Comparação entre os tipos de fratura (teste binomial), excluindo os de cimento de fosfato de zinco

\begin{tabular}{c|c|c}
\hline $\begin{array}{c}\text { Comparação tipos e } \\
\text { freqüência }\end{array}$ & Valor z & $\begin{array}{c}\text { Significância } \\
\text { (em \%) }\end{array}$ \\
\hline $\operatorname{acd}(4) \times \operatorname{acc}(51)$ & 6,20 & 0,0000 \\
$\operatorname{ccc}(25) \times \operatorname{acc}(51)$ & 2,87 & 0,42 \\
$\operatorname{acd}(4) \times \operatorname{ccc}(25)$ & 3,71 & 0,02 \\
\hline
\end{tabular}

Tabela 5.8 - Análise de variância de rugosidade do parâmetro Ra de superfícies de cerâmicas tratadas com ácido fluorídrico a $10 \%$

\begin{tabular}{c|c|c|c|c}
\hline $\begin{array}{c}\text { Fonte de } \\
\text { variação }\end{array}$ & G.L. & $\begin{array}{c}\text { Quadrados } \\
\text { médios }\end{array}$ & “F” & $\begin{array}{c}\text { Prob. }\left(\mathbf{H}_{\mathbf{0}}\right) \\
\text { (\%) }\end{array}$ \\
\hline Cerâmica & 3 & 8,6326 & 15,99 & 0,001 \\
Resíduo & 36 & 0,5399 & - & - \\
Total & 39 & $(1,1624)$ & - & - \\
\hline
\end{tabular}

Tabela 5.9 - Médias de rugosidade $(\mu \mathrm{m})$ do parâmetro Ra de superfícies de cerâmicas tratadas com ácido fluorídrico a $10 \%$ e valor crítico pelo teste de Tukey*

\begin{tabular}{c|c|c|c|c}
\hline \multicolumn{4}{c|}{ Cerâmica } & \multirow{2}{*}{$\begin{array}{c}\text { Tukey } \\
\mathbf{( 5 \% )}\end{array}$} \\
\hline VMK 95 & Omega 900 & IPS d.Sign & Cergogold & \\
\hline $4,26 \mathrm{a}$ & $2,70 \mathrm{~b}$ & $2,53 \mathrm{~b}$ & $2,15 \mathrm{~b}$ & 0,885 \\
\hline
\end{tabular}

${ }^{*}$ Médias com letras iguais são semelhantes 
Tabela 5.10 - Análise de variância de rugosidade dos parâmetros Rt, Ry, Rz, e Rp de superfícies de cerâmicas tratadas com ácido fluorídrico a 10\%

\begin{tabular}{|c|c|c|c|c|}
\hline $\begin{array}{l}\text { Fonte de } \\
\text { variação } \\
\end{array}$ & G.L. & $\begin{array}{c}\text { Quadrados } \\
\text { médios }\end{array}$ & "F" & $\begin{array}{c}\text { Prob }\left(\mathbf{H}_{0}\right) \\
(\%) \\
\end{array}$ \\
\hline Cerâmica (C) & 3 & $1.053,9735$ & 10,66 & 0,011 \\
\hline Resíduo I & 36 & 98,8944 & - & - \\
\hline $\begin{array}{l}\text { Bloco- } \\
\text { principal }\end{array}$ & 39 & $(172,3620)$ & - & - \\
\hline $\begin{array}{l}\text { Parâmetro } \\
\text { rugosidade(R) }\end{array}$ & 3 & $1.102,0839$ & 151,21 & 0,000 \\
\hline Int. $C \times R$ & 9 & 39,2957 & 5,39 & 0,003 \\
\hline Resíduo II & 108 & 7,2885 & - & - \\
\hline Sub-bloco & 120 & $(37,0589)$ & - & - \\
\hline Total & 159 & $(70,2465)$ & - & - \\
\hline
\end{tabular}

Tabela 5.11 - Médias de rugosidade $(\mu \mathrm{m})$ dos parâmetros Rt, Ry, Rz e Rp de cerâmica, correspondentes aos fatores principais (cerâmica e parâmetro de rugosidade) de superfícies tratadas com ácido fluorídrico a 10\% e valores críticos pelo teste de Tukey*

\begin{tabular}{|c|c|c|c|c|}
\hline \multicolumn{4}{|c|}{ Cerâmica } & \multirow{2}{*}{$\begin{array}{r}\text { Tukey } \\
(5 \%)\end{array}$} \\
\hline VMK 95 & Omega 900 & IPS d.Sign & Cergogold & \\
\hline $24,50 \mathrm{a}$ & $15,08 \mathrm{~b}$ & $15,37 \mathrm{~b}$ & $12,95 \mathrm{~b}$ & 5,989 \\
\hline \multicolumn{4}{|c|}{ Parâmetro de rugosidade } & \\
\hline Rt & Ry & $\mathrm{Rz}$ & $\mathrm{Rp}$ & - \\
\hline $21,93 \mathrm{c}$ & $20,79 \mathrm{c}$ & $14,20 \mathrm{~d}$ & $10,99 \mathrm{e}$ & 1,576 \\
\hline
\end{tabular}


Tabela 5.12 - Médias de rugosidade ( $\mu \mathrm{m})$ dos parâmetros Rt, Ry, Rz e Rp de superfícies de cerâmicas, correspondentes à interação cerâmica x parâmetro de rugosidade de superfícies tratadas com ácido fluorídrico a $10 \%$ e valor crítico pelo teste de Tukey*

\begin{tabular}{c|c|c|c|c}
\hline \multirow{2}{*}{ Cerâmica } & \multicolumn{4}{|c}{ Parâmetro de rugosidade } \\
\cline { 2 - 5 } & $\mathrm{Rt}$ & $\mathrm{Ry}$ & $\mathrm{Rz}$ & $\mathrm{Rp}$ \\
\hline VMK 95 & $32,18 \mathrm{a}$ & $30,49 \mathrm{a}$ & $19,00 \mathrm{~b}$ & $16,35 \mathrm{bcd}$ \\
Omega 900 & $19,10 \mathrm{~b}$ & $17,83 \mathrm{~b}$ & $13,93 \mathrm{cde}$ & $9,46 \mathrm{fg}$ \\
IPS d.Sign & $19,67 \mathrm{~b}$ & $19,05 \mathrm{~b}$ & 12,34 def & $10,44 \mathrm{fg}$ \\
Cergogold & $16,76 \mathrm{bc}$ & $15,80 \mathrm{bcd}$ & 11,55 efg & $7,71 \mathrm{~g}$ \\
\hline
\end{tabular}

Tabela 5.13 - Análise de variância da rugosidade do parâmetro Ra de superfícies de cerâmicas polidas

\begin{tabular}{c|c|c|c|c}
\hline $\begin{array}{c}\text { Fonte de } \\
\text { variação }\end{array}$ & G.L. & $\begin{array}{c}\text { Quadrados } \\
\text { médios }\end{array}$ & “F” & $\begin{array}{c}\text { Prob }\left(\mathbf{H}_{\mathbf{0}}\right) \\
\text { (\%) }\end{array}$ \\
\hline $\begin{array}{c}\text { Cerâmica } \\
\text { Resíduo }\end{array}$ & 3 & 0,1871 & 8,04 & 0,052 \\
Total & 36 & 0,0233 & - & - \\
\hline
\end{tabular}


Tabela 5.14 - Médias de rugosidade $(\mu \mathrm{m})$ do parâmetro Ra de superfícies de cerâmicas polidas e valor crítico pelo teste de Tukey*

\begin{tabular}{c|c|c|c|c}
\hline \multicolumn{4}{c|}{ Cerâmica } & \multirow{2}{*}{$\begin{array}{c}\text { Tukey } \\
\mathbf{( 5 \% )}\end{array}$} \\
\hline \multirow{2}{*}{ VMK 95 } & Omega 900 & IPS d.Sign & Cergogold & \\
\hline \multirow{2}{*}{$0,84 \mathrm{a}$} & $0,57 \mathrm{~b}$ & $0,65 \mathrm{~b}$ & $0,53 \mathrm{~b}$ & 0,184 \\
\hline
\end{tabular}

* Médias com letras iguais são semelhantes

Tabela 5.15 - Análise de variância de rugosidade dos parâmetros Rt, Ry, Rz, e Rp de superfícies de cerâmicas polidas

\begin{tabular}{|c|c|c|c|c|}
\hline $\begin{array}{l}\text { Fonte de } \\
\text { variação }\end{array}$ & G.L. & $\begin{array}{c}\text { Quadrados } \\
\text { médios }\end{array}$ & "F" & $\begin{array}{c}\text { Prob }\left(\mathrm{H}_{0}\right) \\
(\%)\end{array}$ \\
\hline Cerâmica $(P)$ & 3 & 44,9038 & 5,33 & 0,412 \\
\hline Resíduo I & 36 & 8,4205 & - & - \\
\hline $\begin{array}{l}\text { Bloco- } \\
\text { principal }\end{array}$ & 39 & $(11,2269)$ & - & - \\
\hline $\begin{array}{l}\text { Parâmetro } \\
\text { rugosidade } \\
\text { (R) }\end{array}$ & 3 & 89,0889 & 89,99 & 0,000 \\
\hline Int. $P \times R$ & 9 & 3,6145 & 3,65 & 0,074 \\
\hline Resíduo II & 108 & 0,9900 & - & - \\
\hline Sub-bloco & 120 & $(3,3893)$ & - & - \\
\hline Total & 159 & $(5,3117)$ & - & - \\
\hline
\end{tabular}


Tabela 5.16 - Médias de rugosidade ( $\mu \mathrm{m})$ dos parâmetros Rt, Ry, Rz e Rp de cerâmica, correspondentes aos fatores principais (cerâmica e parâmetro de rugosidade) de superfícies polidas e valores críticos pelo teste de Tukey*

\begin{tabular}{|c|c|c|c|c|}
\hline \multicolumn{4}{|c|}{ Cerâmica } & \multirow{2}{*}{$\begin{array}{c}\text { Tukey } \\
(5 \%)\end{array}$} \\
\hline VMK 95 & Omega 900 & IPS d.Sign & Cergogold & \\
\hline $5,39 \mathrm{a}$ & $3,36 \mathrm{~b}$ & $3,76 \mathrm{ab}$ & $2,98 \mathrm{~b}$ & 1,748 \\
\hline \multicolumn{4}{|c|}{ Parâmetro de rugosidade } & \\
\hline Rt & Ry & $\mathrm{Rz}$ & $\mathrm{Rp}$ & - \\
\hline $5,23 \mathrm{c}$ & $4,92 \mathrm{c}$ & $3,33 \mathrm{~d}$ & $2,01 \mathrm{e}$ & 0,581 \\
\hline
\end{tabular}

${ }^{*}$ Médias com letras iguais são semelhantes

Tabela 5.17 - Médias de rugosidade ( $\mu \mathrm{m})$ dos parâmetros Rt, Ry, Rz e Rp de superfícies de cerâmicas, correspondentes à interação cerâmica x parâmetro de rugosidade de superfícies polidas e valor crítico pelo teste de Tukey*

\begin{tabular}{c|c|c|c|c}
\hline \multirow{2}{*}{ Cerâmica } & \multicolumn{4}{|c}{ Parâmetro de rugosidade } \\
\cline { 2 - 5 } & $\mathrm{Rt}$ & $\mathrm{Ry}$ & $\mathrm{Rz}$ & $\mathrm{Rp}$ \\
\hline VMK 95 & $7,51 \mathrm{a}$ & $7,15 \mathrm{a}$ & $4,26 \mathrm{bcde}$ & $2,66 \mathrm{efg}$ \\
Omega 900 & $4,53 \mathrm{bcd}$ & $4,19 \mathrm{bcde}$ & $2,98 \mathrm{defg}$ & $1,75 \mathrm{~g}$ \\
IPS d.Sign & $5,02 \mathrm{~b}$ & $4,76 \mathrm{bc}$ & 3,33 cdef & $1,95 \mathrm{fg}$ \\
Cergogold & $3,89 \mathrm{bcde}$ & $3,58 \mathrm{bcde}$ & 2,78 efg & $1,70 \mathrm{~g}$ \\
\hline
\end{tabular}


Tabela 5.18 - Análise de variância das durezas das cerâmicas

\begin{tabular}{c|c|c|c|c}
\hline $\begin{array}{c}\text { Fonte de } \\
\text { variação }\end{array}$ & G.L. & $\begin{array}{c}\text { Quadrados } \\
\text { médios }\end{array}$ & “F” & $\begin{array}{c}\text { Prob (Ho) } \\
\text { (\%) }\end{array}$ \\
\hline $\begin{array}{c}\text { Cerâmica (C) } \\
\text { Tipo de } \\
\text { dureza (D) }\end{array}$ & 3 & $8.496,1670$ & 3,05 & 4,729 \\
Int. CxD & 3 & $49.142,50000$ & 17,64 & 0,054 \\
Resíduo & 24 & $2.786,6250$ & 0,02 & 99,685 \\
Total & 31 & $(4.569,1129)$ & - & - \\
\hline
\end{tabular}

Tabela 5.19 - Médias de dureza $\left(\mathrm{kgf} / \mathrm{cm}^{2}\right)$ correspondentes aos fatores principais (cerâmica e tipo de dureza) e valor crítico pelo teste de Tukey*

\begin{tabular}{|c|c|c|c|c|}
\hline \multicolumn{4}{|c|}{ Cerâmica } & \multirow{2}{*}{$\begin{array}{c}\text { Tukey } \\
(5 \%) \\
\text { ou } \\
\text { significância }\end{array}$} \\
\hline VMK 95 & Omega 900 & IPS d.Sign & Cergogold & \\
\hline $455,7 b$ & $510,5 a b$ & $533,0 \mathrm{a}$ & $494,0 \mathrm{ab}$ & 72,81 \\
\hline \multicolumn{4}{|c|}{ Tipos de dureza } & \\
\hline \multicolumn{2}{|c|}{ Knoop } & \multicolumn{2}{|c|}{ Vickers } & - \\
\hline \multicolumn{2}{|c|}{459,1} & \multicolumn{2}{|c|}{537,5} & $0,054 \%$ \\
\hline
\end{tabular}

* Médias com letras iguais são semelhantes 
Tabela 5.20 - Médias de dureza $\left(\mathrm{kgf} / \mathrm{cm}^{2}\right)$ correspondentes à interação cerâmica $x$ tipo de dureza e diferenças (Knoop-Vickers)

\begin{tabular}{c|c|c|c|c}
\hline \multirow{2}{*}{ Tipo de } & \multicolumn{3}{|c}{ Cerâmica } \\
\cline { 2 - 5 } dureza & VMK 95 & Omega 900 & IPS d.Sign & Cergogold \\
\hline Knoop & 418,9 & 472,1 & 493,8 & 451,5 \\
Vickers & 492,5 & 548,8 & 572,2 & 536,3 \\
Dif (V-K) & 73,6 & 76,7 & 78,4 & 84,8 \\
\hline
\end{tabular}




\section{DISCUSSÃO}

A discussão, como a apresentação dos resultados, também será feita por grandeza. Entretanto, algumas vezes, quando for conveniente, serão feitas interconexões.

\subsection{Resistência de união, por ensaio de tração}

A resistência de união pela fixação com o cimento de fosfato de zinco, foi, sem dúvida, muito baixa (Figura 6.1) quando comparada com a dos cimentos resinosos (Figura 6.2).

Ela foi com o fosfato de zinco cerca de 9 vezes menor em relação a dos cimentos resinosos.

O fato não é de estranhar, uma vez que esse cimento apresenta apenas discreta adesão, talvez por forças de Van der Waals, quer à dentina quer à cerâmica. Por outro lado, isto não quer dizer que o cimento de fosfato de zinco não tenha sido um agente cimentante bastante satisfatório, no caso de fixação de coroas metálicas, quer sobre dentina, quer sobre núcleos metálicos. Lembrese que, nesse caso, a retenção é promovida por imbricamento mecânico entre substrato e coroa, garantindo resistência ao cisalhamento, no sentido axial na 
remoção. Contanto que, o cimento de fosfato de zinco foi empregado clinicamente por muitas décadas, o que ocorre, também ainda, na atualidade, embora com menor freqüência. A retenção no caso é influenciada bastante pelo ângulo do preparo em relação ao eixo do dente. Assim Hirata e Muench (1982), em relação à parede lateral do preparo, com 10 graus de inclinação, encontraram uma resistência à remoção de coroas metálicas cimentadas sobre dentes humanos com fosfato de zinco, $41,1 \mathrm{kgf} / \mathrm{cm}^{2}$ (4,03MPa). Em condições semelhantes, mas com 2 graus de inclinação, a resistência foi de $61,5 \mathrm{kgf} / \mathrm{cm}^{2}$ (6,03MPa). Também, Miyake, Carvalho e Muench (1995) desenvolveram uma pesquisa sobre retenção de coroas metálicas cimentadas sobre núcleos metálicos. Empregaram os cimentos: um de fosfato de zinco, um de ionômero de vidro e um resinoso. Os ensaios foram realizados nas seguintes condições: em um dia após a cimentação e imersão em solução fisiológica a $37^{\circ} \mathrm{C}$, sem ciclagem térmica; após 56 dias de imersão com 800 ciclos térmicos intercalados. Nessas condições as forças de remoção das coroas foram (kgf): com um dia de armazenagem - fosfato de zinco; 59,2 - ionômero de vidro, 57,7 - resinoso, 40,0; com armazenagem por 56 dias, os resultados correspondentes foram respectivamente: - $86,9-29,2-49,0$. Isto mostrou que o fosfato de zinco, nas circunstâncias, apresentou o máximo valor de força de retenção, que foi aumentada consideravelmente com o tempo de armazenagem e ciclagem térmica. A rugosidade parece não ter influenciado a resistência de união, pois a cerâmica com maior retenção, com fosfato de zinco, foi a Omega 900, mas a maior rugosidade, em geral, corresponde à cerâmica VMK 95. 
Cergogold 0 Mas $1,61 b$

IPS d.Sign $1,77 \mathrm{~b}$

Omega 900 Dis. 2,91 a

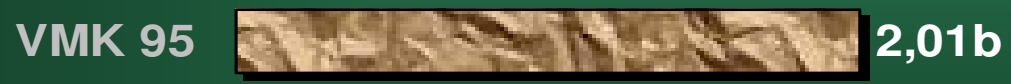

$\begin{array}{llllllll}0 & 0,5 & 1 & 1,5 & 2 & 2,5 & 3 & 3,5\end{array}$

Figura 6.1 - Médias de resistência de união (MPa) de cerâmicas em dentina humana, cimentadas com o cimento de fosfato de zinco, por ensaio de tração Médias com letras iguais indicam semelhança

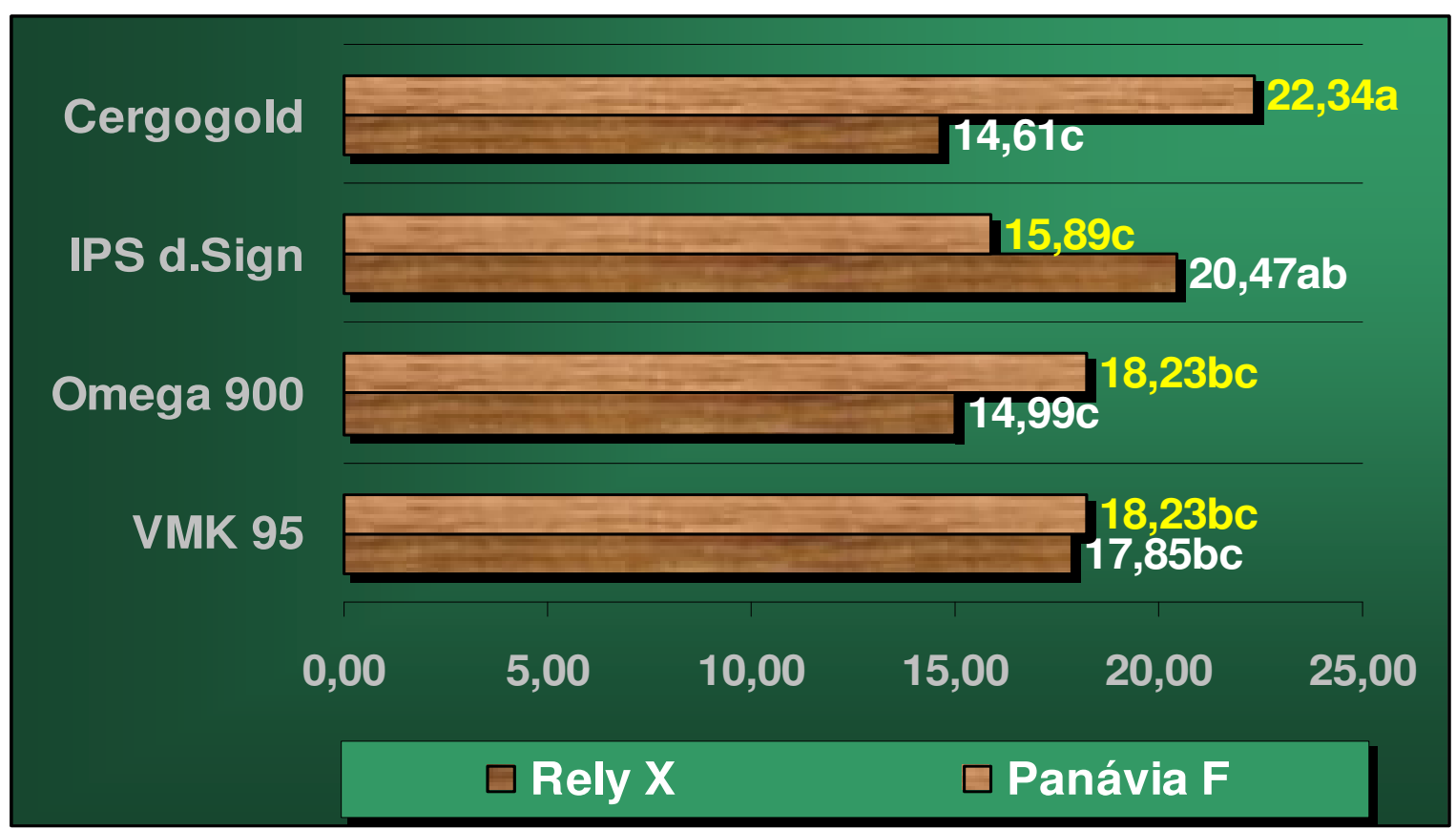

Figura 6.2 - Médias de resistência de união (MPa) de cerâmicas em dentina humana, correspondente à interação cerâmica $x$ cimento cimentadas com os cimentos Rely Xe Panávia $F$ Médias com letras iguais são semelhantes 
Verifica-se assim, que o cimento de fosfato de zinco, como no presente trabalho, apresenta baixa resistência de união, mas apresenta alta retentividade como no caso das coroas.

A fixação com os cimentos resinosos, conforme já visto, apresentou resistências de união bem maior que a do fosfato de zinco. Contudo com este cimento houve diferença significante entre cerâmicas. No caso dos cimentos resinosos não houve diferença significante entre cerâmicas, mas houve entre cimentos resinosos, o que, também, precisa ser interpretado com certa ressalva, já que existe uma interação correspondente significante. As cerâmicas VMK $95 \mathrm{e}$ Omega 900 apresentaram resistências semelhantes com os dois cimentos embora o Panávia F, com a cerâmica Omega 900 apresente com tendência maior valor, embora não significante. Fato interessante ocorreu com as cerâmicas IPS d.Sign e Cergogold. Com a cerâmica IPS d.Sign, o cimento Rely $X$ apresentou maior resistência de união que o Panávia $F$ significantemente. $O$ contrário ocorreu com a cerâmica Cergogold, em que a menor resistência significante corresponde ao cimento Rely $X$. Isto explica bem a significância da interção cerâmica $x$ cimento. Mais complicado é a justificativa físico-química. É possível que seja uma melhor ou pior afinidade, de molhamento e interpenetração mais ou menos favorável.

Os valores médios de resistência de união, por ensaio de tração, das diversas condições experimentais, variaram de 14,61 a 22,34MPa. Não se sabe exatamente se os valores são altos ou baixos. Na literatura encontram-se valores muito diversos, que além de serem dependentes de uma série de fatores, também são dependentes do tipo de ensaio. 
Shell e Nielsen (1962) introduziram um tipo de teste de cisalhamento para avaliar a resistência de união entre porcelana e liga de ouro. A porcelana era aplicada em volta de um bastão da liga e depois da cocção da porcelana, era tracionado. Com isto a retenção era por tensões de cisalhamento entre metal/porcelana. Com ligas de ouro não modificadas encontraram como valor mínimo 3.560libras/pol ${ }^{2}$ (24,6MPa). Já com ligas modificadas os valores de resistência chegaram de 9.810 a 11.280 libras/pol ${ }^{2}$ (67,7 a 77,8MPa). Em adição Oilo, Johansson e Syverud (1981) modificaram um pouco o método de Shell e Nielsen (1962), comparando os resultados com os de um teste que chamaram de push test (seria como um teste de cisalhamento como atualmente é realizado). Com o primeiro método obtiveram resistência de união de 70,1 a 122,4MPa e com o segundo 13,1 a 15,2MPa. Também, Muench (1976), determinando resistência de união de resina composta em esmalte dental humano, encontrou com ensaio por tração $92,1 \mathrm{kgf} / \mathrm{cm}^{2}(9,03 \mathrm{MPa})$ e com ensaio por cisalhamento $151,9 \mathrm{kgf} / \mathrm{cm}^{2}$ (14,90MPa). Ainda Cardoso, Braga e Carrilho (1998), também pesquisando resistência de união com sistemas adesivos em dentina, empregando três tipos de teste, encontraram os seguintes valores (MPa): ensaio por tração tradicional, 4,18 a 9,34; cisalhamento tradicional, 6,43 a 12,96; microtração, 27,77 a 34,60. Verifica-se assim, a grande influência do tipo de ensaio na resistência adesiva registrada. Além do que outros fatores apresentam grandes influencias.

Outros trabalhos ainda podem ser citados para fins comparativos de resultados. Scaranelo e Muench (1994), avaliaram a resistência de união entre porcelana e liga de níquel-cromo, por teste de extrusão do cone truncado (de 
bases 0,624 e $0,410 \mathrm{~cm}$ e altura de $0,480 \mathrm{~cm}$ ). Os fatores foram liga, jateamento, porcelana, mistura de opaco e uso ou não de vácuo. No caso, a ruptura ocorre essencialmente por tensões de tração. Os valores de resistência de união foram de 56 a $371 \mathrm{kgf} / \mathrm{cm}^{2}$ (5,5 a 37,2MPa), conforme a condição experimental. França , Muench e Cardoso (1998) encontraram como resistência de união, por ensaio de tração entre liga de níquel-cromo e cimentos resinosos, valores de $0,94 \mathrm{MPa}$ (metal liso) a 40,25MPa (tratamento com Silicoater). Martuci et al. (1999) também avaliaram a resistência de união de liga de níquel-cromo com cimentos resinosos, por ensaio de tração. Encontraram valores de 3,10MPa (cimento de ionômero de vidro) até $15,04 \mathrm{MPa}$ (resina Enforce só com adesivo e sem o primer, após 40 dias de armazenagem com ciclagem térmica). A influência de diferentes substratos dentinários (dentes humanos recem extraídos, bovino e humanos com 5 anos pós-morte, secados por 6 meses e rehidratados) foi investigada por Muench, Silva e Ballester (2000). Não foi encontrada diferença significante entre substratos nem entre adesivos. Os valores de resistência de união, por ensaio de tração, variaram de 11,6 a 14,2MPa. Lodovici et al. (2003), com microtração, armazenagens diferentes e dois adesivos, com uma resina composta encontraram valores de 39,7 a 45,1 MPa. Ainda por ensaio de tração, Muench et al. (2004) determinaram a resistência de união de liga de níquelcromo e titânio, variando o cimento, tratamento superficial e antes e após desgaste das superfícies metálicas. Encontraram valores de 6,6 a 39,7MPa. Por ensaio de microtração Campos et al. (2005) entre cerâmica e cimento resinoso encontraram valores de 12,99 e 14,97MPa (incluindo os palitos com valor zero) e 20,19 e 22,31MPa, excluindo esses valores. 
Os resultados da presente pesquisa (de 14,61 a 22,34MPa) são, portanto, bastante comparáveis com resistências de união de outros materiais, conforme visto.

Ainda alguns trabalhos relacionados diretamente com resistência de união entre cerâmicas e dentina, por cimentos resinosos, podem ser utilizados para fins comparativos. Braga, Ballester e Carrilho (1999), por ensaio de cisalhamento, em 7 dias, após cimentação, encontraram 70,2 e 72,2MPa, conforme o cimento. Em outro trabalho, Braga, Ballester e Daronch, por ensaio de cisalhamento por extrusão de cone, encontraram, após 7 dias de imersão, 7,72 a 15,04MPa, conforme a condição. Ferrari et al. (2000) por ensaio de cisalhamento encontraram valores de 6,90 a 19,9MPa. Stewart, Jain e Hedges (2002), também por ensaio de cisalhamento, verificaram que o condicionamento com o ácido fluorídrico, seguido de silanização da porcelana forneceu os melhores resultados (15,0 a 21,8MPa). Della Bona, Anusavice e Mecholsky-Júnior (2003), por ensaio de tração, encontraram valores de resistência de união de 9,9 a 56,1 MPa, conforme a condição experimental. Ainda Witzel et al. (2003), por ensaio de cisalhamento de extrusão do cone, com ciclagem de carga, encontraram os valores de 4,4 a $14,0 \mathrm{MPa}$. O cimento dual conduziu aos maiores e mais uniformes resultados, quando comparado com o de ativação química. A ciclagem mecânica (60N, 20 vezes) aos 15 minutos, não influenciou nos espécimes que não falharam durante o processo.

Uma comparação geral dos resultados da presente pesquisa mostra que eles são bastante consistentes, quando comparado com os da literatura em geral 
e, freqüentemente apresentam resistências maiores, mesmo com ensaio por tração.

Um aspecto de grande importância, quando da cimentação de coroas de cerâmicas sobre a dentina, sem substrato metálico, é que esteja provida de considerável resistência de união com essa dentina. Assim, a união impediria a fácil propagação de eventuais trincas na porcelana, que levaria ao colapso da mesma, separando-se facilmente da dentina, pela falta de contenção. Fato que ocorria freqüentemente, há décadas atrás, com as chamadas coroas de jaqueta, que eram fixadas sobre a dentina com fosfato de zinco, de baixa resistência de união à dentina, conforme visto no presente trabalho. $O$ fato, provavelmente, explica o sucesso da metalocerâmica, onde sobre o material de alta resistência mecânica, que apresenta o metal é unida, com boa retentividade, a cerâmica.

Os resultados dos tipos de fratura encontram-se nas Tabelas 5.6 e 5.7 . Verifica-se que a maioria $(63,8 \%)$, excluindo os correspondentes ao cimento de fosfato de zinco, ocorreu na interface adesivo cimento/lado da cerâmica (acc). Por outro lado, na interface adesivo cimento/lado da dentina (acd) ocorreu apenas em $5 \%$ dos casos. O colapso coesivo da cerâmica (ccc) ocorreu em $31,2 \%$ dos casos.

O teste qui-quadrado mostrou significância das freqüências. O teste binomial mostrou diferenças significantes entre as três freqüências. Em princípio a fratura adesivo cimento/lado da dentina (acd) é a mais resistente, já que ocorreu com freqüência baixa (5\%). A freqüência da fratura coesiva da cerâmica, com valor bem menor que nas interfaces, parece indicar que o teste de tração utilizado seja adequado. 


\subsection{Rugosidade superficial}

6.2.1 Rugosidade de superfícies tratadas com o ácido fluorídrico a 10\%

A análise de variância do parâmetro $\mathrm{Ra}$ mostrou significância entre cerâmicas, que ocorreu, no entanto à custa da cerâmica VMK 95. Ela apresentou maior rugosidade significantemente, não apenas no parâmetro $\mathrm{Ra}$, más, também, nos demais. Provavelmente isto se deve à estrutura da mesma, pois é uma cerâmica feldspática. Em princípio poderia se pensar que ela apresentasse maior retentividade, mas não foi o que aconteceu.

O tratamento superficial da cerâmica com ácido fluorídrico a 10\% conduziu a valores muito altos de rugosidade, mostrando que, provavelmente, ocorrem dissoluções seletivas e não uniformemente em profundidade, o que pode indicar distribuição não homogênea dos componentes, ao longo da superfície.

O parâmetro Ra registrou valores acima de $4 \mu \mathrm{m}$ com a cerâmica VMK 95. Com essa mesma cerâmica e o parâmetro Rt, que registra os maiores valores, a rugosidade passou de $32 \mu \mathrm{m}$. 


\section{Cergogold Ays $2,15 b$}

\section{IPS d.Sign $2,53 \mathrm{~b}$}

Omega 900 NMA $2,70 \mathrm{~b}$

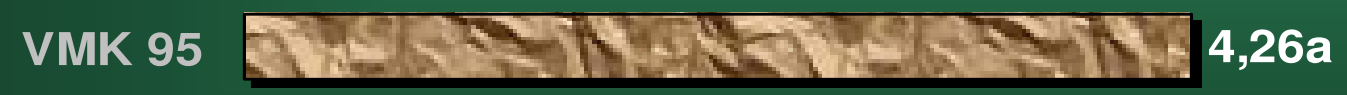

$\begin{array}{llllll}0 & 1 & 2 & 3 & 4 & 5\end{array}$

Figura 6.3 - Médias de rugosidade $(\mu \mathrm{m})$ do parâmetro Ra de superfícies de cerâmicas tratadas com ácido fluorídrico a $10 \%$

Médias com letras iguais indicam semelhança

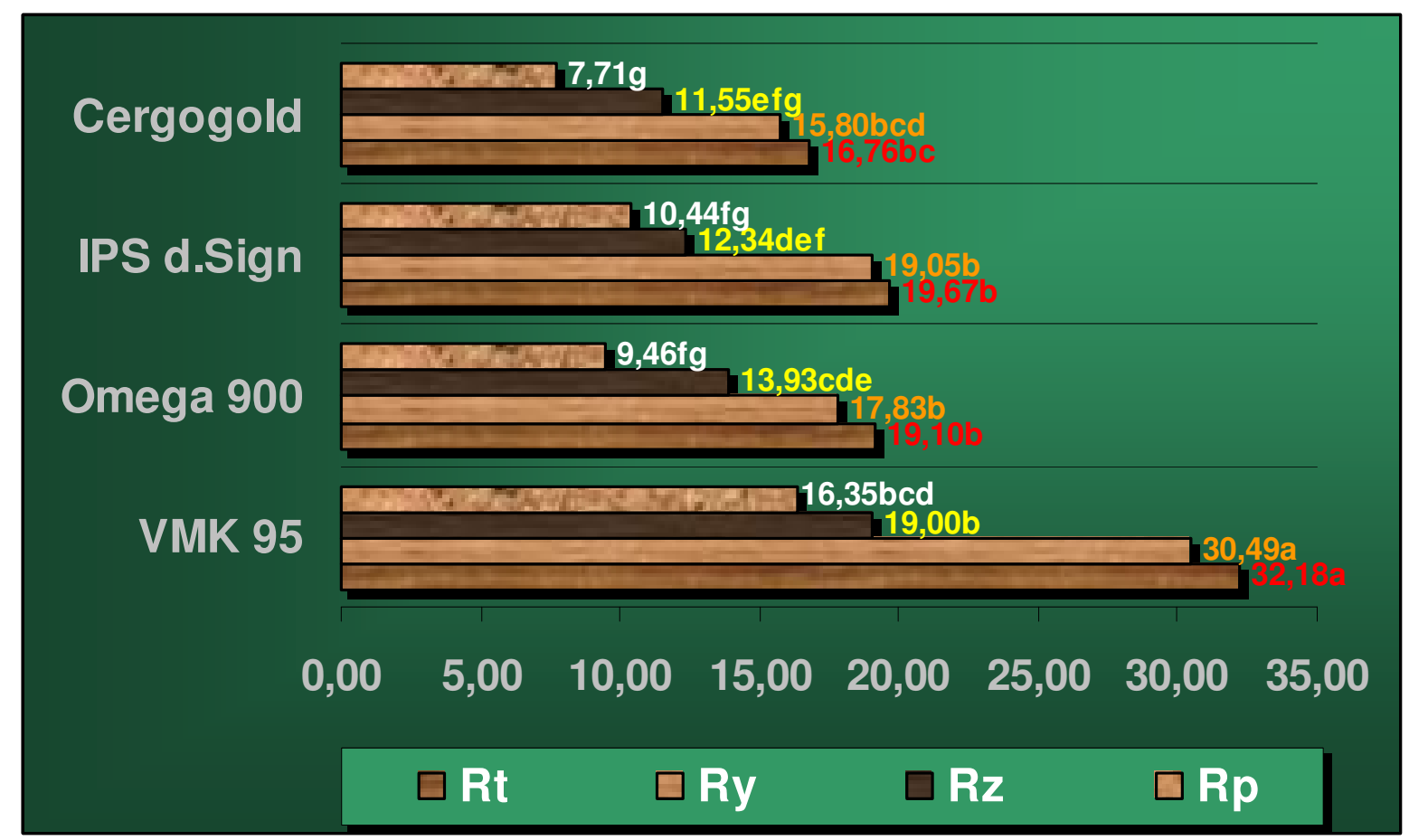

Figura 6.4 - Médias de rugosidade $(\mu \mathrm{m})$ dos parâmetros Rt, Ry, Rz e Rp de superfícies de cerâmicas, correspondentes à interação cerâmica x parâmetro de rugosidade de superfícies tratadas com ácido fluorídrico a 10\% Médias com letras iguais são semelhantes 
$\mathrm{Na}$ literatura é difícil encontrar valores de rugosidade após o tratamento com ácido fluorídrico a $10 \%$. Os trabalhos, em geral, relacionam-se com rugosidades em superfícies polidas e/ou glazeadas.

A diferença pequena entre os valores Rt e Ry (Tabela 5.12 e Figura 6.4) indica uma certa regularidade da superfície ao longo do trajeto avaliado. Isto porque Rt é a diferença entre o maior pico e vale do trajeto todo e Ry é essa diferença, mas apenas em um sub-trajeto.

\subsubsection{Rugosidade de superfícies polidas}

Os valores de rugosidade como não poderia deixar de ser, são bem menores do que aqueles correspondentes ao tratamento com o ácido fluorídrico.

$\mathrm{Na}$ avaliação do parâmetro Ra em superfícies polidas, embora a cerâmica VMK 95 apresente rugosidade significantemente maior que as demais cerâmicas não chega a $1 \mu \mathrm{m}(0,84 \mu \mathrm{m})$. Nos demais parâmetros 0 valor máximo chega a $7,51 \mu \mathrm{m}$, bem menor do que no caso da superfície tratada com ácido fluorídrico.

Os valores encontrados na presente pesquisa, com o parâmetro Ra são comparáveis com muitos dos encontrados na literatura. Bessing e Wiktorsson

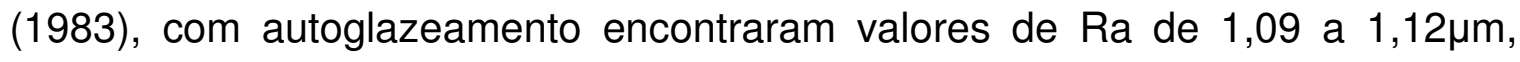
polido com sistema Shofu, $0,65 \mu \mathrm{m}$ polido com pedra pomes e $0,74 \mu \mathrm{m}$ polido com carbonato de cálcio. Valores com que a presente pesquisa apresenta semelhanças. Com o parâmetro Ry, os valores da presente pesquisa, em geral, 
até são menores. Scurria e Powers (1994) encontraram valores de Ry até menores. Fato semelhante ocorreu, em geral, em outros trabalhos com outros parâmetros (AGRA; VIEIRA, 2002; BUTLER et al., 2004; JUNG; 2002; WARD; TATE; POWERS, 1995; WHITEHEAD et al., 1995; WRIGHT et al., 2004).

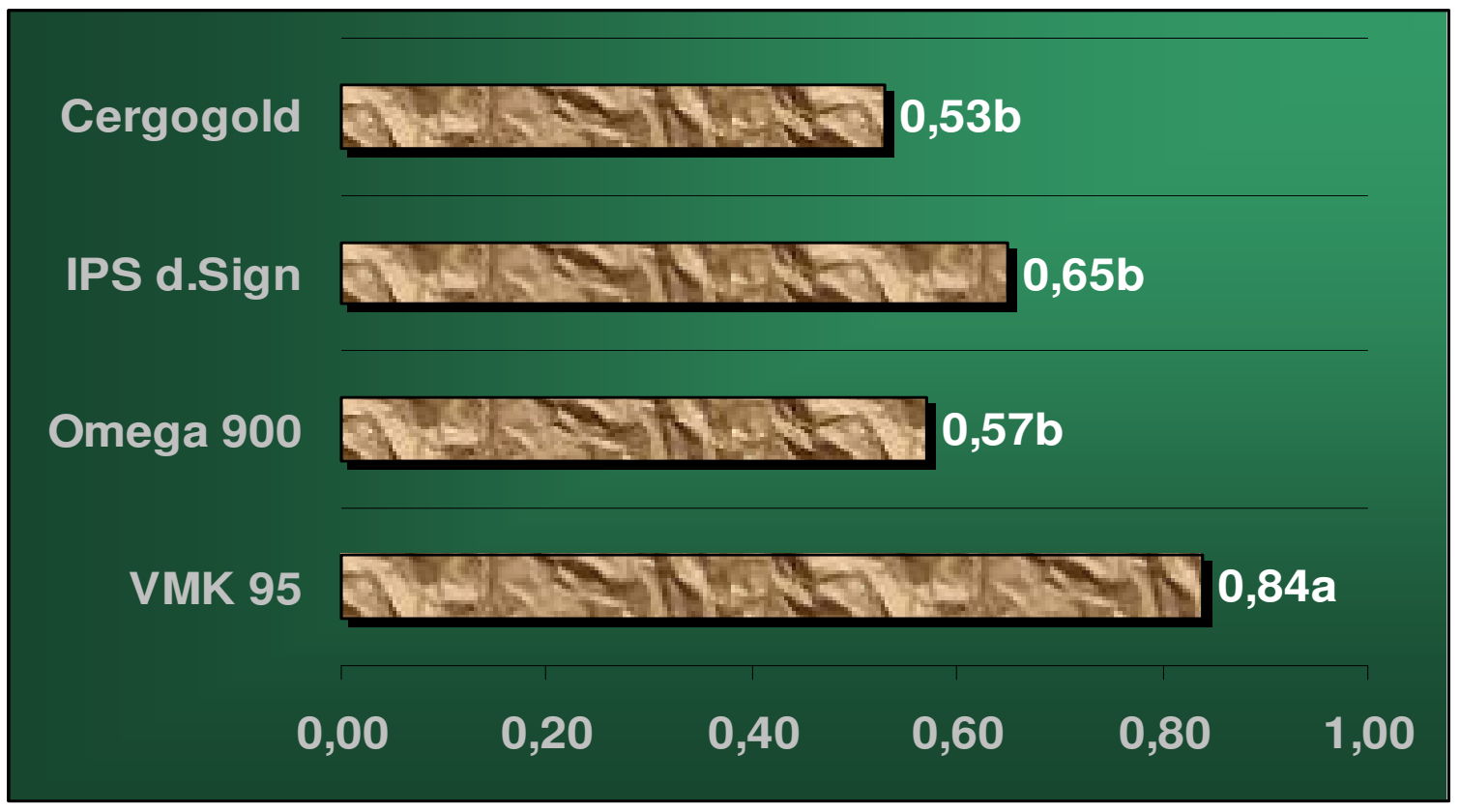

Figura 6.5 - Médias de rugosidade $(\mu \mathrm{m})$ do parâmetro Ra de superfícies de cerâmicas polidas. Médias com letras iguais são semelhantes

A rugosidade comparativa com curetagem manual e ultrassônica sobre porcelana foi conduzida por Lee, Lai e Morgano (1995). Verificaram que os dois métodos conduziram a valores semelhantes cerca de $(\mu \mathrm{m})$ : Ra, 0,$14 ; \mathrm{Rz}, 1,4$; Rt, 2,1. 


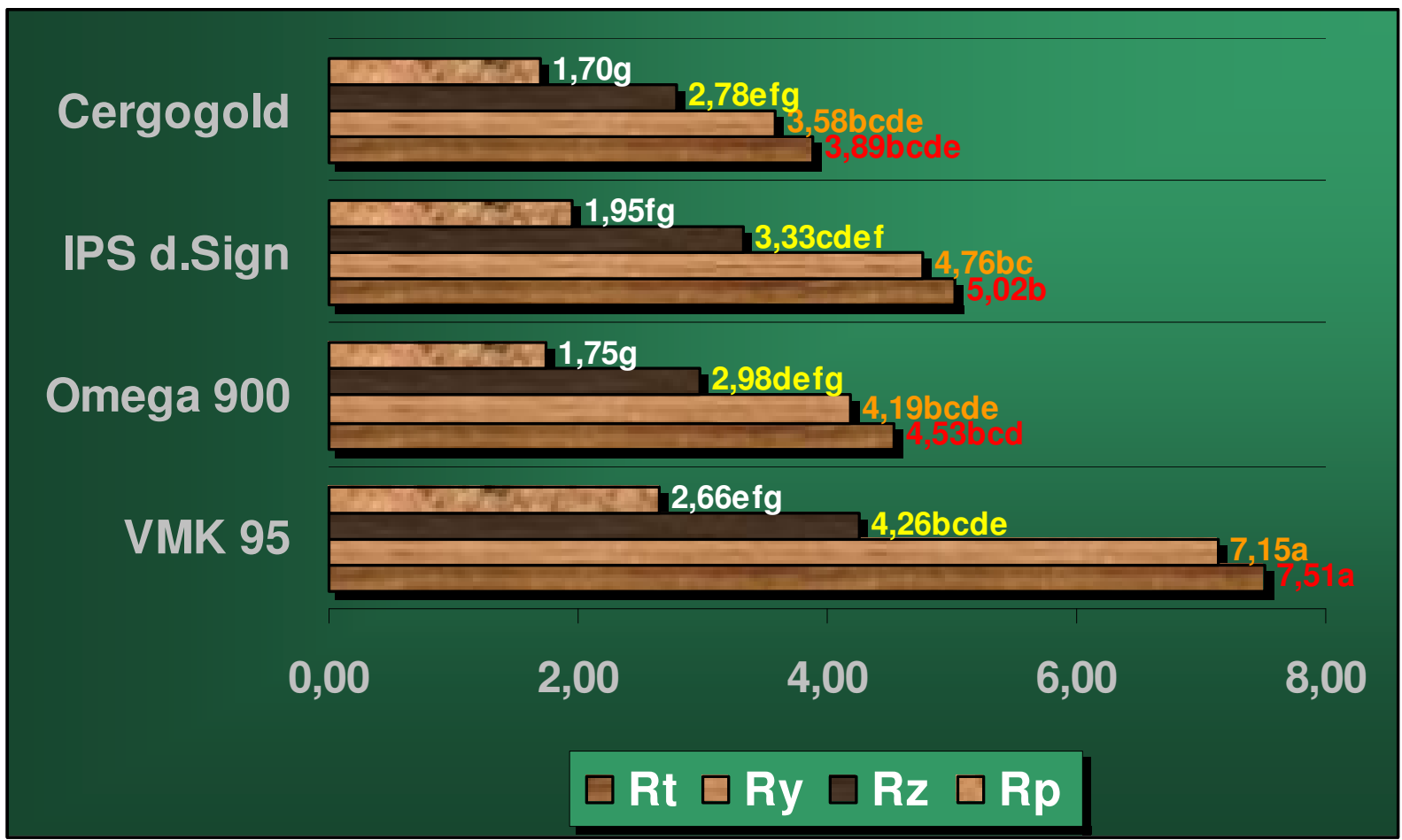

Figura 6.6 - Médias de rugosidade $(\mu \mathrm{m})$ dos parâmetros Rt, Ry, Rz e Rp de superfícies de cerâmicas, correspondentes à interação cerâmica x parâmetro de rugosidade de superfícies polidas. Médias com letras iguais são semelhantes

Kawai, Urano e Ebísu (2000) estudaram o efeito da rugosidade da porcelana na adesão de bactérias. Concluíram que, com exceção de superfícies glazeadas, foi encontrada uma correlação entre rugosidade e quantidade de acúmulo de placas. O que mostra a importância de superfícies com rugosidade bem baixa.

Outros autores (CHU; FRANKEL; SMALES, 2000; De JAGER; FEILZER; DAVIDSON, 2000) correlacionaram a resistência flexural com a rugosidade superficial dos espécimes. Concluíram que quanto maior a rugosidade, menor a resistência flexural. 


\subsection{Microdurezas}

Há décadas a dureza da cerâmica era geralmente determinada pelo tipo Knoop. Atualmente encontram-se, freqüentemente, resultados correspondentes ao tipo Vickers.

A análise de variância mostrou significância baixa entre cerâmicas $(p=0,047)$, mas acentuada entre tipos de ensaios Knoop e Vickers $(P=0,005)$. A interação não apresentou significância.

Em linhas gerais, as durezas foram semelhantes entre cerâmicas, tanto no tipo Knoop como Vickers. Na média geral, a dureza Knoop foi menor. A diferença é de 73,6 a $84,8 \mathrm{kgf} / \mathrm{cm}^{2}$. A diferença, talvez, possa ser atribuída ao fato da dureza Knoop realizar a leitura apenas da penetração comprida e não da transversal, que é de dimensão bem menor. Na dureza Vickers a penetração é quadrangular e de dimensões bem maiores que a transversal da Knoop. Neste tipo, a penetração comprida praticamente não envolve deformação elástica, o que ocorre no tipo Vickers. Como a deformação elástica não é lida, a deformação permanente é menor e conseqüentemente a dureza computada maior. Os resultados não concordam com os de Higashimo et al. (2003), que encontraram valores maiores com o tipo Knoop. 


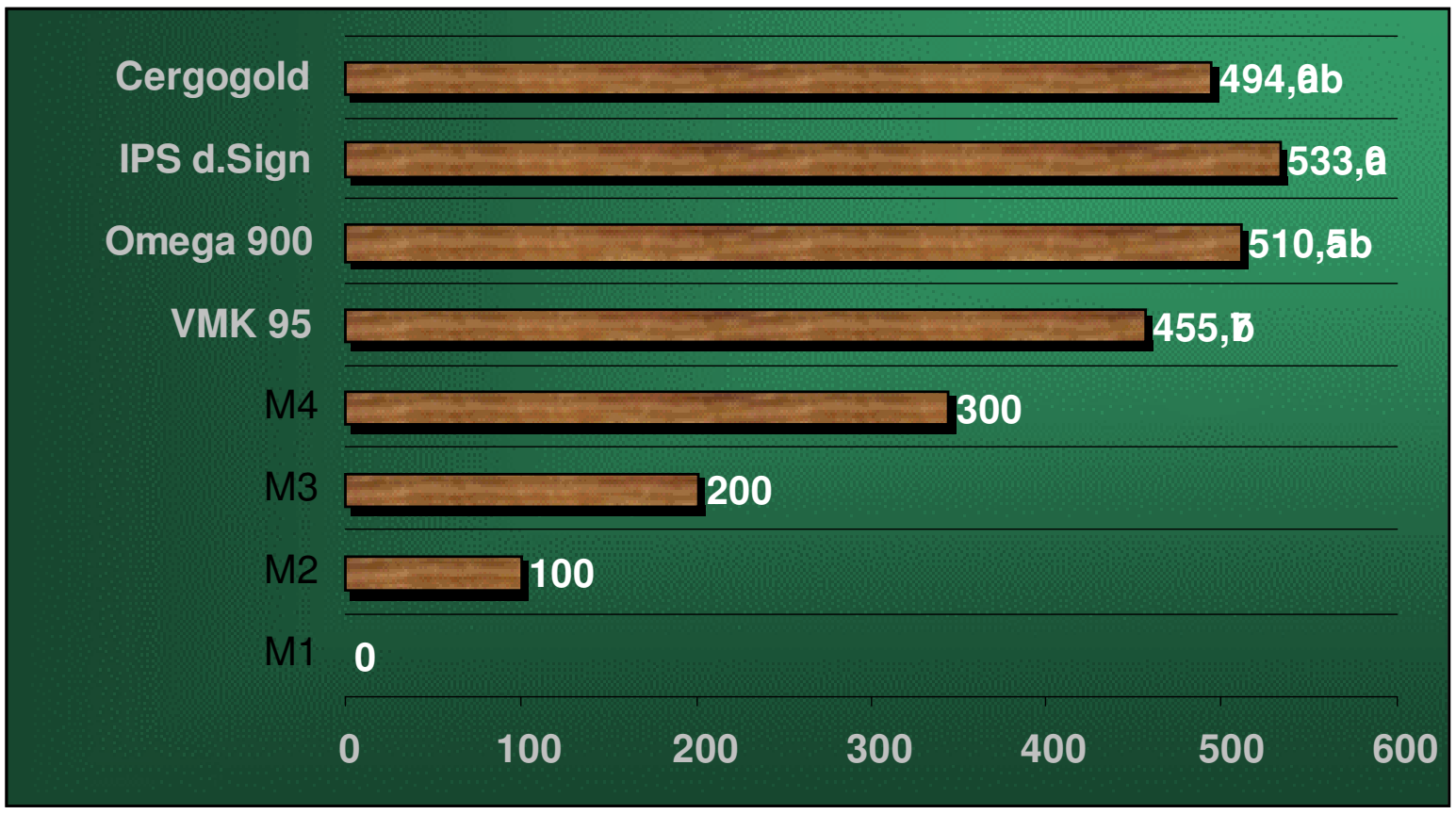

Figura 6.7 - Médias de dureza $\left(\mathrm{kgf} / \mathrm{cm}^{2}\right)$ correspondentes ao fator principal (cerâmica) Médias com letras iguais indicam semelhança

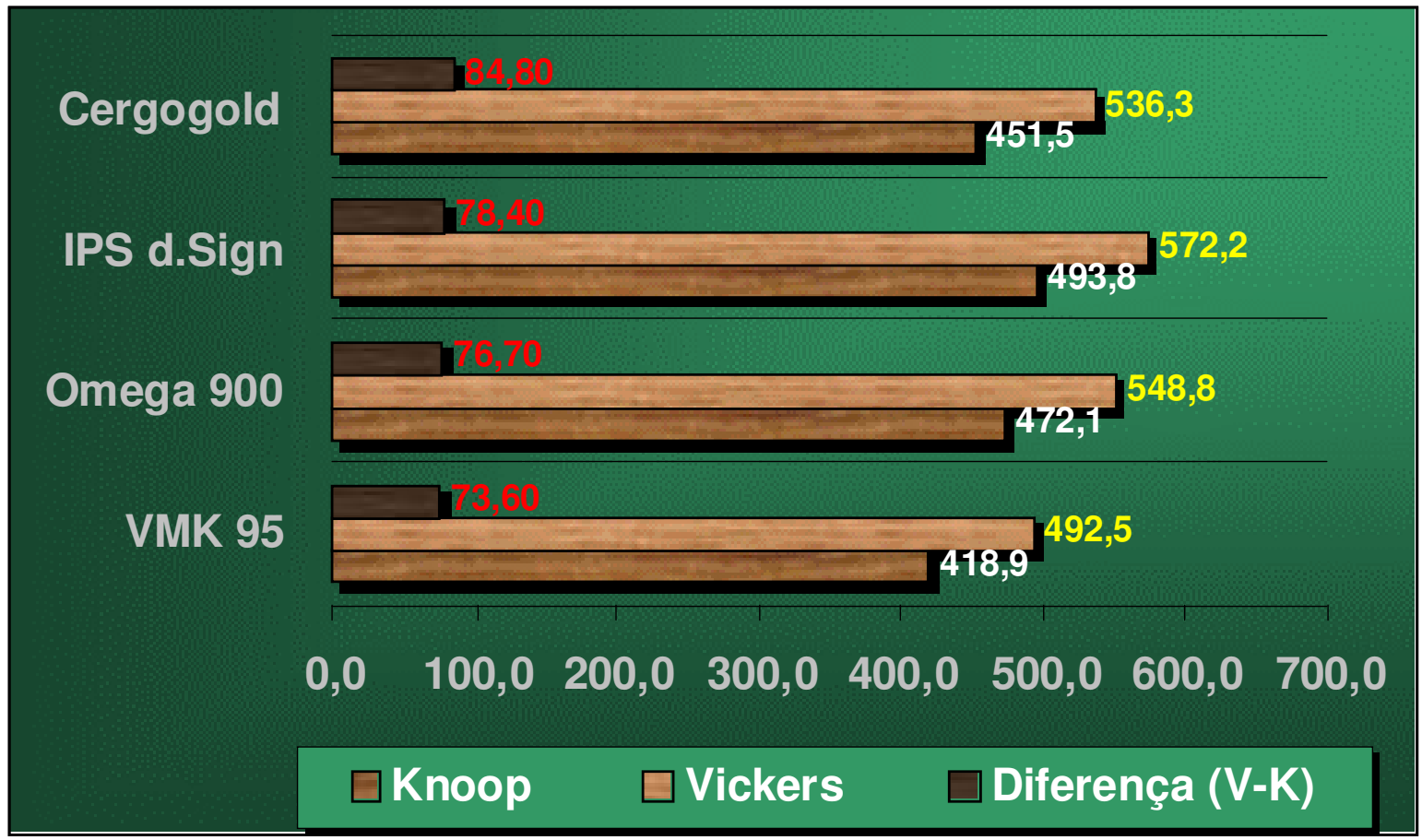

Figura 6.8 - Médias de dureza $\left(\mathrm{kgf} / \mathrm{cm}^{2}\right)$ correspondentes à interação cerâmica $x$ tipo de dureza e diferenças (Vickers-Knoop) 
As durezas encontradas, que não variam muito com a marca de cerâmica estão em torno de $500 \mathrm{kgf} / \mathrm{mm}^{2}(4,96 \mathrm{MPa})$, conforme Figuras 6.7 e 6.8 . São valores encontrados com freqüência na literatura. Peyton et al. (1960), com as porcelanas da época apresentaram o valor de $460 \mathrm{~kg} / \mathrm{mm}^{2}$ para a dureza Knoop. Comparado com o esmalte dental de $343 \mathrm{kgf} / \mathrm{mm}^{2}$. Também, Abe et al. (1997) apresentaram durezas Knoop comparativamente $\left(\mathrm{kgf} / \mathrm{mm}^{2}\right)$ : liga de ouro/paládio, 260; liga de cobalto-cromo, 448; porcelana feldspática, 568; esmalte humano, 337. Isto mostra que os materiais cerâmicos, empregados na Odontologia, apresentam durezas muito altas. Rasmussen, Groh e O'Brien (1998) encontraram dureza Vickers de 3,75 a 4,25GPa. Baharav et al. (1999) estudaram a dureza Vickers em função do tempo de glazeamento, que foi de $510,8 \mathrm{kgf} / \mathrm{mm}^{2}$ com tempo zero e chegou a um mínimo com 60 minutos de glazeamento $\left(454,5 \mathrm{kgf} / \mathrm{mm}^{2}\right)$. Alcançou o valor máximo com 90 minutos de glazeamento. Denry e Holloway (2000) observaram aumento de dureza com a adição de maior quantidade de magnésio (5,56 a 8,15GPa). Valores surpreendentemente altos foram encontrados por Guazzato et al. (2002), com cerâmicas com alumina ou zircônia. As durezas Vickers, determinadas pelo método da American Sciety for Testing Materials, foram de 10,0 e 11,5 GPa. Conforme a cerâmica Kawai, Inoue e Tsuchitani (2003) encontraram durezas Vickers de cerca de 580 a 800GPa. Já Denry e Holloway (2004) determinaram a dureza Vickers em função da adição de sódio, encontrando valores máximos com menor quantidade adicionada (6,44GPa). Gorman e Hill (2004) determinaram a dureza Vickers em função de tratamentos térmicos e encontraram valores de 621,7 a $645,5 \mathrm{kgf} / \mathrm{mm}^{2}$. 
Verifica-se que nos mais diversos estudos, as durezas são de valores relativamente altos como material restaurador, quase sempre em torno de $500 \mathrm{~kg} / \mathrm{mm}^{2}$. As porcelanas estudadas no presente trabalho enquadram-se assim, dentro dos intervalos encontrados na literatura.

\subsection{Microscopia de força atômica}

Marshall-Júnior et al. (1993) julgaram que a microscopia de força atômica (AFM), que é da família de microscopia de tunelamento por varredura, parece ser uma nova poderosa ferramenta no estudo da desmineralização da dentina. Hegedüs et al. (1999), pelo emprego da AFM encontraram sulcos em esmalte dental sadio e julgaram ser isto parte da morfologia superficial. Fizeram a determinação apenas ao longo de $10 \mu \mathrm{m}$ e pelas imagens notam-se muitas irregularidades. Wen et al. (2000), varreram ao longo de biovidro em solução calcificadora, apenas por $1 \mu \mathrm{m}$. Pelas imagens notam-se irregularidades bem acentuadas. El Feninat et al. (2001) atribuíram à análise da AFM a vantagem de não requerer o preparo especial das amostras, como ocorre em outros métodos.

A observação qualitativa das Figuras 5.1 a 5.4 da presente pesquisa mostra que aquelas correspondentes à cerâmica VMK 95 são aparentemente as mais lisas, embora esse material tenha apresentado a maior rugosidade determinada com todos os parâmetros. Já as Figuras correspondentes aos demais materiais aparentam maior irregularidade, em qualquer angulação de 
tomada das imagens. Talvez, as aparentes irregularidades, sejam mais decorrentes da heterogeneidade de composição das cerâmicas.

\subsection{Generalidades}

Uma análise geral dos resultados mostra que as cerâmicas estudadas parecem satisfazer as propriedades necessárias para um bom desempenho clínico. As durezas estão nas vizinhanças das existentes. As rugosidades estudadas, pelos diversos parâmetros, mostram que elas aceitam polimento satisfatório, do ponto de vista clínico. Uma propriedade de grande importância que necessitam, e parece que elas apresentam, para um bom desempenho clínico, é a alta resistência de união à dentina, para garantir alta resistência mecânica do conjunto, durante a função. 


\section{CONCLUSÕES}

Tendo em vista os resultados obtidos pelas análises estatísticas, e discutidos, parece lícito concluir que:

\subsection{Resistência de união, por ensaio de tração}

7.1.1 O cimento de fosfato de zinco apresentou resistência de união muito baixa, embora a maior significantemente, corresponda ao material Omega 900, ainda seja muito baixa.

7.1.2 A resistência de união com os cimentos resinosos foi cerca de 9 vezes maior, em média, do que a do fosfato de zinco.

7.1.3 Considerando médias dos níveis dos fatores principais, não houve diferenças significantes entre cerâmicas, mas houve entre cimentos. Isto precisa, no entanto, ser interpretado com ressalvas, já que a interação correspondente foi significante. Assim, se nas cerâmicas VMK 95 e Omega 900 os cimentos não 
influenciaram significantemente, com a IPS d.Sign o cimento Rely $X$ apresentou a maior resistência e com a Cergogold a menor.

7.1.4 A fratura com o cimento de fosfato de zinco foi $100 \%$ na interface adesiva cimento/lado da cerâmica. Com os cimentos resinosos esta falha ocorreu em $63,8 \%$ dos casos e apenas em $5 \%$ dos casos no lado da dentina. A fratura coesiva na cerâmica ocorreu em $31,2 \%$ dos casos.

\subsection{Rugosidade superficial}

7.2.1 A rugosidade pelo parâmetro $\mathrm{Ra}$ em superfícies tratadas com ácido fluorídrico a 10\% foi muito elevada e a maior correspondeu à cerâmica VMK 95.

7.2.2 Ainda com o tratamento superficial com ácido fluorídrico a $10 \%$, com os demais parâmetros de rugosidade ( $R t, R y, R z$ e $R p$ ) os fatores principais cerâmica e tipo de rugosidade, bem como a interação correspondente foram significantes. Assim a cerâmica VMK 95 apresentou a maior rugosidade em todos os parâmetros e nas demais cerâmicas, não foram encontradas diferenças significantes nos diversos parâmetros. 
7.2.3 Nas superfícies polidas todas as cerâmicas com o parâmetro Ra apresentaram rugosidade abaixo de $1 \mu \mathrm{m}$, e a cerâmica VMK 95 apresentou a maior significantemente.

7.2.4 Nas superfícies polidas, os fatores principais cerâmica e parâmetros (Rt, Ry, Rz e Rp), bem como a interação correspondente foram significantes. A maior rugosidade corresponde à cerâmica $V M K$ 95. Os parâmetros Rt e Ry não apresentaram diferenças significantes em nenhuma cerâmica.

\subsection{Microdurezas}

7.3.1 Em média a dureza Vickers apresentou maior valor de dureza.

7.3.2 Das cerâmicas apenas entre a maior (IPS d.Sign) e a menor (VMK 95) houve diferença significante de durezas. 


\subsection{Microscopia de força atômica}

A microsocopia de força atômica permite visualizar com nitidez a estrutura superficial, sem necessidade de preparo especial das amostras. 


\section{REFERÊNCIAS ${ }^{1}$}

Abe $\mathrm{Y}$, Sato $\mathrm{Y}$, Akagawa $\mathrm{Y}$, Ohkawa $\mathrm{S}$. An in vitro study of high-strength resin posterior denture tooth wear. Int J Prosthodont 1997;10(1):28-34.

Agra CM, Vieira GF. Quantitative analysis of dental porcelain surfaces following different treatments: Correlation between parameters obtained by a surface profiling instrument. Dent Mater J 2002;21(1):44-52.

Akgungor G, Akkayan B, Gaucher H. Influence of ceramic thickness and polymerization mode of a resin luting agent on early bond strength and durability with a lithium disilicate-based ceramic system. J Prosthet Dent 2005;94(3):23441.

Albakry M, Guazzato M, Swain MV. Fracture toughness and hardness evaluation of three pressable all-ceramics materials. J Dent 2003;31(3):181-8.

Al-Hiyasat AS, Saunders WP, Sharkey SW, Smith GMcR, Gilmour WH. The abrasive effect of glazed, unglazed and polished porcelain on the wear of human enamel, and the influence of carbonated soft drinks on the rate of wear. Int $\mathrm{J}$ Prosthodont 1997;10(3):269-82.

Almeida MAB, Salvio LA, Borges GA, Correr-Sobrinho L, Spohr AM. Avaliação da dureza Vickers e rugosidade superficial de uma cerâmica prensada antes e após simulação de ajuste. [resumo Pc 180]. Pesqui Odontol Bras 2002;16(Supl):238.

Baharav H, Laufer BZ, Mizrachi A, Cardash HS. Effect of different cooling rates on fracture toughness and microhardness of a glazed alumina reinforced porcelain. J Prosthet Dent 1996;76(1):19-22.

\footnotetext{
${ }^{1}$ De acordo com o Estilo Vancouver. Abreviatura de periódicos segundo base de dados MEDLINE (fonte arial)
} 
Baharav H, Laufer BZ, Pilo R, Cardash HS. Effect of glaze thickness on the fracture toughness and hardness of alumina-reinforced porcelain. J Prosthet Dent 1999;81(5):515-9.

Bessing C, Wiktorsson A. Comparison of two different methods of polishing porcelain. Scand J Dent Res 1983;91(6):482-7.

Blatz MB, Sadan A, Arch-Júnior GH, Lang BR. In vitro evaluation of long-term bonding of Procera AllCeram alumina restorations with a modified resin luting agent. J Prosthet Dent 2003;89(4):381-7.

Borba M, Della Bona A, Diefenthaeler GL. Efeito de tratamentos de superfície na resistência à tração de uma cerâmica infiltrada por vidro aderido a resina. [resumo lb 095]. Braz Oral Res 2004;18(Supl): 78.

Borges GA, Correr-Sobrinho L, Almeida MAB, Spohr AM. Avaliação da dureza e rugosidade superficial da cerâmica feldspática glazeada e polida. Rev Odonto Ciênc 2002;17(37):302-6.

Braga RR, Ballester RY, Carrilho MOR. Pilot study on the early shear strength of porcelain-dentin bonding using dual-cure cements. J Prosthet Dent 1999;81(3):285-9.

Braga, RR, Ballester RY, Daronch M. Influence of time and adhesive system on the extrusion shear strength between feldspathic porcelain and bovine dentin. Dent Mater 2000;16(4):303-10.

Butler CJ, Masri R, Driscall CF, Thompson GA, Runyan DA, Fraunhofer JA von. Effect of fluoride and $10 \%$ carbamide peroxide on the surface roughness of lowfusing and ultra low-fusing porcelain. J Prosthet Dent 2004;92(2):179-83.

Campos L, Telles M, Galhano GA, Camargo FP, Valandro LF, Mallman A. Efeito do tempo de condicionamento da superfície cerâmica sobre a resistência adesiva entre uma cerâmica de fluorapatita e um cimento resinoso. Cienc Odontol Bras $2005 ; 8(3): 71-6$. 
Cardoso PEC, Braga RR, Carrilho MRO. Evaluation of micro-tensile, shear and tensile testes determining the bond strength of three adhesive systems. Dent Mater 1998;14(6):394-8.

Chu FCS, Frankel N, Smales RJ. Surface roughness and flexural strength of selfglazed, polished, and reglazed In-Ceram/Vitadur Alpha Porcelain laminates. Int J Prosthodont 2000;13(1):66-71.

Correr-Sobrinho L, Sphor AM, Consani S, Sinhoretti MAC, Borges GA. Efeito dos tipos de cimento e de tratamentos de superfície na resistência à tração da cerâmica IPS Empress II. [resumo Pa 190]. Pesqui Odontol Bras 2002;16(Supl):146.

Craig RG, Powers JM. Materiais dentários restauradores. Traduzido por Cimara Fortes Ferreira. 11ª ed. São Paulo: Santos; 2004.

Dantas MH, Spyrides GM, Spyrides SMM, Maltez MM, Silva RC, Copello R. Adesão dos cimentos Bistite II DC, Variolink II e Enforce à porcelana IPS Empress II. [resumo la 171]. Braz Oral Res 2004;18 (Supl):66.

De Jager N, Feilzer AJ, Davidson CL. The influence of surface roughness on porcelain strength. Dent Mater 2000;16(6):381-8.

Della Bona A, Anusavice KJ, Mecholsky-Júnior JJ. Failure analysis of resin composite bonded to ceramic. Dent Mater 2003;19(8):693-9.

Denry IL, Holloway JA. Effect of magnesium content on the microstructure and crystalline phase of fluoramphibole glass-ceramics. J Biomed Mater Res 2000; 53(4):289-96.

Denry IL, Holloway JA. Elastic constants, Vickers hardness, and fracture toughness of fluorrichterite-based glass-ceramics. Dent Mater 2004;20(3):213-9.

El Feninat F, Ellis TH, Sacher E, Stangel I. A tapping mode AFM study of collapse and denaturation in dentinal collagen. Dent Mater 2001;17(4):284-8. 
El Zohairy AA, De Gee AJ, Asan FM, Feilzer AJ. The effect of adhesives with various degress of hydrophilicity on resin ceramic bond durability. Dent Mater $2004 ; 20(8): 778-87$.

Feher A, Mormann WH. The preparation of ceramic restorations with superfine diamond intrument. Schweiz Monatsschr Zahnmed 1995;105(4):474-9.

Ferrari M, Mannocci F, Vichi A, Goracci G. Bond strengths of a porcelain material to different abutment substrates. Oper Dent 2000;25(4):299-305.

Filho AM, Vieira LC, Araújo E, Monteiro-Júnior S. Effect of different ceramic surface treatments on resin microtensile bond strength. J Prosthodont 2004; 13(1):28-35.

França, RO, Muench A, Cardoso PEC. Resistência de união entre liga de níquelcromo e cimentos resinosos. Rev Odontol Univ São Paulo 1998;12(3):267-70.

Freiman SW. Science of whitewares. Westerville: The American Ceramic Society; 1996.

Fuzzi M, Zaccheroni Z, Vallania G. Scanning electron microscopy and profilometer evaluation of glazead and polished dental porcelain. Int $\mathrm{J}$ Prosthodont 1996;9(5):452-8.

German RM. Powder metallurgy science. New Jersey: Metal Powder Industries Federation; 1989.

Gonçalves J, Bottino MA, Leite FPP, Peixe S, Yoshiga SR, Michida SMA et al. Avaliação da resistência a microtração entre dois cimentos resinosos e uma cerâmica prensada [resumo la 195]. Pesqui Odontol Bras 2002;16 (Supl):56.

Gorman CM, Hill RG. Heat-pressed ionomer glass-ceramics. Part II. Mechanical property evaluation. Dent Mater 2004;20(3):252-61.

Gorman CM, McDevitt WE, Hill RG. Comparison of two heat-pressed all-ceramic dental materials. Dent Mater 2000;16(6):389-95. 
Guazzato M, Albakry M, Ringer SP, Swain MV. Strength, fracture toughness and microstructure of a selection of all-ceramic materials. Part I. Pressable and alumina glass-infiltrated ceramics. Dent Mater 2004a;20(5):441-8.

Guazzato M, Albakry M, Ringer SP, Swain MV. Strength, fracture toughness and microstructure of a selection of all-ceramic materials. Part II. Zirconia-based dental ceramics. Dent Mater 2004b;20(5):449-56.

Guazzato M, Albakry M, Swain MV, Ironside J. Mechanical properties of InCeram Alumina and In-Ceram Zirconia. Int J Prosthodont 2002;15(4):339-46.

Hegedüs C, Bistey T, Flóra-Nagy E, Keszthelyi G, Jenei A. An atomic force microscopy study on the effect of bleaching agents on enamel surface. J Dent 1999;27(7):509-15.

Higashino Y, Yamauchi M, Goto T, Nagasawa T. Evalution of brittleness of porcelain fused to pure titanium by fracture hardness and fracture energy. Dent Mater J 2003;22(4):532-42.

Hirata JM, Muench A. Estudo da retenção de coroas totais fundidas, em função da área preparada e do ângulo de inclinação das paredes, em dentes naturais. Rev Assoc Paul Cir Dent 1982;36(5):468-74.

Hooshmand T, van Noort R, Keshvad A. Bond durability of the resin-bonded and silane treated ceramic surface. Dent Mater 2002;18(2):179-88.

Ide T, Tanoue N, Yanagida H, Atsuta M, Matsumura H. Effectiveness of bonding systems on bonding durability of a prefabricated porcelain material. Dent Mater $\mathrm{J}$ 2005;24(4):257-60.

Imai M. Pre-treatment of porcelain surface for adhesive restorations. Shika Zairyo Kikai 1990;9(2):301-13.

Jung M. Finishing and polishing of a hybrid composite and a heat-pressed glass ceramic. Oper Dent 2002;27(2):175-83. 
Kawai K, Inoue M, Tsuchitani Y. Effect of ion-exchange treatment on mechanical properties of new dental ceramics. Am J Dent 2003;16(5):347-50.

Kawai K, Urano M, Ebisu S. Effect of surface roughness of porcelain on adhesion of bacteria and their syntherizing glucans. J Prosthet Dent 2000;83(6):664-7.

Kedeci PS, Kalipicilar B, Bilir OG. Effect of glass ionomer liners on bonding strength of laminate veneers. J Prosthet Dent 1992;68(1):29-32.

Khairy AE, Sobhy F. Bonding of laminate veneer materials to enamel. Egypt Dent J 1994;40(4):941-8.

Kraul A, Vasconcelos BT, Macedo, MRP, Miranda-Júnior, WG, Oda M. Avaliação em AFM e rugosímetro da rugosidade superficial de um material cerâmico polido com e sem refrigeração [resumo Pc 241]. Braz Oral Res 2004; 18 (Supl):223.

Lee SY, Lai YL, Morgano SM. Effects of ultrasonic scaling and periodontal curettage on surface roughness of porcelain. J Prosthet Dent 1995;73(3):227-32.

Leitão J, Hegdahl T. On the measuring of roughness. Acta Odontol Scand 1981; 39(6):379-84.

Leite FPP, Kimpara ET, Soares LF, Anreatta OD, Lopes AG, Gianinni V, et al. Resistência à microtração entre dois cimentos resinosos e uma cerâmica vítrea de dissilicato de lítio. [resumo Pb 263]. Pesqui Odontol Bras 2002;16 (Supl):202.

Lodovici E, Sadek FT, Muench A, Rodrigues Filho LE, Cardoso PEC. Influência do tempo de armazenamento na resistência de união à dentina de dois tipos de adesivos dentários por ensaio de microtração. Cienc Odontol Bras 2003;6(4):7986.

Machado, N. Rugosidade superficial do esmalte dental humano, determinada sob vários parâmetros. [Tese de Doutorado]. São Paulo: Faculdade de Odontologia da USP; 2002. 
Marshall-Júnior GW, Chang YJ, Gansky SA, Marshall SJ. Demineralization of caries-affected transparent dentin by citric acid: an atomic force microscopy study. Dent Mater 2001;17(1):45-52.

Marshall-Júnior GW, Balooch M, Tench RJ, Kinney JH, Marshall SJ. Atomic force microscopy of acid effects on dentin. Dent Mater 1993;9(4):265-8.

Marshall-Júnior GW, Wu-Magidi IC, Watanabe LG, Inoi N, Balooch M, Kinney JH et al. Effect of citric acid concentration on dentin desmineralization, hydration, and rehydration: Atomic force microscopy study. J Biomed Mater Res 1998;42(4): 500-7.

Marson FC, Sensi LG, Vieira LCC, Baratieri LN, Gondo R, Souza SM. Resistência adesiva à microtração de cimentos resinosos na interface entre cerâmica e dentina [resumo Pa 226]. Braz Oral Res 2004;18(Supl):139.

Martuci RR, Muench A. Cerâmicas odontológicas: microscopia de força atômica (AFM) e análise de rugosidade superficial [resumo Pa 196]. Braz Oral Res 2004; 18 (Supl):135.

Martuci RR, Muench A, Bianchi J, Rodrigues Filho LE. Resistência de união entre cimentos e liga de níquel-cromo, em função da ciclagem térmica e variações no procedimento de união. Rev Odontol Univ São Paulo 1999;13(3):269-73.

Metzler KT, Woody RD, Miller AW, Miller BH. In vitro investigation of the wear of human enamel by dental porcelain. J Prosthet Dent 1999;81(3):356-64.

Miyake CY, Carvalho JA, Muench A. Retenção de coroas metálicas cimentadas sobre núcleos metálicos. RPG 1995;2(3):117-20.

Muench A. Retenção de resina composta em função do método de aplicação da solução ácida, da orientação dos esforças e da refixação. Rev Assoc Paul Cir Dent 1976;30(6):299-302.

Muench A, Silva EM, Ballester RY. Influence of different dentinal substrates on the tensile bond strength of three adhesive systems. J Adhesive Dent 2000;2(3): 209-12. 
Muench A, França RO, Rodrigues Filho LE, Grande RHM. Resistência das uniões cimentadas de titânio e liga de níquel-cromo. RPG 2004; 11(1):39-43.

Naylor WP, Munoz CA, Goodacre CJ, Swartz ML, Moore BK. The effect of surface treatment on the Knoop hardness of Dicor. Int J Prosthodont 1991;4(2): $147-51$.

Oh WS, Shen C, Alegre B, Anusavice KJ. Wetting characteristic of ceramic to water and adhesive resin. J Prosthet Dent 2002;88(6):616-21.

Öilo G, Johanson B, Syverud M. Bond strength of porcelain to dental alloys - an evaluation of two test methods. Scand J Dent Res 1981;89(3):289-96.

Oliveira NDM, Rocha JM, Borges GA, Correr-Sobrinho L, Soares CJ. Avaliação da dureza Vickers de cinco cerâmicas glazeadas e polidas. [resumo Ic 098]. Braz Oral Res 2004;18(Supl):101.

Peyton FA, Anthony DH, Asgar K, Charbeneau GT, Craig RC, Myers GE. Restorative dental materials. St Louis: Mosby; 1960.

Pinto ECT, Neppelenbroek KH, Urban VM, Oliva EA, Schalch MV, Cruz CADS. Influência do método de processamento de uma cerâmica feldspática na resistência de união com um cimento resinoso dual. [resumo lc 093]. Braz Oral Res 2004;18(Supl):100.

Quirynem M, Bollen CML. The influence of surface roughness and surface-free energy on supra- and subgingival plaque formation in man. J Clin Periodontol $1995 ; 22(1): 1-14$.

Rasmussen ST, Groh CL, O'Brien WJ. Stress induced phase transformation of a cesium stabilized leucite porcelain and associated properties. Dent Mater 1998; 14(3):202-11.

Rosa V, Della-Bona A, Pinzetta C. Tenacidade de fratura e dureza de uma nova cerâmica de uso odontológico [resumo PI 022]. Braz Oral Res 2004;18 (Supl): 37. 
Scaranello RM, Muench A. Contribuição para o estudo da resistência de união entre porcelanas e ligas de níquel-cromo. RPG 1994;1(1):22-6.

Scurria MS, Powers JM. Surface roughness of two polished ceramic materials. J Prosthet Dent 1994;71(2):174-7.

Shell JS, Nielsen JP. Study of the bond between gold alloys and porcelain. J Dent Res 1962;41(6):1424-37.

Siedlecki CA, Marchant RE. Atomic force microscopy for characterization of the biomaterial interface. Biomaterials 1998;19(4/5):441-54.

Silva RC, Roizman E, Spyrides GM. Comparação in vitro da adesão das porcelanas Vitadur Alpha e In Ceram ao esmalte bovino com o cimento Panávia F [resumo Ic 105]. Pesqui Odontol Bras 2002;16 (Supl):102.

Steward GP, Jain P, Hodjes J. Shear bond strength of resin to both ceramic and dentin. J Prosthet Dent 2002;88(3):277-84 .

Szep S, Schmid C, Weigl P, Hahn L, Heidemann D. Effect of the silicone disclosing procedure on the shear bond strength of composite cements to ceramic restorations. J Prosthet Dent 2003;89(1):60-5.

Tseng EY, Cooley RL, Evans JG. Porcelain to dentin bond strength with a dentin adhesive. J Esthet Dent 1992;4(4):131-3.

Turker SB, Biskin T. Effect of three bleaching agents on the surface properties of three different esthetic restorative materials. J Prosthet Dent 2003;89(5):466-73.

Uno S, Tanaka T, Kawamoto C, Konishi J, Sano H. Microtensilebond strength to dentin and cavity adaptation of Cerec 2 inlay restoration. Am J Dent 2000;13(2): 59-63.

Urban VM, Neppelenbroek KH, Oliva EA, Schalch MV, Cruz CADS. Resistência ao cisalhamento da união entre um cimento resinoso e materiais cerâmicos para infra-estrutura [resumo Pb 156]. Braz Oral Res 2004;18 (Supl):176. 
Usumez A, Aykent F. Bond strengths of porcelain laminate veneers to tooh surfaces prepared with acid and Er,Cr:YSGG laser etching. J Prosthet Dent 2003; 90(1):24-30.

Usumez A, Ozturk AN, Usumez S, Ozturk B. The efficiency of different light sources to polymerize resin cement beneath porcelain laminate veneers. J Oral Rehabil 2004;31(2):160-5.

Van Noort R. Introdução aos materiais dentários. Traduzido por Luís Narciso Baratieri e Sílvio Monteiro. 2ª ed. Porto Alegre: Artmed; 2004.

Van Vlack LH. Princípios de ciência e tecnologia dos materiais. Traduzido por Edson Monteiro. 4를 ed. Rio de Janeiro: Campos; 1984.

Ward MT, Tate WH, Powers JM. Surface roughness of opalescent porcelain after polishing. Oper Dent 1995;20(3):106-10.

Wen HB, Moradian-Oldak J, Zhong JP, Greenspan DC, Fincham AG. Effects of amelogenin on the transforming surface microstructures of Bioglass in a calcifying solution. J Biomed Mater Res 2000;52(4):762-73.

Whitehead SA, Shearer AC, Watts DC, Wilson NHF. Comparison of methods for measuring surface roughness. J Oral Rehabil 1995;22(6):421-7.

Witzel MF, Braga RR, Singer JM, Azevedo CLN. Bond strength between polymer resin-based cement and porcelain-dentin surfaces: influence of polymerization mode and early cyclic loading. Int J Prosthodont 2003;16(2):145-9.

Wright MD, Masri R, Driscall CF, Romberg E, Thompson GA, Runyan DA. Comparison of three systems for the polishing of an ultra-low fusing dental porcelain. J Prosthet Dent 2004;92(5):486-90. 
APÊNDICE A - Dados individuais de resistência de união (MPa), de cerâmicas cimentadas em dentina humana (por ensaio de tração) e tipo de fratura*

\begin{tabular}{|c|c|c|c|c|c|c|c|c|c|c|c|}
\hline \multirow{2}{*}{ Cerâmica } & \multirow{2}{*}{ Cimento } & \multicolumn{10}{|c|}{ Número de repetições } \\
\hline & & $1^{\underline{a}}$ & $2^{\mathrm{a}}$ & $3^{\underline{a}}$ & $4^{\mathrm{a}}$ & $5^{\mathrm{a}}$ & $6^{\underline{a}}$ & $7^{\mathrm{a}}$ & $8^{\underline{a}}$ & $9^{\underline{a}}$ & $10^{\mathrm{a}}$ \\
\hline $\begin{array}{c}V M K \\
95\end{array}$ & $\begin{array}{c}\text { Fosfato } \\
\text { Zinco } \\
\text { Rely X } \\
\text { Panávia F }\end{array}$ & $\begin{array}{c}1,66 \\
\text { acc } \\
19,70 \\
\text { ccc } \\
19,00 \\
\text { acc }\end{array}$ & $\begin{array}{c}1,66 \\
\text { acc } \\
19,56 \\
\text { ccc } \\
16,37 \\
\text { acc }\end{array}$ & $\begin{array}{c}3,88 \\
\text { acc } \\
13,87 \\
\text { acc } \\
19,97 \\
\text { ccc }\end{array}$ & $\begin{array}{c}1,80 \\
\text { acp } \\
16,37 \\
\text { acc } \\
\\
18,86 \\
\text { acc }\end{array}$ & $\begin{array}{c}2,36 \\
\text { acc } \\
11,93 \\
\text { acc } \\
18,17 \\
\text { acc }\end{array}$ & $\begin{array}{c}2,08 \\
\text { acc } \\
\\
21,08 \\
\text { ccc } \\
16,78 \\
\text { acc }\end{array}$ & $\begin{array}{c}1,66 \\
\text { acc } \\
19,00 \\
\text { acc } \\
19,00 \\
\text { acc }\end{array}$ & $\begin{array}{c}1,52 \\
\text { acc } \\
20,11 \\
\text { acd } \\
16,23 \\
\text { acc }\end{array}$ & $\begin{array}{c}1,80 \\
\text { acc } \\
\\
19,28 \\
\text { acc } \\
\\
20,39 \\
\text { acc }\end{array}$ & $\begin{array}{c}1,66 \\
\text { acc } \\
17,61 \\
\text { acc } \\
\\
17,48 \\
\text { acc }\end{array}$ \\
\hline $\begin{array}{c}\text { Omega } \\
900\end{array}$ & $\begin{array}{c}\text { Fosfato } \\
\text { Zinco } \\
\text { Rely X } \\
\text { Panávia F }\end{array}$ & $\begin{array}{c}3,47 \\
\text { acc } \\
11,79 \\
\text { acd } \\
14,84 \\
\text { acc }\end{array}$ & $\begin{array}{c}2,36 \\
\text { acc } \\
15,95 \\
\text { acc } \\
8,88 \\
\text { acd }\end{array}$ & $\begin{array}{c}2,77 \\
\text { acc } \\
\\
13,45 \\
\text { acc } \\
\\
22,33 \\
\text { ccc }\end{array}$ & $\begin{array}{c}2,63 \\
\text { acc } \\
17,06 \\
\text { ccc } \\
19,83 \\
\text { ccc }\end{array}$ & $\begin{array}{c}3,19 \\
\text { acc } \\
\\
15,67 \\
\text { acc } \\
\\
21,36 \\
\text { acc }\end{array}$ & $\begin{array}{c}3,05 \\
\text { acc } \\
\\
17,20 \\
\text { ccc } \\
\\
16,37 \\
\text { acc }\end{array}$ & $\begin{array}{c}2,77 \\
\text { acc } \\
\\
14,15 \\
\text { acd } \\
19,97 \\
\text { acc }\end{array}$ & $\begin{array}{c}2,63 \\
\text { acc } \\
\\
16,23 \\
\text { acc } \\
17,75 \\
\text { acc }\end{array}$ & $\begin{array}{c}3,05 \\
\text { acc } \\
14,98 \\
\text { acc } \\
19,28 \\
\text { acc }\end{array}$ & $\begin{array}{c}3,19 \\
\text { acc } \\
\\
13,45 \\
\text { acc } \\
\\
21,64 \\
\text { ccc }\end{array}$ \\
\hline $\begin{array}{c}\text { IPS } \\
\text { d.Sign }\end{array}$ & $\begin{array}{c}\text { Fosfato } \\
\text { Zinco } \\
\text { Rely X } \\
\text { Panávia F }\end{array}$ & $\begin{array}{c}1,80 \\
\text { acc } \\
22,61 \\
\text { acc } \\
16,23 \\
\text { acc }\end{array}$ & $\begin{array}{c}1,52 \\
\text { acc } \\
\\
23,86 \\
\text { ccc } \\
16,92 \\
\text { ccc }\end{array}$ & $\begin{array}{c}1,66 \\
\text { acc } \\
19,56 \\
\text { acc } \\
16,50 \\
\text { acc }\end{array}$ & $\begin{array}{c}2,77 \\
\text { acc } \\
17,61 \\
\text { acc } \\
14,98 \\
\text { acc }\end{array}$ & $\begin{array}{c}1,52 \\
\text { acc } \\
\\
20,39 \\
\text { acc } \\
\\
14,28 \\
\text { acc }\end{array}$ & $\begin{array}{c}1,25 \\
\text { acc } \\
\\
18,31 \\
\text { acc } \\
\\
17,48 \\
\text { ccc }\end{array}$ & $\begin{array}{c}2,08 \\
\text { acc } \\
\\
21,36 \\
\text { acc } \\
\\
14,84 \\
\text { acc }\end{array}$ & $\begin{array}{c}1,25 \\
\text { acc } \\
\\
17,75 \\
\text { acc } \\
\\
16,78 \\
\text { ccc }\end{array}$ & $\begin{array}{c}1,66 \\
\text { acc } \\
20,11 \\
\text { acc } \\
14,98 \\
\text { acc }\end{array}$ & $\begin{array}{c}2,22 \\
\text { acc } \\
\\
23,16 \\
\text { ccc } \\
\\
15,95 \\
\text { acc }\end{array}$ \\
\hline Cergogold & $\begin{array}{c}\begin{array}{c}\text { Fosfato } \\
\text { Zinco }\end{array} \\
\text { Rely X } \\
\text { Panávia F }\end{array}$ & $\begin{array}{c}1,11 \\
\text { acc } \\
12,07 \\
\text { acc } \\
19,28 \\
\text { acc }\end{array}$ & $\begin{array}{c}1,52 \\
\text { acc } \\
\\
22,89 \\
\text { ccc } \\
27,88 \\
\text { ccc }\end{array}$ & $\begin{array}{c}1,80 \\
\text { acc } \\
\\
12,90 \\
\text { ccc } \\
\\
23,02 \\
\text { ccc }\end{array}$ & $\begin{array}{c}1,25 \\
\text { acc } \\
\\
16,78 \\
\text { ccc } \\
\\
17,48 \\
\text { acc }\end{array}$ & $\begin{array}{c}1,94 \\
\text { acc } \\
\\
10,68 \\
\text { acc } \\
\\
16,78 \\
\text { acc }\end{array}$ & $\begin{array}{c}1,52 \\
\text { acc } \\
\\
12,34 \\
\text { acc } \\
\\
20,25 \\
\text { acc }\end{array}$ & $\begin{array}{c}1,66 \\
\text { acc } \\
\\
13,59 \\
\text { ccc } \\
\\
22,61 \\
\text { ccc }\end{array}$ & $\begin{array}{c}1,25 \\
\text { acc } \\
\\
16,23 \\
\text { ccc } \\
\\
20,39 \\
\text { acc }\end{array}$ & $\begin{array}{c}2,22 \\
\text { acc } \\
\\
11,51 \\
\text { acc } \\
\\
29,54 \\
\text { ccc }\end{array}$ & $\begin{array}{c}1,80 \\
\text { acc } \\
\\
17,06 \\
\text { ccc } \\
\\
26,21 \\
\text { ccc }\end{array}$ \\
\hline
\end{tabular}

*acc - adesivo cimento / lado da cerâmica acd - adesivo cimento / lado da dentina ccc - coesivo no corpo da cerâmica 
APÊNDICE B - Dados individuais da rugosidade de diversos parâmetros, frente ao condicionamento superficial com ácido fluorídrico a 10\% $(\mu \mathrm{m})$

\begin{tabular}{|c|c|c|c|c|c|c|c|c|c|c|c|}
\hline \multirow{2}{*}{ Cerâmica } & \multirow{2}{*}{$\begin{array}{c}\text { Parâmetro } \\
\text { Rugosidade } \\
\text { Superficial }\end{array}$} & \multicolumn{10}{|c|}{ Número de repetições } \\
\hline & & $1^{\mathrm{a}}$ & $2^{\mathrm{a}}$ & $3^{\mathrm{a}}$ & $4^{\mathrm{a}}$ & $5^{\mathrm{a}}$ & $6^{\underline{a}}$ & $7^{\mathrm{a}}$ & $8^{\underline{a}}$ & $9^{\underline{a}}$ & $10^{\mathrm{a}}$ \\
\hline \multirow{5}{*}{$\begin{array}{c}\text { VMK } \\
95\end{array}$} & $\mathrm{Ra}$ & 5,49 & 3,04 & 6,25 & 5,20 & 3,13 & 3,77 & 3,52 & 4.93 & 2.97 & 4,28 \\
\hline & $\mathrm{Rt}$ & 38,80 & 21,80 & 46,40 & 44,30 & 25,75 & 25,95 & 22,95 & 38,10 & 20,65 & 37,10 \\
\hline & Ry & 37,95 & 20,40 & 45,70 & 39,20 & 21,70 & 25,02 & 21,00 & 38,10 & 20,60 & 35,25 \\
\hline & $\mathrm{Rz}$ & 18,55 & 15,75 & 24,80 & 21,85 & 13,80 & 20,25 & 17,25 & 21,40 & 15,75 & 20,60 \\
\hline & $\mathrm{Rp}$ & 19,60 & 11,45 & 23,95 & 21,15 & 13,75 & 14,30 & 11,70 & 19,85 & 10,60 & 17,10 \\
\hline \multirow{5}{*}{$\begin{array}{c}\text { Omega } \\
900\end{array}$} & $\mathrm{Ra}$ & 1,77 & 2,85 & 2,93 & 2,65 & 2,60 & 3,11 & 3,22 & 2,79 & 2,85 & 2,20 \\
\hline & Rt & 10,75 & 19,70 & 22,30 & 17,70 & 16,10 & 20,95 & 24,15 & 21,90 & 19,80 & 17,60 \\
\hline & Ry & 10,40 & 17,50 & 22,30 & 17,60 & 15,95 & 18,90 & 21,10 & 20,60 & 19,35 & 14,55 \\
\hline & $\mathrm{Rz}$ & 9,05 & 15,45 & 15,70 & 13,40 & 14,20 & 15,30 & 15,90 & 13,55 & 14,75 & 11,95 \\
\hline & $\mathrm{Rp}$ & 5,70 & 9,75 & 8,70 & 10,20 & 9,40 & 10,35 & 10,95 & 10,10 & 11,30 & 8,10 \\
\hline \multirow{5}{*}{$\begin{array}{l}\text { IPS } \\
\text { d.Sign }\end{array}$} & $\mathrm{Ra}$ & 2,21 & 2,56 & 2,02 & 2,14 & 2,04 & 3,40 & 2,92 & 2,54 & 2,32 & 3,14 \\
\hline & Rt & 16,85 & 20,60 & 15,90 & 15,10 & 14,00 & 37,55 & 16,70 & 14,85 & 15,70 & 29,45 \\
\hline & Ry & 15,30 & 20,60 & 13,85 & 13,75 & 13,90 & 37,35 & 16,45 & 14,15 & 15,70 & 29,45 \\
\hline & $\mathrm{Rz}$ & 11,40 & 12,80 & 10,50 & 10,10 & 10,25 & 16,00 & 12,90 & 12,00 & 11,20 & 16,20 \\
\hline & $\mathrm{Rp}$ & 8,65 & 10,80 & 8,10 & 8,70 & 7,85 & 17,70 & 8,25 & 7,50 & 9,00 & 17,80 \\
\hline \multirow{5}{*}{ Cergogold } & $\mathrm{Ra}$ & 1,35 & 1,51 & 2,44 & 2,64 & 3,04 & 3,00 & 1,77 & 1,36 & 2,16 & 2,20 \\
\hline & $\mathrm{Rt}$ & 9,90 & 10,60 & 18,50 & 24,45 & 23,65 & 23,80 & 13,75 & 9,40 & 18,85 & 14,70 \\
\hline & Ry & 9,65 & 10,60 & 17,00 & 22,35 & 23,00 & 22,05 & 12,25 & 8,35 & 18,85 & 13,90 \\
\hline & $\mathrm{Rz}$ & 7,55 & 8,10 & 14,00 & 13,90 & 15,20 & 16,00 & 9,80 & 7,25 & 11,95 & 11,70 \\
\hline & $\mathrm{Rp}$ & 5,15 & 5,75 & 7,50 & 11,90 & 9,25 & 9,20 & 7,60 & 4,30 & 9,25 & 7,15 \\
\hline
\end{tabular}


APÊNDICE C - Dados individuais da rugosidade de diversos parâmetros, frente ao tratamento superficial com um sistema de acabamento e polimento com borrachas $(\mu \mathrm{m})$

\begin{tabular}{|c|c|c|c|c|c|c|c|c|c|c|c|}
\hline \multirow{2}{*}{ Cerâmica } & \multirow{2}{*}{$\begin{array}{l}\text { Parâmetro } \\
\text { Rugosidade } \\
\text { Superficial }\end{array}$} & \multicolumn{10}{|c|}{ Número de repetições } \\
\hline & & $1^{a}$ & $2^{\mathrm{a}}$ & $3^{\mathrm{a}}$ & $4^{\mathrm{a}}$ & $5^{\underline{a}}$ & $6^{\underline{a}}$ & $7^{\mathrm{a}}$ & $8^{\underline{a}}$ & $9^{a}$ & $10^{\mathrm{a}}$ \\
\hline \multirow{5}{*}{$\begin{array}{c}\text { VMK } \\
95\end{array}$} & $\mathrm{Ra}$ & 0,67 & 0,63 & 1,22 & 0,70 & 0,66 & 1,06 & 0,65 & 0,69 & 0,79 & 1,30 \\
\hline & Rt & 4,65 & 3,90 & 17,75 & 6,95 & 4,75 & 12,15 & 4,05 & 5,40 & 7,60 & 7,85 \\
\hline & Ry & 4,65 & 3,70 & 17,35 & 6,85 & 4,45 & 11,45 & 3,75 & 5,25 & 6,30 & 7,70 \\
\hline & $\mathrm{Rz}$ & 3,30 & 3,30 & 6,40 & 4,65 & 3,60 & 4,70 & 3,10 & 3,70 & 4,50 & 5,30 \\
\hline & $\mathrm{Rp}$ & 2,25 & 1,60 & 5,30 & 2,10 & 1,80 & 3,95 & 1,60 & 2,00 & 2,70 & 3,25 \\
\hline \multirow{5}{*}{$\begin{array}{c}\text { Omega } \\
900\end{array}$} & $\mathrm{Ra}$ & 0,62 & 0,68 & 0,55 & 0,51 & 0,73 & 0,53 & 0,38 & 0,67 & 0,56 & 0,49 \\
\hline & Rt & 4,50 & 5,00 & 5,70 & 4,00 & 6,75 & 3,90 & 2,85 & 4,95 & 4,05 & 3,55 \\
\hline & Ry & 4,35 & 4,35 & 5,10 & 3,80 & 5,85 & 3,90 & 2,65 & 4,85 & 3,70 & 3,30 \\
\hline & $\mathrm{Rz}$ & 3,25 & 3,40 & 3,05 & 2,70 & 3,60 & 2,75 & 2,05 & 3,65 & 2,80 & 2,55 \\
\hline & $\mathrm{Rp}$ & 1,55 & 1,60 & 2,05 & 1,25 & 3,25 & 1,70 & 1,10 & 2,05 & 1,55 & 1,40 \\
\hline \multirow{5}{*}{$\begin{array}{c}\text { IPS } \\
\text { d.Sign }\end{array}$} & $\mathrm{Ra}$ & 0,53 & 0,57 & 0,66 & 0,55 & 0,59 & 0,79 & 0,60 & 0,58 & 0,88 & 0,70 \\
\hline & Rt & 3,40 & 4,40 & 5,25 & 4,35 & 4,70 & 6,90 & 4,80 & 4,30 & 5,90 & 6,15 \\
\hline & Ry & 3,30 & 4,10 & 5,20 & 4,10 & 4,70 & 6,10 & 4,50 & 3,80 & 5,75 & 6,00 \\
\hline & $\mathrm{Rz}$ & 2,55 & 2,90 & 3,75 & 2,95 & 2,90 & 4,30 & 3,00 & 2,95 & 3,95 & 4,00 \\
\hline & $\mathrm{Rp}$ & 1,50 & 1,85 & 1,95 & 1,45 & 2,10 & 2,95 & 1,70 & 1,85 & 2,30 & 1,85 \\
\hline \multirow{5}{*}{ Cergogold } & $\mathrm{Ra}$ & 0,54 & 0,60 & 0,43 & 0,44 & 0,55 & 0,60 & 0,53 & 0,48 & 0,53 & 0,57 \\
\hline & Rt & 3,35 & 4,00 & 3,35 & 3,50 & 4,25 & 4,20 & 4,25 & 3,85 & 3,85 & 4,25 \\
\hline & Ry & 3,30 & 3,95 & 3,10 & 3,30 & 3,80 & 3,45 & 3,80 & 3,65 & 3,55 & 3,85 \\
\hline & $\mathrm{Rz}$ & 2,65 & 3,20 & 2,60 & 2,45 & 3,00 & 2,70 & 3,00 & 2,60 & 2,55 & 3,00 \\
\hline & $\mathrm{Rp}$ & 1,45 & 1,60 & 1,75 & 1,60 & 2,00 & 2,00 & 1,70 & 1,60 & 1,55 & 1,75 \\
\hline
\end{tabular}


APÊNDICE D - Dados individuais das durezas Knoop e Vickers $\left(\mathrm{kgf} / \mathrm{mm}^{2}\right)$

\begin{tabular}{|c|c|c|c|}
\hline Cerâmica & Penertração & Dureza Knoop & Dureza Vickers \\
\hline \multirow{4}{*}{$\begin{array}{c}V M K \\
95\end{array}$} & CP 1 & 347,4 & 511,0 \\
\hline & CP 2 & 373,4 & 518,8 \\
\hline & CP 3 & 469,4 & 485,8 \\
\hline & CP 4 & 485,4 & 454,2 \\
\hline \multirow{4}{*}{$\begin{array}{c}\text { Omega } \\
900\end{array}$} & $\mathrm{CP} 1$ & 462,6 & 522,6 \\
\hline & CP 2 & 489,2 & 552,8 \\
\hline & CP 3 & 459,2 & 518,8 \\
\hline & CP 4 & 477,4 & 601,0 \\
\hline \multirow{4}{*}{$\begin{array}{c}\text { IPS } \\
\text { d.Sign }\end{array}$} & CP 1 & 431,4 & 552,0 \\
\hline & $\mathrm{CP} 2$ & 630,8 & 560,6 \\
\hline & CP 3 & 487,8 & 610,2 \\
\hline & CP 4 & 425,0 & 566,0 \\
\hline \multirow{4}{*}{ Cergogold } & CP 1 & 493,6 & 495,8 \\
\hline & CP 2 & 426,6 & 508,4 \\
\hline & CP 3 & 378,4 & 579,6 \\
\hline & CP 4 & 507,6 & 561,6 \\
\hline
\end{tabular}


ANEXO A - Parecer do Comitê de Ética em Pesquisa

\title{
Faculdade de Odontologia
}

\section{Universidade de Săo Paulo}

\author{
PARECER $n^{\circ} 185 / 03$ \\ Protocolo 183/03
}

O Grupo de Trabalho indicado pelo Comitê de Ética em Pesquisa, APROVOU o protocolo de pesquisa "Avaliação de Cerámicas odontológicas em relação à resistência de uniăo por ensaio de tração, durezas knoop e vickers, rugosidade superficial e microscopia de força atômica", de responsabilidade do pesquisador Ricardo Ruiz Martuci, sob orientação do Prof. Dr. Antonio Muench.

Tendo em vista a legislação vigente, devem ser encaminhados a este Comitē relatórios anuais (parciais ou finais, em função da duração da pesquisa) referentes ao andamento da pesquisa e ao término cópia do trabalho em " $c d^{\text {". }}$ Qualquer emenda do projeto original deve ser apresentada a este CEP para apreciação, de forma clara e sucinta, identificando a parte do protocolo a ser modificada e suas justificativas.

São Paulo, 31 de outubro de 2003.

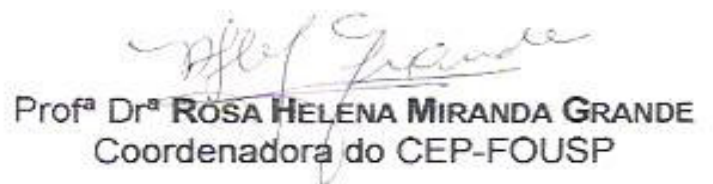

